\title{
Arctide2017, a high-resolution regional tidal model in the Arctic Ocean
}

\author{
Cancet, M.; Andersen, O. B.; Lyard, F.; Cotton, D.; Benveniste, J.
}

Published in:

Advances in Space Research

Link to article, DOI:

10.1016/j.asr.2018.01.007

Publication date:

2018

Document Version

Peer reviewed version

Link back to DTU Orbit

Citation (APA):

Cancet, M., Andersen, O. B., Lyard, F., Cotton, D., \& Benveniste, J. (2018). Arctide2017, a high-resolution regional tidal model in the Arctic Ocean. Advances in Space Research, 62(6), 1324-1343.

https://doi.org/10.1016/j.asr.2018.01.007

\section{General rights}

Copyright and moral rights for the publications made accessible in the public portal are retained by the authors and/or other copyright owners and it is a condition of accessing publications that users recognise and abide by the legal requirements associated with these rights.

- Users may download and print one copy of any publication from the public portal for the purpose of private study or research.

- You may not further distribute the material or use it for any profit-making activity or commercial gain

- You may freely distribute the URL identifying the publication in the public portal

If you believe that this document breaches copyright please contact us providing details, and we will remove access to the work immediately and investigate your claim 


\section{Accepted Manuscript}

Arctide2017, A High-Resolution Regional Tidal Model in the Arctic Ocean

M. Cancet, O.B. Andersen, F. Lyard, D. Cotton, J. Benveniste

PII:

S0273-1177(18)30030-9

DOI:

https://doi.org/10.1016/j.asr.2018.01.007

Reference:

JASR 13580

To appear in:

Advances in Space Research

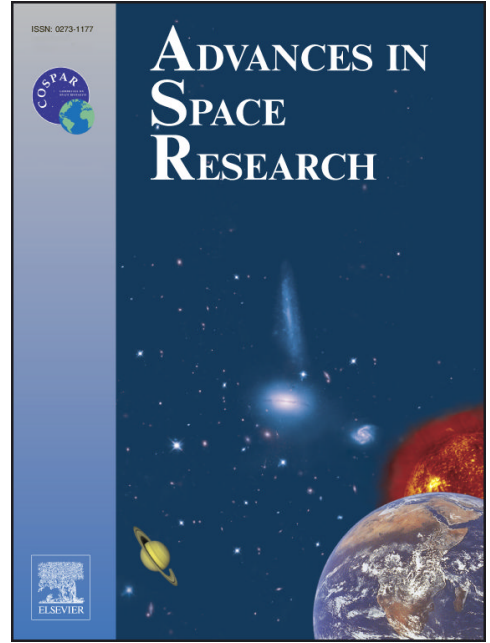

Received Date: $\quad 7$ February 2017

Revised Date: $\quad 3$ January 2018

Accepted Date: $\quad 5$ January 2018

Please cite this article as: Cancet, M., Andersen, O.B., Lyard, F., Cotton, D., Benveniste, J., Arctide2017, A HighResolution Regional Tidal Model in the Arctic Ocean, Advances in Space Research (2018), doi: https://doi.org/ 10.1016/j.asr.2018.01.007

This is a PDF file of an unedited manuscript that has been accepted for publication. As a service to our customers we are providing this early version of the manuscript. The manuscript will undergo copyediting, typesetting, and review of the resulting proof before it is published in its final form. Please note that during the production process errors may be discovered which could affect the content, and all legal disclaimers that apply to the journal pertain. 


\title{
Arctide2017, A High-Resolution Regional Tidal Model in the Arctic Ocean
}

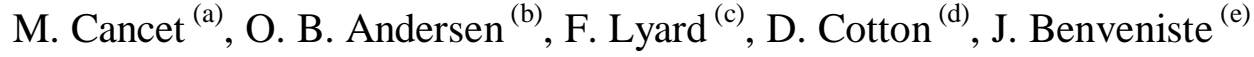 \\ ${ }^{(a)}$ NOVELTIS, 153 rue du Lac, 31670 Labège, France, mathilde.cancet@noveltis.fr \\ ${ }^{(b)}$ DTU Space, Elektrovej, Bldg 328, 2800 Lyngby, Denmark \\ ${ }^{(c)}$ LEGOS/OMP/UPS, 14 Avenue Edouard Belin, 31400 Toulouse, France \\ ${ }^{(d)}$ Satellite Oceanographic Consultants, 49 Seal Road, Bramhall, Stockport, SK7 2JS, UK \\ (e) ESA-ESRIN, Via Galileo Galilei, CP 64, 00044 Frascati, Italy
}

\begin{abstract}
The Arctic Ocean is a challenging region for tidal modelling. The accuracy of the global tidal models decreases by several centimeters in the Polar Regions, which has a large impact on the quality of the satellite altimeter sea surface heights and the altimetry-derived products.

NOVELTIS, DTU Space and LEGOS have developed Arctide2017, a regional, highresolution tidal atlas in the Arctic Ocean, in the framework of an extension of the CryoSat Plus for Ocean (CP4O) ESA STSE (Support to Science Element) project. In particular, this atlas benefits from the assimilation of the most complete satellite altimetry dataset ever used in this region, including Envisat data up to $82^{\circ} \mathrm{N}$ and CryoSat 2 data between $82^{\circ} \mathrm{N}$ and $88^{\circ} \mathrm{N}$. The combination of these satellite altimetry missions gives the best possible coverage of altimetry-derived tidal constituents. The available tide gauge data were also used for data assimilation and validation.

This paper presents the implementation methodology and the performance of this new regional tidal model in the Arctic Ocean, compared to the existing global and regional tidal models.
\end{abstract}

Keywords: Tide modelling; Arctic Ocean; satellite altimetry; data assimilation; CryoSat-2 mission

\section{Introduction}

In the context of climate change, the Arctic Ocean is ever more becoming a region of interest, be it for scientific studies, for geopolitical reasons, for transportation and trade evolutions, or for oil and gas resources exploration and exploitation.

The ocean tide is one of the main contributors to the ocean dynamics on the global ocean continental shelves. But if tidal modelling benefited from many improvements these last years, such as the description of the physics in the hydrodynamic models, the resolution of the model grids and the assimilation of longer time series of satellite altimetry observations, even the most recent global tidal models still show errors of several centimetres on the continental shelves and in the regions where the tide is more complex to model (Stammer et al, 2014). This is particularly true in the Arctic Ocean, where the indented coastline and the seasonal variations of the sea ice cover bring additional difficulty to the modelling of the non-linear tidal process. In addition, the bathymetry is strategic information in this region and it is challenging to get access to high-resolution sea floor data.

Arctide2017, a new regional tidal model, was implemented in the Arctic Ocean in order to provide a better tidal solution than the current global models. It was developed following the same methodology as for the FES2004 (Lyard et al., 2006), FES2012 (Carrère et al, 2012) and FES2014 (Carrère et al, 2015) global tidal models, which are based on hydrodynamic simulation with data assimilation. The Arctide2017 regional tidal atlas was computed on a finite element unstructured grid with a spatially-variable resolution. This enables to increase the resolution of the model on the 
shelves and on the major topographic patterns in order to concentrate on the areas where the tidal process shows the most complex features. In addition to high-resolution mesh and regional tuning of the hydrodynamic model, the Arctide2017 regional tidal model benefited from Envisat and CryoSat-2 altimetry data assimilation. To our knowledge, this is the first time that CryoSat-2 altimetry data is used to improve tidal modelling. This is a challenging process because the longterm repeat period of the CryoSat-2 mission (369 days) must be tackled very differently from the 10-day or 35-day repeat periods of the Topex/Jason and ERS/Envisat missions respectively, classically used for the analysis of the tidal signals.

This paper presents the modelling strategy and the performance of the Arctide2017 regional tidal model in the Arctic Ocean, compared to the existing global and regional tidal models.

\section{Model domain}

The regional unstructured mesh was built with the idea that the Arctide2017 regional tidal model could be patched into the recent FES2014 global tidal model in the future. As a consequence, the mesh was built on the basis of the existing FES2014 global model grid. The unstructured elements at the open boundaries of the regional mesh are thus consistent with the elements of the global mesh.

The open ocean boundaries were chosen as such to benefit from the assimilation of Topex/Jason data in the global model used as boundary conditions (i.e. under $66^{\circ} \mathrm{N}$ ), but also in order to avoid some complex tidal structures that would not be well solved in the global model, in particular between Iceland and Scotland. As shown in Fig. 1.a, the model open boundary with the North Pacific Ocean goes from Kwinhagak in Alaska to the Northern part of the Olyutorsky District in Siberia. In the North Atlantic Ocean, it starts in the Labrador Sea, near Makkovik on the Canadian coastline, then it almost follows the $55^{\circ} \mathrm{N}$ line of latitude up to the longitude of $25^{\circ} \mathrm{W}$, on the West of Iceland, then goes between Iceland and the Faroe Islands and finally reaches the Norwegian coast in Brønnøy.

The resolution of the mesh was set to $4 \mathrm{~km}$ all along the coastline and it ranges between a few hundreds of meters at some local coastal refinements, around islands for example, and $40 \mathrm{~km}$ offshore. In comparison, the resolution of the original FES2014 global grid ranges between $7 \mathrm{~km}$ at the coast and more than $80 \mathrm{~km}$ offshore (Fig. 1.b). Fig. 2 shows a zoom in on the local refinement of the mesh resolution in the North West Passage. For this example, the resolution of the FES2014 mesh ranges from $15 \mathrm{~km}$ at the coast to about $25 \mathrm{~km}$ offshore, whereas for the refined mesh, the resolution is $4 \mathrm{~km}$ along the coast (and even finer locally, down to $500 \mathrm{~m}$ around some islands) and about $8 \mathrm{~km}$ offshore.

The final refined regional mesh contains more than three times the number of vertices in the FES2014 global mesh over the same region, which shows the large improvement made to the mesh resolution in the Arctic Ocean. However, it is very difficult to establish a direct link between the mesh resolution and the expected accuracy of the tidal model, because of possible compensations between bathymetry errors and model errors due to a lack of resolution. 


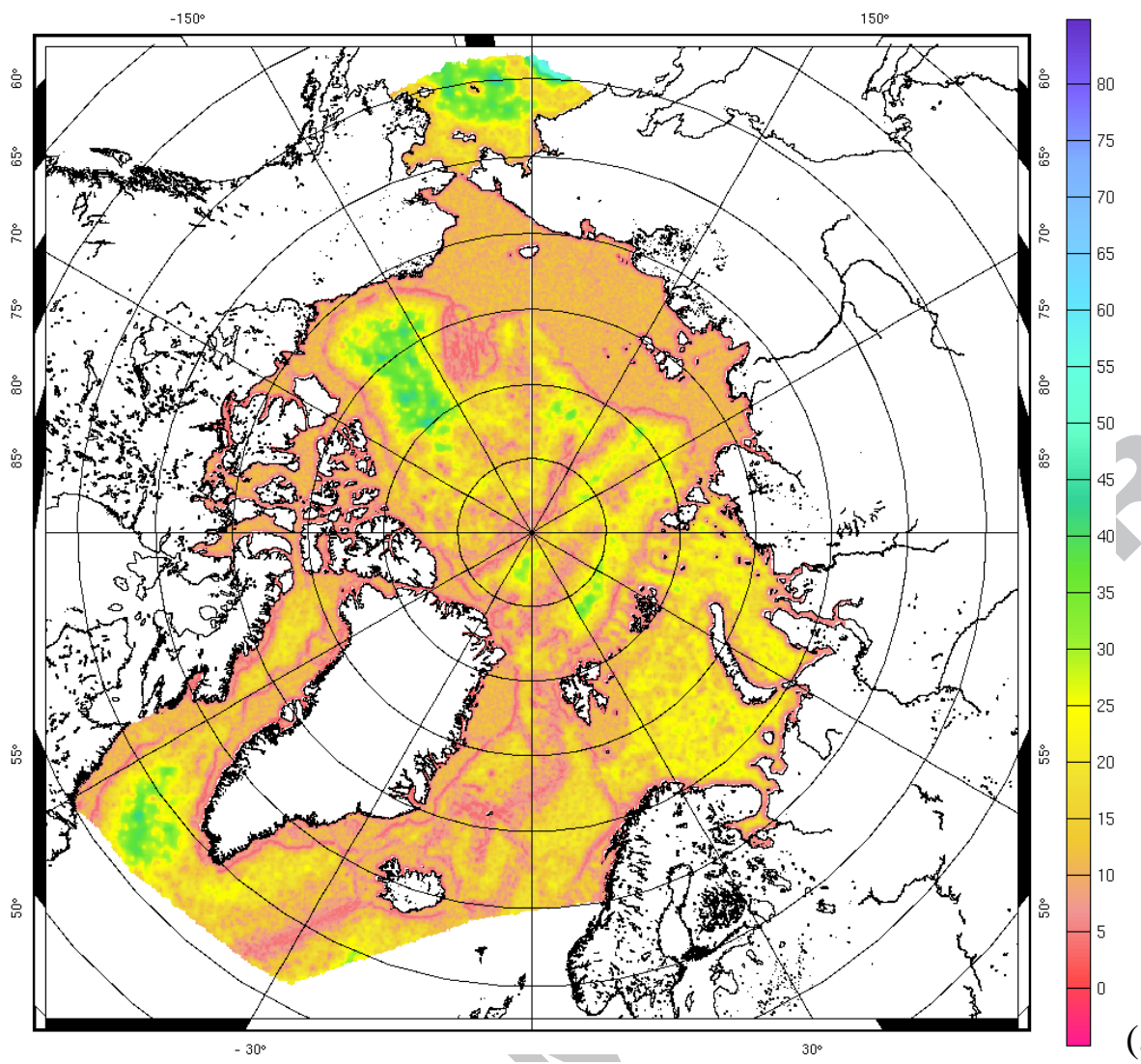

(a)

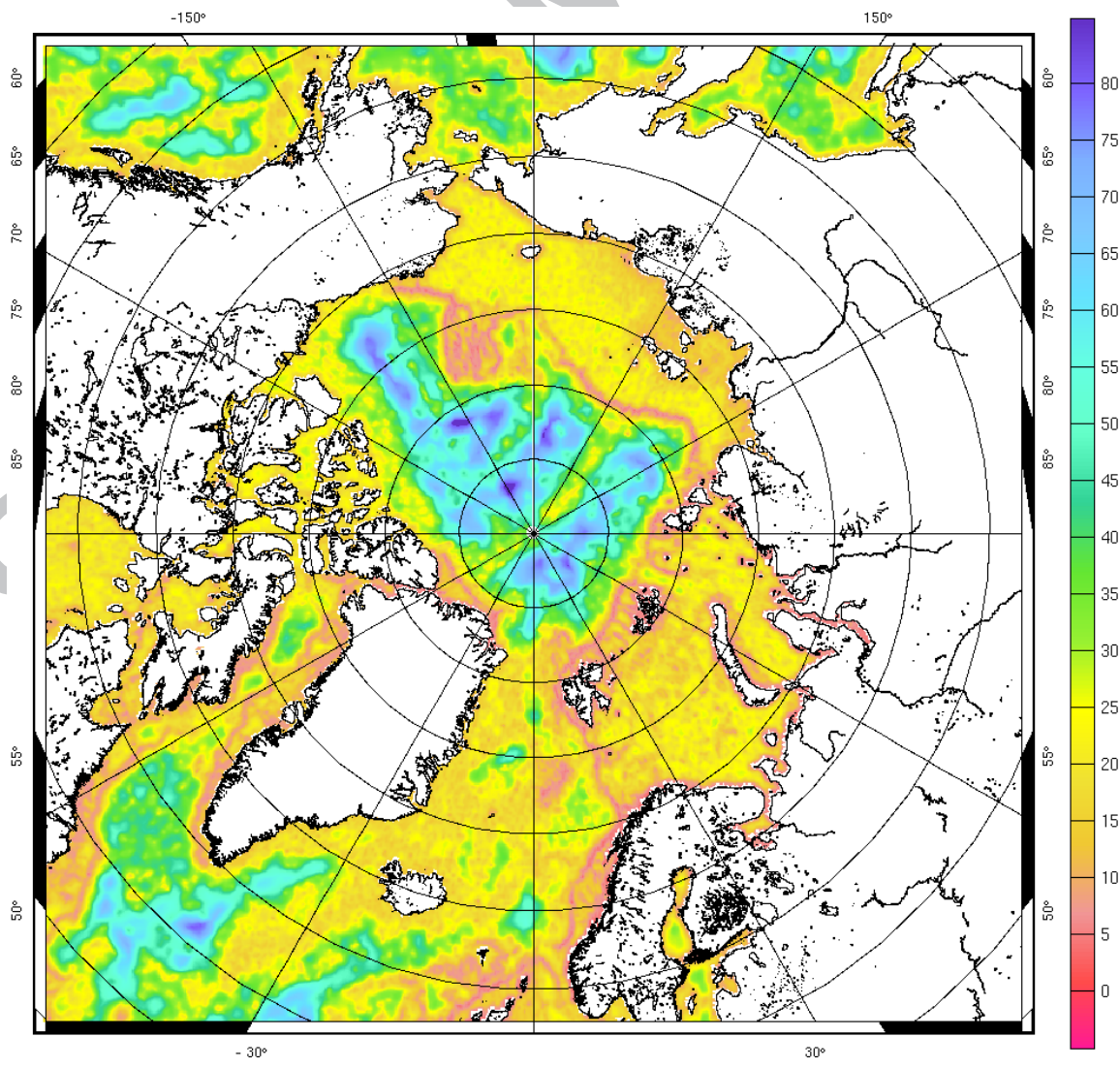

(b)

Figure 1: Resolution (in km) of the refined regional (a) and the FES2014 (b) unstructured grids in the Arctic Ocean. 


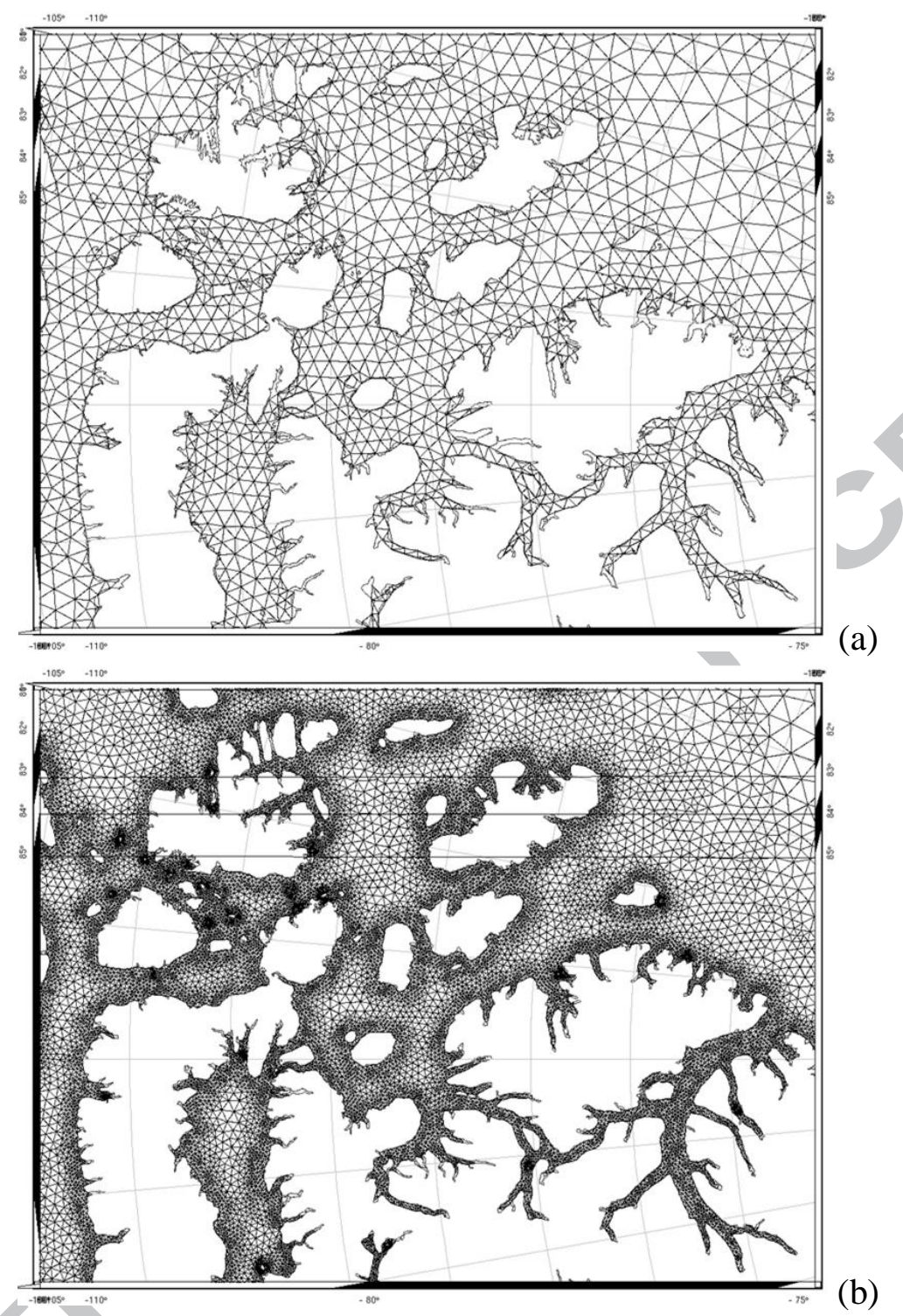

Figure 2: Zoom on the FES2014 (a) and refined regional (b) unstructured grids in the North West Passage.

\section{Validation dataset}

The number of accurate and reliable in situ tidal observations in the Arctic Ocean is quite limited. The tide gauge database that was used for the validation of the models in this work consists in the long-term collation of various historical databases from international programs (International Hydrographic Organization - IHO, World Ocean Circulation Experiment - WOCE) as well as Canadian (Fisheries and Oceans Canada, http://www.isdm-gdsi.gc.ca) and Russian (Z. Kowalik and A.Y. Proshutinsky, 1994) sources. The quality of this dataset of about 400 stations is uneven. Some stations have dubious locations (located on the ground), some of them have clock errors (provided in local time), some of them were used during very short periods and no date is available, and some of them are provided as tidal harmonic constituents for only two or three main tidal components. For most of them, the elevation time series are not available, which means that the harmonic analysis cannot be run again and cross-checked.

All these points lead to the conclusion that not too much confidence should be put into this 
tide gauge dataset if it is not strictly edited. This is the reason why a strict editing of this database was performed, leading to the constitution of a validation dataset of 121 tide gauge stations (Fig. 3). This editing was based on the length of the time series (when available) and on the consistency between the neighbouring stations. In particular, some stations were available both in the IHO dataset and in the Kowalik and Proshutinsky dataset, with different tidal estimates. The stations that showed very different values from their close neighbours were discarded. More generally, when there was a doubt on the accuracy of the tidal estimate, the station was discarded.

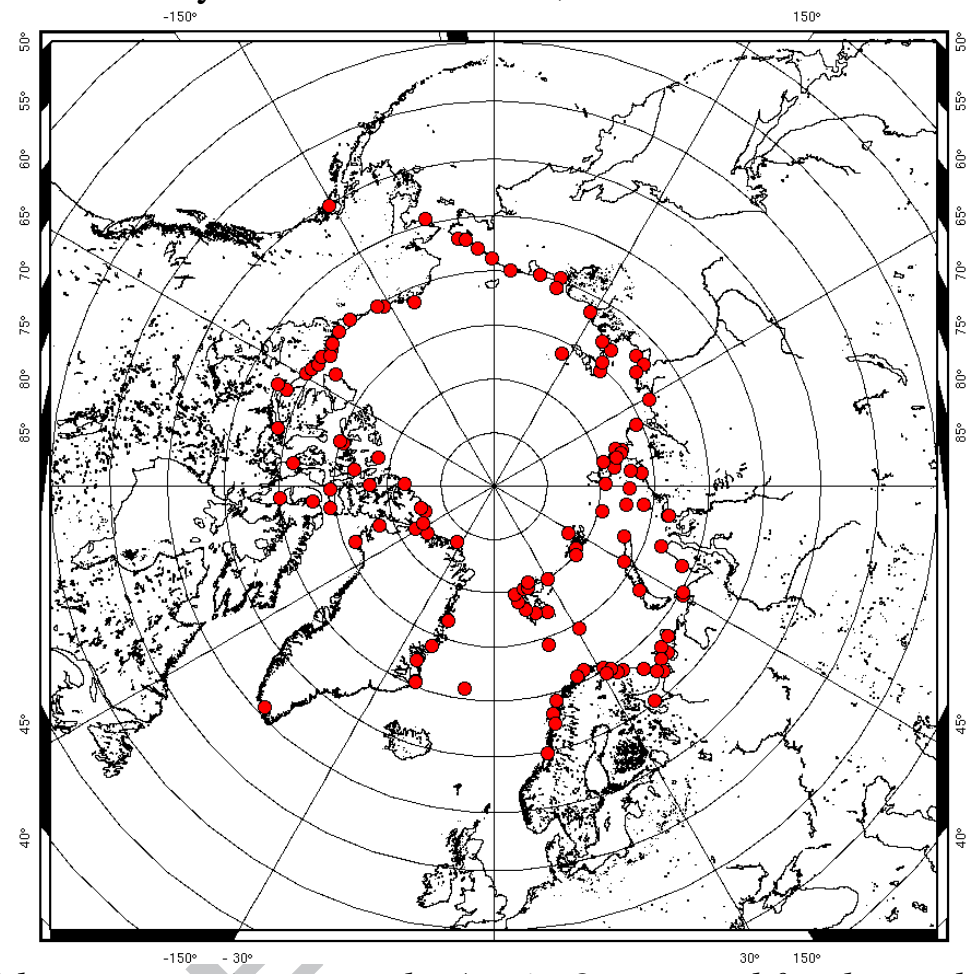

Figure 3: Tide gauge stations over the Arctic Ocean used for the model validation.

\section{Hydrodynamic modelling}

The first stage in the implementation of the Arctide2017 regional tidal model in the Arctic Ocean consisted in generating the best possible hydrodynamic simulation of the ocean tides in this region. The implementation of this hydrodynamic solution was done with the T-UGOm (Toulouse Unstructured Grid Ocean model) hydrodynamic model (Le Bars et al, 2010).

\subsection{The T-UGOm hydrodynamic model}

The T-UGOm model is an unstructured grid 2D/3D hydrodynamic model developed at LEGOS. The 2D equations of the model are based on the classical shallow-water equations of continuity and movement. The model is run using the finite elements discretization, with triangular elements. The unstructured grid enables to increase the resolution in the most demanding parts of the model, in terms of coastal geometry and hydrodynamic constraints. It is of particular interest in areas of steep topographic gradients, where the currents generally show high variability and the internal waves are generated, as well as in the shallow waters, where the energy dissipation is the highest due to the bottom friction.

In the case of tide simulation, two modes are available in the model to solve the equations.

The time-stepping mode consists in running the model over a given period, long enough (generally one year) to be able to discriminate the various tide waves with good accuracy. The 
equations of the ocean dynamics are integrated over the time with a time step adapted to the grid resolution and to the tide propagation. Once the simulation is achieved, a harmonic analysis is performed on the sea surface elevations generated by the model, in order to compute the harmonic constituents (amplitude and phase) of the tide components. This method enables to model the nonlinear tide components following the natural process of dynamical interactions between the various components of the spectrum. This mode is also able to deal with wetting and drying flats, and with river discharge.

The spectral mode, initially inspired by the CEFMO (Code aux Eléments Finis pour la Marée Océanique) code used to compute the FES2004 reference tidal atlas (Lyard et al, 2006), solves the quasi-linearized Navier-Stokes equations in the spectral domain, in a wave by wave, iterative process. This mode is very well adapted to compute the waves resulting of the astronomical forcing, whereas it is more complex for the non-linear components, which are better resolved with the timestepping mode. However, the iterative process enables to solve the non-linear tides with sufficient accuracy in most cases. The run duration is drastically reduced with the spectral mode (a few minutes to a few hours depending on the mesh size), compared to the time-stepping mode that would require several days.

\subsection{Model inputs}

\subsubsection{Bathymetry}

The accuracy of the tidal model highly depends on the quality of the bathymetry data used as input of the hydrodynamic model. In particular, the tidal processes interact with the bathymetry in the shallow water regions, which leads to the generation of non-linear tidal components. Errors in the bathymetry can consequently have large consequences on the model results and performances.

The Arctic Ocean is a region of more than 14 billion $\mathrm{km}^{2}$, partly covered with sea ice throughout the year, with large seasonal variations in the sea ice cover. This means that it is practically very difficult to measure accurate bathymetry information in the whole region. In addition, it is a highly strategic region for commercial activities and geopolitical reasons, which means that any high-resolution observations, when they exist, are generally not widely distributed, even for scientific exploitation.

The bathymetry datasets most commonly used for scientific studies in the Arctic Ocean are the IBCAO grids (International Bathymetric Chart of the Arctic Ocean), an international initiative that started in the late 90s (Jakobsson et al., 2008 and 2012). Timmerman et al. have also developed the R-Topo-1.0.5 global bathymetry with some improvements at the poles, using multi-beam survey data (Timmermann et al., 2010).

For the implementation of the new tidal model presented in this paper, a composite bathymetry was used (Fig. 4). It was built by LEGOS and a former version of this composite bathymetry was successfully used for the implementation of the FES2014 global tidal model. It is based on the etopo-1 global bathymetry (Amante and Eakins, 2009) and the IBCAO v2 bathymetry (Jakobsson et al., 2008) in the Arctic Ocean. In this region, some patches from the Smith and Sandwell bathymetry (Smith and Sandwell, 1997) and other local improvements using various datasets have also been included, in particular in the Laptev Sea and in the White Sea.

Both bathymetry datasets (RTopo-1.0.5 and composite) have been tested for the implementation of the Arctic tide model, in order to choose the dataset that would prove the most appropriate. Fig. 5 shows the performances of the hydrodynamic model towards tide gauge stations (see the next section for the details about the model set-up and validation), for each bathymetry dataset and for the M2 main tidal component. The larger the red dot, the larger the vector difference to the tide gauge station. The most noticeable difference between the two simulations is clearly located in the South of Greenland, where the model based on the R-Topo bathymetry shows a 
vector difference of more than $40 \mathrm{~cm}$ at the Qaqortoq tide gauge station. The difference is of only a few centimeters in the case of the model based on the composite bathymetry.

The analysis of the differences between these two bathymetry datasets have highlighted some differences of more than 200 m near the south-western coast of Greenland (not shown here) that could explain the very different results obtained with the hydrodynamic modelling in this region. For the M2 main tidal component, the global vector difference to the tide gauge database is 60.5 $\mathrm{mm}$ for the simulation based on the composite bathymetry and $79.4 \mathrm{~mm}$ for the simulation based on the RTopo-1.0.5 bathymetry. If the Qaqortoq tide gauge is removed from the validation database, the M2 global vector difference decreases to $67.0 \mathrm{~mm}$ for the simulation based on the RTopo-1.0.5 bathymetry, while it remains stable $(60.4 \mathrm{~mm})$ for the simulation based on the composite bathymetry. This analysis confirms that the composite bathymetry dataset is the better choice for this study. It should be noted that a new version of the R-Topo bathymetry (R-Topo-2.0.1, Schaffer et al., 2016) was released very recently with improvements around Greenland. Analysis of this new bathymetry dataset is ongoing and will be presented in a later paper.

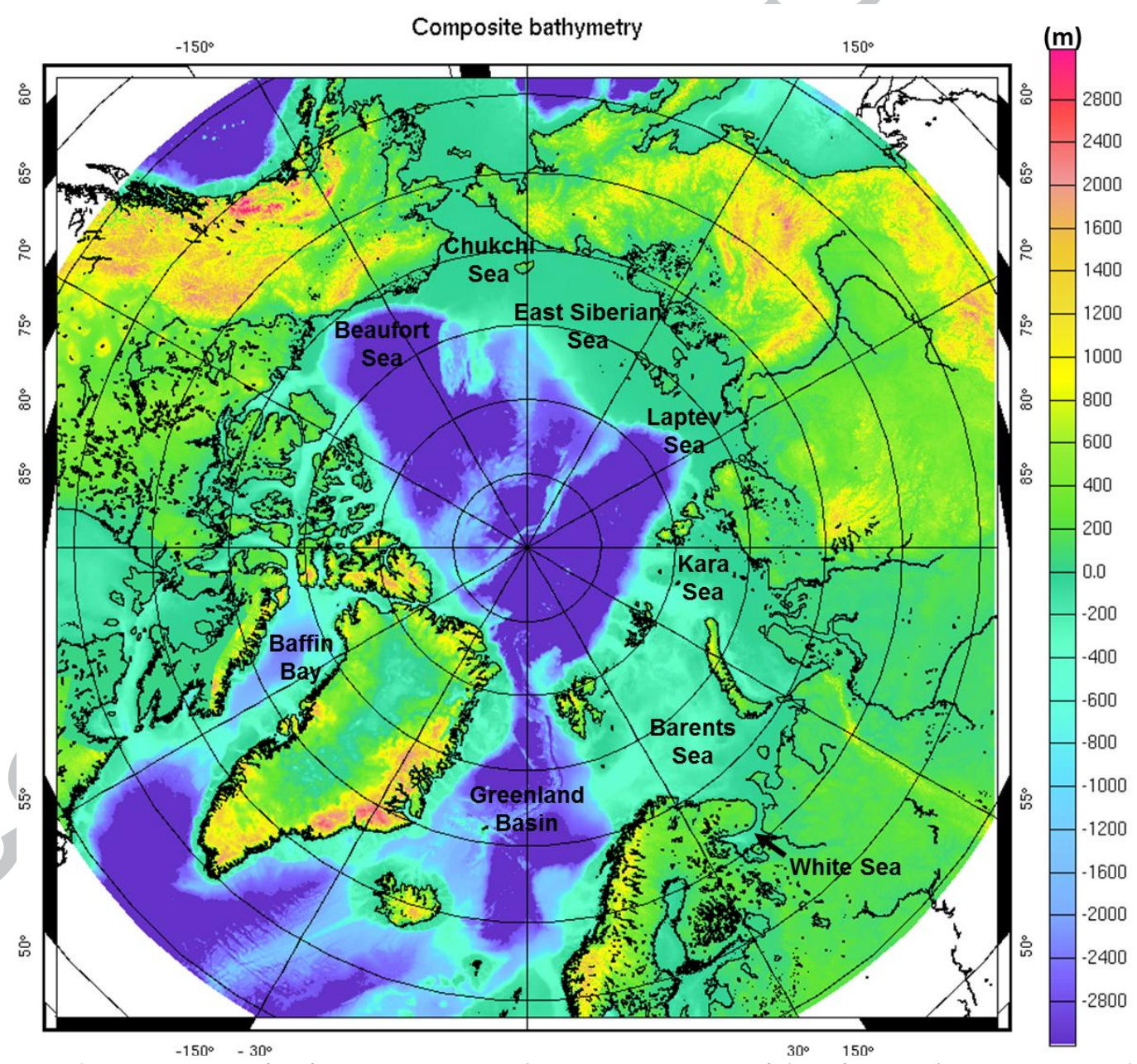

Figure 4: Composite bathymetry (in $m$ ) from LEGOS used for the implementation of the regional tidal model in the Arctic Ocean. The main seas of the region are also indicated. 


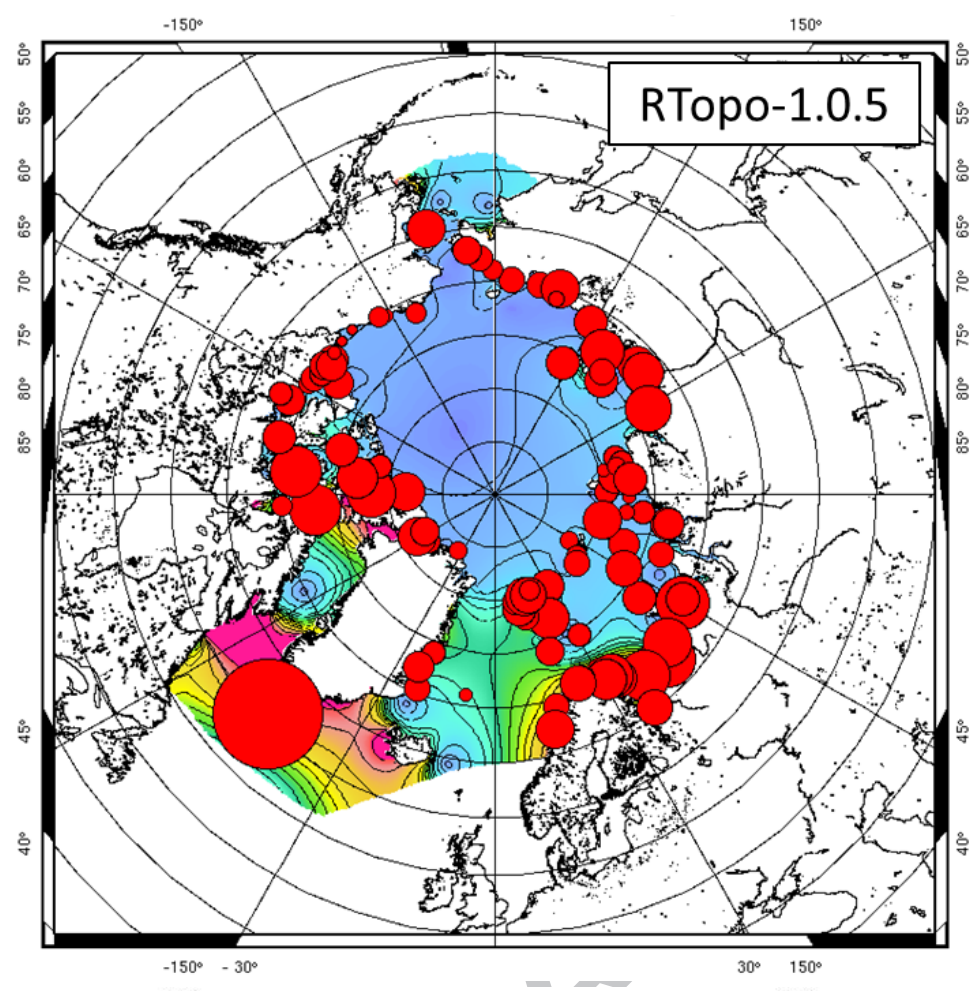

(a)

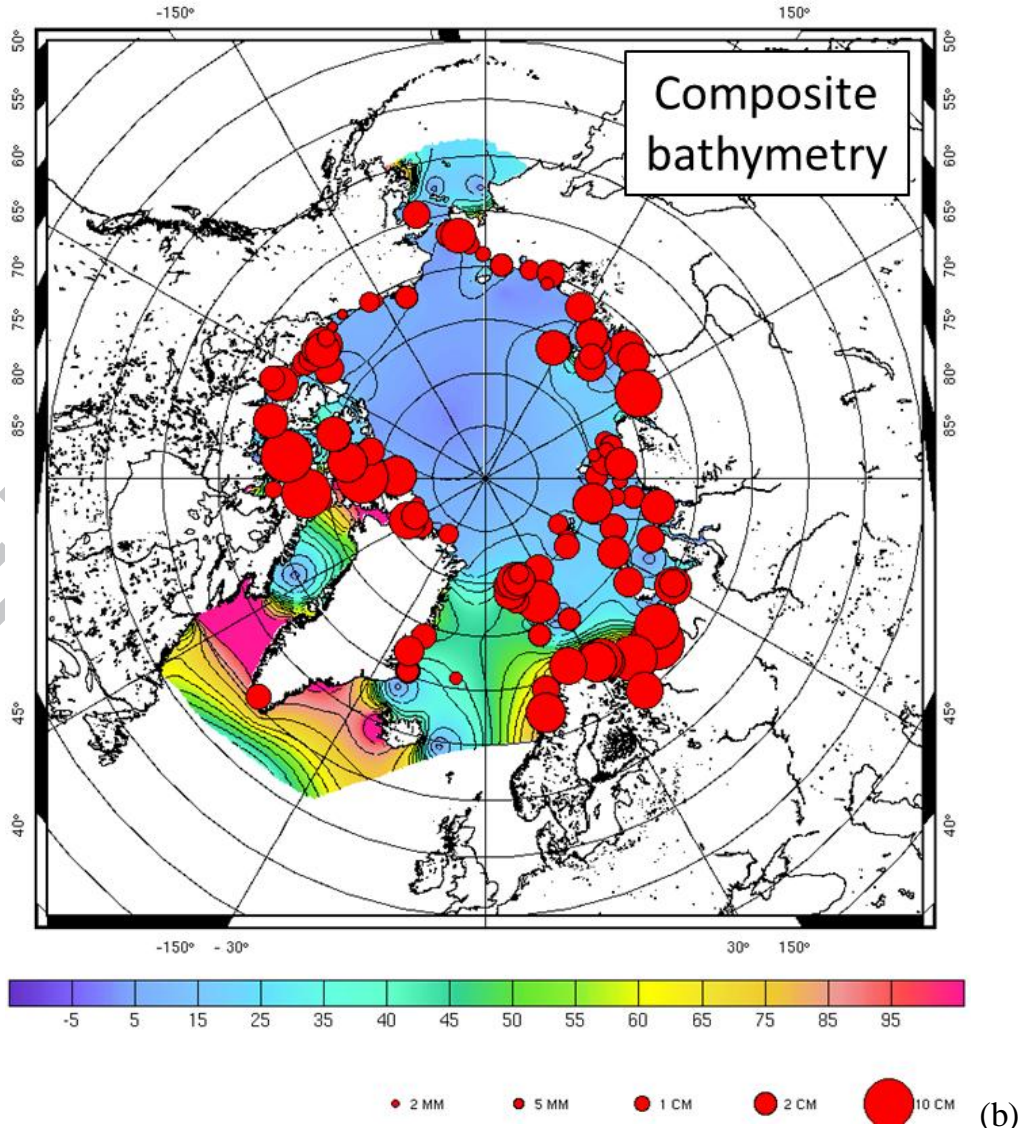

Figure 5: Hydrodynamic model performance for the M2 tidal component, using either the R-Topo1.0.5 beta bathymetry (a) or the composite bathymetry from LEGOS (b). The colors show the M2 amplitude (in $\mathrm{cm}$ ) and the red dots show the vector differences between the model simulations and the tide gauges. 


\subsubsection{Boundary conditions}

The tidal boundary conditions used to run the regional hydrodynamic model in the Arctic Ocean are extracted from the FES2014 global model. At the coast, the boundaries are closed (no flow). At the open boundaries (ocean), the boundary conditions are applied to the tidal elevations (Dirichlet). The Neuman boundary conditions are known to be poorly efficient for tidal modelling, in particular in the case of a model formulated in wave equations, such as T-UGOm.

\subsection{Hydrodynamic solution}

The T-UGOm hydrodynamic model needs to be tuned in order to obtain the most accurate hydrodynamic solution. In general, it is particularly sensitive to two parameters: the bottom friction coefficient and the coefficient that characterizes the energy transfer from the barotropic mode to the baroclinic mode (internal tides), also called the wave drag coefficient. The bottom friction dissipation is generally confined to the shelf regions, whereas the wave drag dissipation is widely spread in the ocean and can be the dominant dissipation mechanism in basins where the continental shelves are of relatively small extent (Lyard et al, 2006).

The model set-up consists in varying each of these parameters separately in a large range of values in order to find the combination of parameters that gives the best solution. The parameters are varied around classical mean values, in an iterative process.

As the model is in general more sensitive to the bottom friction, especially in regions characterized by large shelf areas such as the Arctic Ocean (Fig. 4), it was the first parameter to be tuned. Then, the wave drag value was tested. Fig. 6 shows the sensitivity of the T-UGOm hydrodynamic model to the bottom friction, for the four main tidal components in the Arctic Ocean (M2, S2, K1 and O1). The chosen formulation for the bottom friction coefficient CD depends on the depth and on the roughness length Z0. In particular, using low values of bottom friction coefficient (i. e. less bottom friction) clearly increases the error of the model, as shown by the vector differences to the tide gauge stations. The value of bottom friction coefficient that minimizes the model errors for all the tidal components and in particular for M2, the main one, is $0.005 \mathrm{~m}$. Contrary to the bottom friction, the model is not sensitive to the wave drag coefficient value in this high-latitude region. As a consequence, the classical value of 50 was chosen for this parameter.

It should be noticed that the frictional stress at the top of the water column, under the sea ice cover, was not considered when tuning the parameters of the hydrodynamic model. The ensemble simulations done in the frame of the data assimilation process show that the T-UGOm hydrodynamic model is also sensitive to this aspect (see section 5.1 for more details), which was also explored in Lyard (1997a). However, the sea ice cover seasonality was not accounted for in any of the global models as well and these global tidal models are likely closer to "sea-ice-free" configuration, as the tide gauge and altimetry observations used for data assimilation or for optimal interpolation were mainly measured in sea-ice-free conditions. 


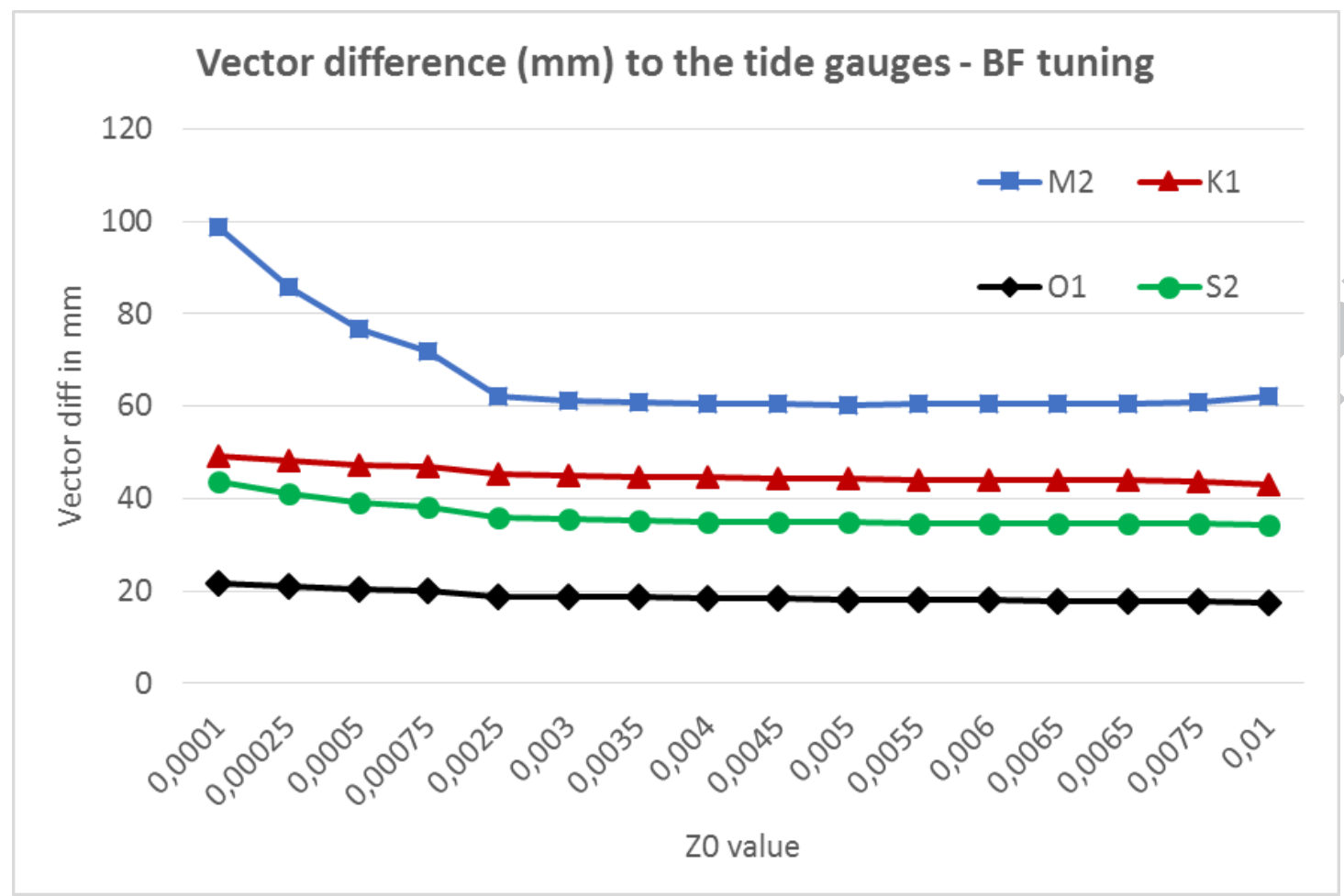

Figure 6: Vector difference between the hydrodynamic model and the tide gauge stations for the main tidal components (M2, S2, K1 and O1), for each hydrodynamic simulation performed in order to tune the bottom friction coefficient (roughness length $\mathrm{ZO}$ in $\mathrm{m}$ ).

The performances of the best hydrodynamic simulation resulting from this tuning are illustrated in Fig. 7 ("Arctic hydro" column) through the comparison to the tide gauge database. This hydrodynamic simulation is compared to the reference model AODTM, a regional hydrodynamic tidal solution computed by Padman and Erofeeva (2004), as well as to the hydrodynamic simulation (no data assimilation) used for the computation of the FES2014 global model ("FES2014 hydro" column) and the FES2014 global model (with assimilation), used as boundary conditions.

As expected, the model that globally obtains the best results is the assimilated FES2014 global model ("FES2014" column), as part of the tide gauge observations assimilated in this model is used in this validation, so the exercise is biased.

However, the regional Arctic hydrodynamic simulation performs equally or even better than the assimilated FES2014 global model for the semi-diurnal components (M2 and S2). This is due to two main reasons: the high resolution of the mesh and the boundary conditions extracted from the FES2014 global model.

For the diurnal tidal components (K1 and O1), the performances of the regional hydrodynamic model are still good, but the FES2014 global model performs better, in particular for K1. This result could be linked to the definition of the wave drag parameter physics at high latitudes in the TUGOm model. Indeed, the critical latitudes of the diurnal tidal components are far below $60^{\circ}$ and the physics in the T-UGOm model might be different from reality at the scales reached by the regional model resolution. This effect is certainly smoothed in the FES2014 global model due to its larger grid, which explains the better performance of the global model for these tidal components. Improving these results would demand some developments and changes in the physics of the TUGOm model that are far beyond the scope of this work. In addition, data assimilation is a way to 
constrain the tidal solution and obtain better performances, as it is shown in the following sections.

Regarding the comparison to the AODTM regional model, our regional prior non-assimilated hydrodynamic solution performs quite better or equally (for O1) than this model, with a dramatic improvement of $3 \mathrm{~cm}$ on $\mathrm{M} 2$ and almost $2 \mathrm{~cm}$ on $\mathrm{S} 2$.

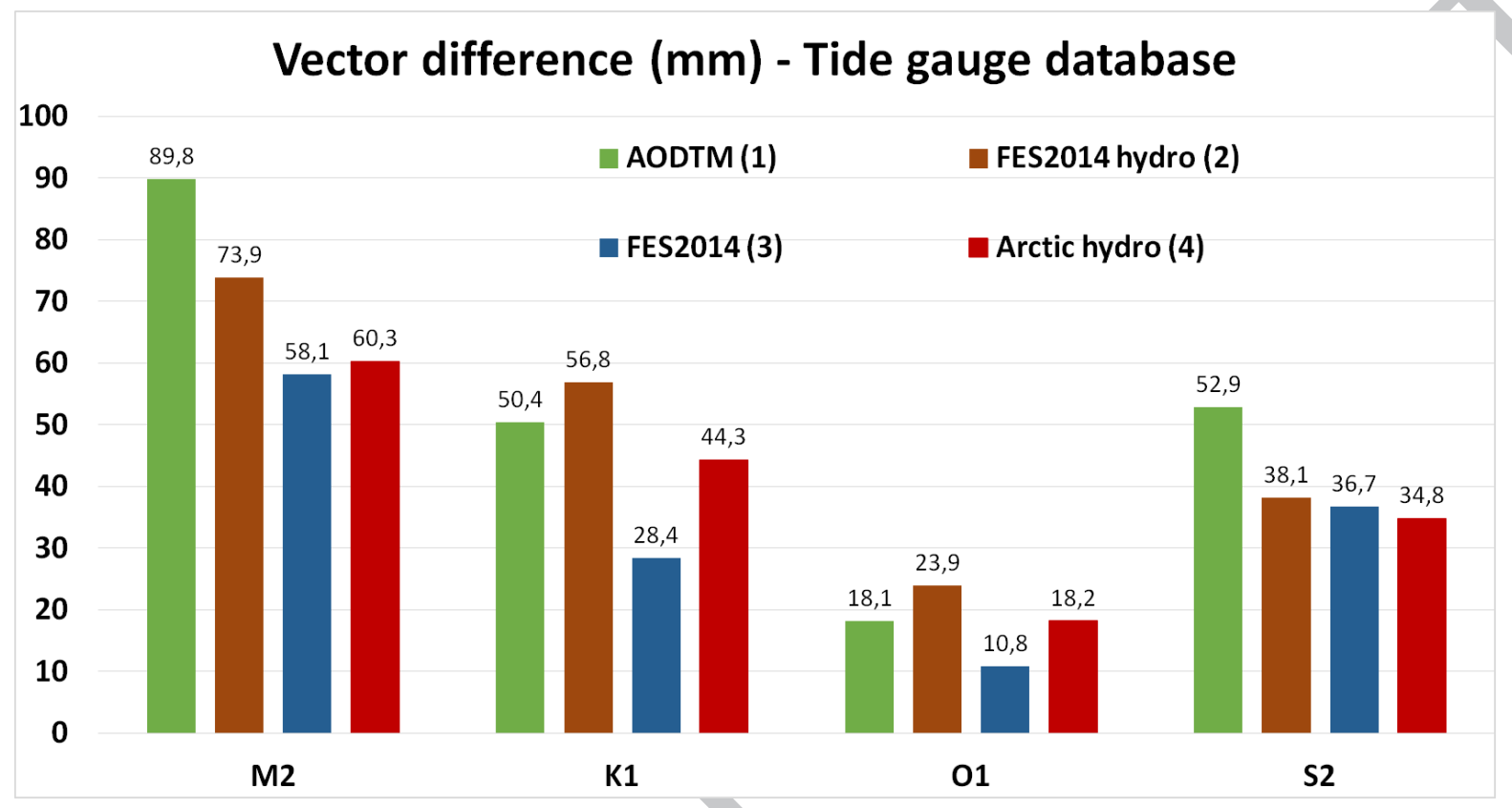

Figure 7: Vector differences between the tide gauge observations and tidal models: the regional hydrodynamic simulation in the Arctic Ocean (no data assimilation), the AODTM regional hydrodynamic simulation, the FES2014 global hydrodynamic simulation and the FES2014 assimilated global model, for the main tidal components. The numbers in brackets give the bar number of each model.

\section{Data assimilation}

The assimilation process enables to generate data assimilated solutions that minimize the distance between the prior non-assimilated hydrodynamic simulation and the observations, taking into account their respective errors. The assimilated solutions are thus optimal in the least squares sense as they are coherent with both the observations and the physical structures described by the hydrodynamic model.

The assimilation method used for the implementation of the Arctide2017 regional tidal model is based on the ensemble Kalman Filter in a formulation based on the notion of representer functions for the observations (Bennett, 1992; Lyard, 1997 b; Echevin et al, 2000; Evensen, 2003). The representers define the influence domain of the observations. With this approach, the covariances of the model errors are estimated by the ensemble covariances of the model errors, through ensemble stochastic modelling. In the frame of the hypotheses of BLUE (Best Linear Unbiased Estimator) and stochastic modelling, the errors of the model are supposed to be unbiased, i.e. zero-mean. As a consequence, the ensemble covariances of the model errors can be identified to the ensemble covariances of the model variables. To estimate the ensemble covariances of the model variables, an ensemble of model simulations is generated with perturbations of one or more parameters of the model.

The correction obtained through the assimilation of a given observation depends on the correlations between the errors associated with both the observed variable and the model variable to 
be corrected. If the observation error is higher than the model error, there is no need to strongly constrain the model and the correction is weak. If the model error is higher than the observation error, it is the reverse.

It should be noticed that for this very work the assimilation is not performed in time-stepping mode but in the spectral domain, as the objective is to correct the tidal harmonic constituents (amplitude and phase lag) generated with the hydrodynamic model with tidal harmonic constituents derived from the harmonic analysis of altimetry and tide gauge sea surface height time series.

\subsection{Ensemble simulations}

As mentioned above, a way to describe the errors in the hydrodynamic model consists in varying the parameters that drive these errors, thus generating an ensemble of perturbed simulations centred on the reference prior hydrodynamic simulation. The dispersion of this ensemble of simulations gives a geographical picture of the sensitivity of the model to these perturbations. In order to be sure that the perturbed simulations are realistic, each of them is systematically validated against observations (tide gauge and/or satellite altimetry data).

The tide variables (amplitude and phase lag of the elevations and the currents) computed with a numerical model such as T-UGOm contain errors for several reasons:

- The physics in the model is not perfect: the parameters that characterize the ocean dynamics processes are not all well-known and some of them are approximated or even neglected. For example, the local variations of the bottom friction coefficient are badly known. The definition of the wave drag coefficient that characterizes the energy transfer from the barotropic mode to the baroclinic mode also raises questions in some cases, such as the diurnal tidal components at high latitudes.

- The environmental data used as inputs in the model contain errors (bathymetry, coastline).

- The boundary conditions are not totally reliable, as they come from another model with a lower resolution.

In the case of the Arctic Ocean, the physical parameter that mainly drives the model errors is the bottom friction coefficient, as previously shown. The wave drag coefficient, as currently defined in T-UGOm, has no strong impact on the hydrodynamic simulations in this region. Regarding the bathymetry, the strategy to generate the ensemble of simulations is generally to compute hydrodynamic simulations with different bathymetry datasets. This is possible in the case of a global model, as there are different versions of the various bathymetry products, with improvements in various regions of the globe. However in the case of the Arctic Ocean, the number of really different datasets is too small to build an ensemble of perturbed simulations that would be representative of the model sensitivity to this parameter.

As a consequence, the perturbed simulations in the Arctic Ocean were only performed on the bottom friction coefficient. The analysis of the hydrodynamic model errors due to the bottom friction was done by dividing the model into sub-basins, based on the rate of energy dissipated because of the bottom friction. The sub-basins where the bottom friction coefficient has been varied are the areas of highest dissipation (polygons in Fig. 8). In each of these polygons, the roughness length was varied as follows: $0.0001 \mathrm{~m} ; 0.0005 \mathrm{~m} ; 0.001 \mathrm{~m} ; 0.0025 \mathrm{~m} ; 0.0075 \mathrm{~m} ; 0.01 \mathrm{~m} ; 0.015 \mathrm{~m}$; $0.02 \mathrm{~m} ; 0.025 \mathrm{~m} ; 0.03 \mathrm{~m} ; 0.04 \mathrm{~m} ; 0.05 \mathrm{~m} ; 0.1 \mathrm{~m}$. This led to an ensemble of 104 simulations that were all validated against the tide gauge database. 


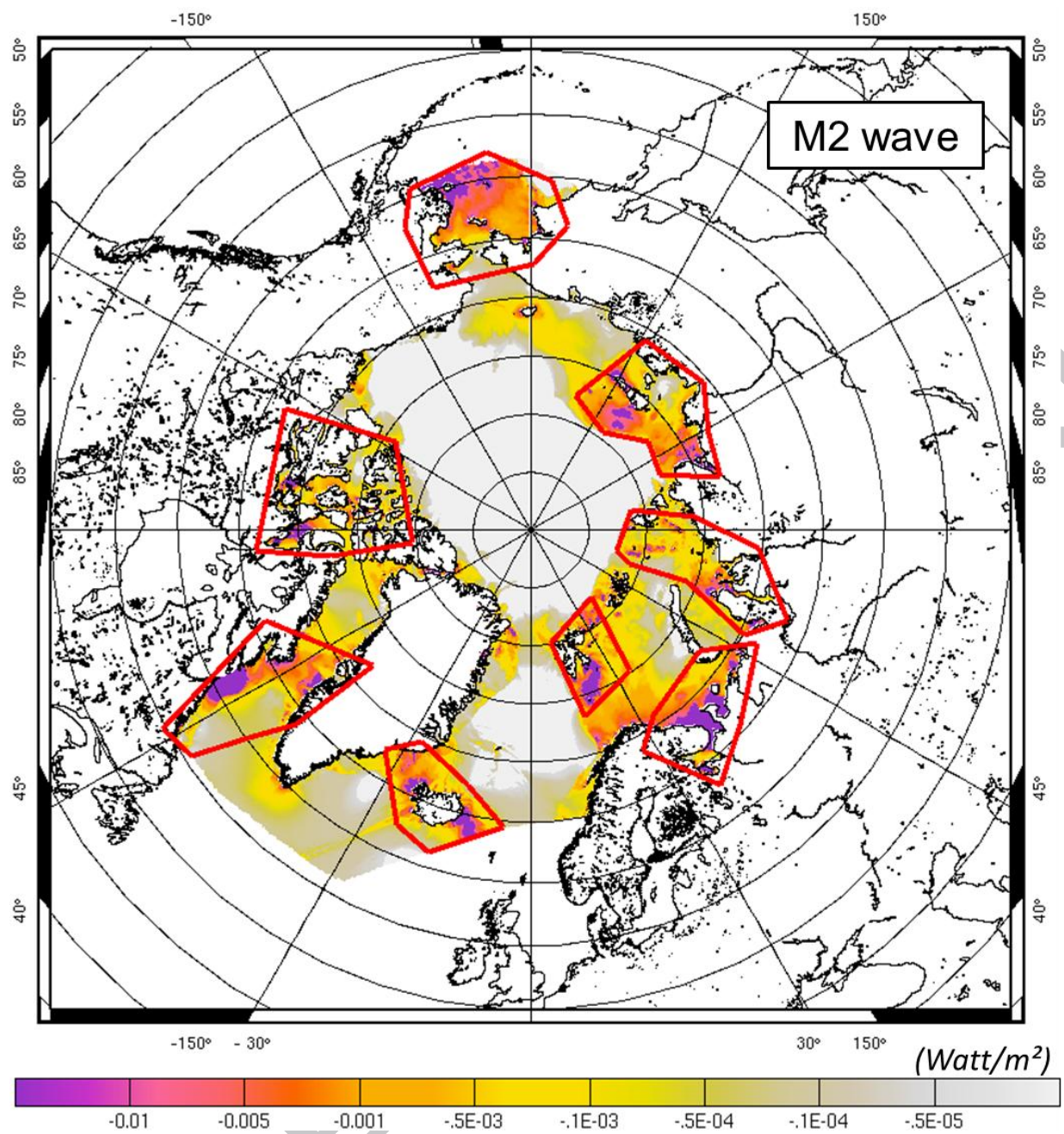

Figure 8: Energy dissipation due to the bottom friction for the prior hydrodynamic solution. The polygons show the zones where the bottom friction coefficient was varied in order to build the ensemble of simulations.

In the Arctic Ocean, another possible source of errors in the hydrodynamic model is the presence of sea ice, which is an important local process with strong seasonal variations. Fig. 9 shows the sea ice extent in winter and summer 2014, as provided by the NSIDC (National Snow and Ice Data Center). The thin pink line on each plot shows the median sea ice extent computed over a 30-year period. The question of the impact of the sea ice on the tides in the Arctic has been investigated by different groups (Godin, 1980 \& 1986; Kowalik, 1981; St-Laurent et al, 2008; Kagan and Sofina, 2010). They generally observe that, both in observations and models, the seasonal variations of the global patterns of the M2 semidiurnal tide (main tidal component in the Arctic Ocean) are minor in open ocean regions and in basins that are connected to the open ocean through deep channels. On the contrary, the impact of the seasonal sea ice cover friction can reach several centimetres in terms of tidal elevations in semi-enclosed basins (such as the Hudson Bay, which is not included in the domain of the model presented in this paper) and on the Siberian continental shelf.

However, the precise parameterization of the sea ice cover friction at the top of the water column is a very complex problem. A basic solution (Lyard, 1997a) consists in considering that the friction due to the sea ice cover at the top of the water column is the same as the friction due to the bottom topography, and simply multiplying by a factor of two the friction in the area covered with 
sea ice. Of course, using a factor of two is a first approximation, as this factor should depend on the type and roughness of the sea ice.

Given the fact that the hydrodynamic simulations are done in the spectral domain and not in a time-stepping configuration for which a time-dependent sea ice cover forcing could have been implemented, several fixed conditions of sea ice cover were considered:

- winter configuration, based on the median extent of the month of March (Fig. 9 a);

- summer configuration, based on the median extent of the month of September (Fig. 9 b).

All the simulations with the perturbations of the bottom friction coefficient were done for these two sea-ice configurations, in addition to the sea-ice-free configuration. In total, the final ensemble of perturbed simulations is composed of more than 300 hydrodynamic simulations.
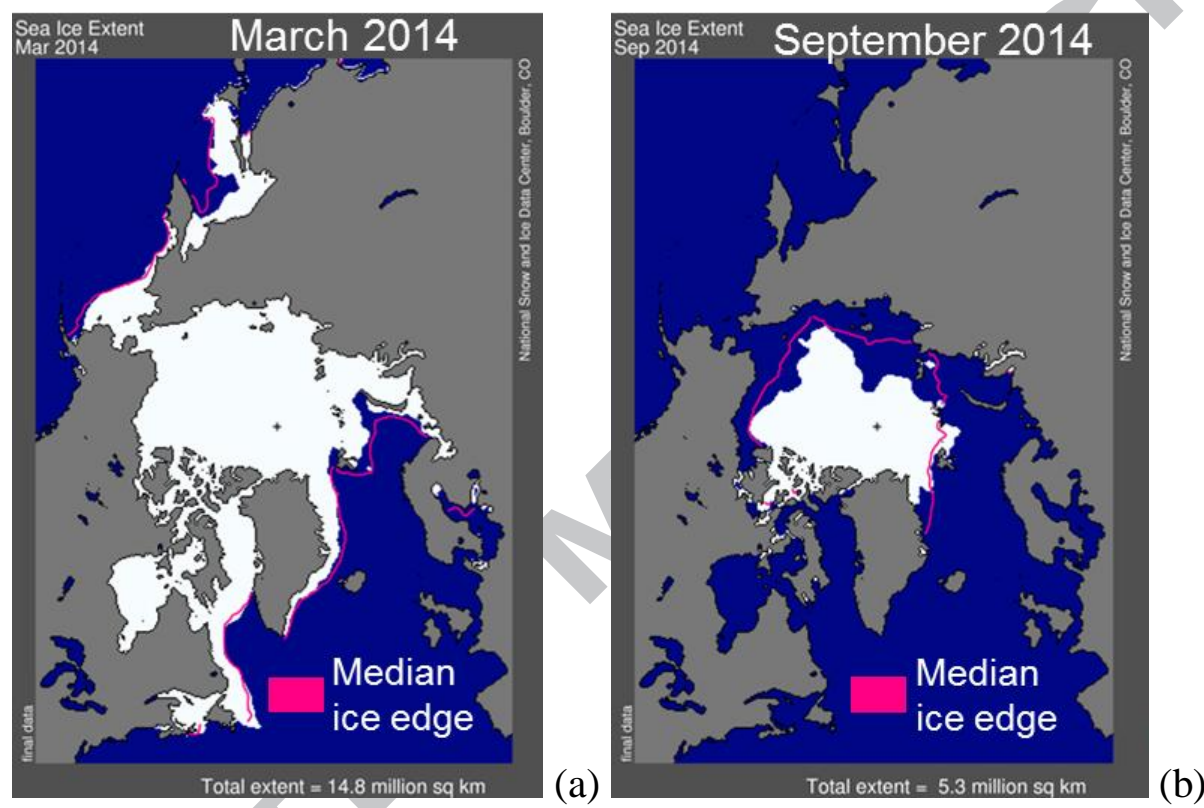

Figure 9: Sea ice extent in March 2014 (a) and September 2014 (b) and median ice edge (thin pink line) computed over 30 months of March (a) and September (b), from 1981 to 2010. Maps from the NSIDC.

\subsection{Observations}

\subsubsection{Altimetry data}

The altimetry-derived tidal harmonic constants (amplitude and phase lag) used for the data assimilation process in the Arctide2017 model were derived from the following missions:

- Envisat data (2002-2010), from $55^{\circ} \mathrm{N}$ to $82^{\circ} \mathrm{N}$;

- CryoSat-2 data in LRM mode (2010-2014), from $55^{\circ} \mathrm{N}$ to $88^{\circ} \mathrm{N}$;

- CryoSat-2 data in SAR and SARin mode (2010-2014), from $55^{\circ} \mathrm{N}$ to $88^{\circ} \mathrm{N}$.

The CryoSat-2 data in LRM mode as well as the Envisat data were taken from the RADS data archive (Radar Altimetry Database System RADS, http://rads.tudelft.nl), using the state of the art range corrections as detailed in Andersen \& Scharroo (2010). The Cryosat-2 data in SAR and SARin modes in the Arctic Ocean were retracked in-house using the primary peak retracker from the DTU-LARS retracking system (Stenseng, 2011). No ocean tide correction was applied to the altimetry data during this processing.

The RADS data were extracted using a custom-made editing selection for Polar Ocean use. 
This specific editing is based on the results of Cheng \& Andersen (2011), who showed that a high number of good sea surface height observations in RADS is rejected because the default editing rejects the sea surface heights corresponding to significant wave heights lower than 0.1 meter. The specific Polar Ocean editing retrieves roughly twice as much altimetry data in the Arctic Ocean compared to the default editing in RADS. As we partly by-pass the normal editing, an a posteriori editing must be performed. This was done by editing the sea surface height (SSH) data with respect to a $50 \mathrm{~cm}$ threshold to the DTU13 mean sea surface (Andersen et al, 2015), in order to remove possible outliers (Cheng \& Andersen, 2011). The resulting dataset did not show any increase in the standard deviation compared to the standard edited RADS dataset.

The determination of the tidal constituents was performed through a remove/restore methodology (Andersen \& Scharroo, 2010). Here, the FES2004 geocentric tide was removed from the altimetry SSH prior to tidal prediction in order to remove the known tidal signal and in particular the small scale signals that are not fully resolved with satellite altimetry. Then the tidal analysis was performed on the de-tided altimetry data and subsequently the FES2004 harmonic constituents were added/restored to the estimated harmonic constituents to obtain the final full tidal signal.

However, with a repeat period of 369 days, the alias periods of most tidal constituents are far longer than the duration of the CryoSat- 2 mission, as shown in Tab. 1 . Hence it is not possible to apply tidal analysis at each co-linear point of the CryoSat-2 altimeter ground-tracks for estimating the ocean tide as it is generally done for missions with shorter repeat periods (the Topex/Jason suite for example). For Envisat also, the direct estimation of the $\mathrm{S} 2$ tidal component is not possible due to the infinite alias period (Tab. 1 and Chen \& Hui, 2000).

Table 1: Alias periods for the main tidal components, for the CryoSat-2 and Envisat repeat periods.

\begin{tabular}{|l|c|c|c|c|}
\hline Mission & M2 & S2 & K1 & O1 \\
\hline CryoSat-2 & 112 years & Infinite & 90 years & 60 years \\
\hline Envisat & 95 days & Infinite & 1 year & 75 days \\
\hline
\end{tabular}

Another reason for not applying co-linear analysis is the fact that a large amount of data is missing or less accurate in the Arctic Ocean, in particular because of the seasonal sea ice cover. In addition, Envisat and CryoSat-2 do not have similar ground-tracks.

For all these reasons, CryoSat-2 and Envisat are in orbits that hamper the use of a classical harmonic method for tide prediction (Andersen, 1994). Consequently we decided to adapt the response formalism for tidal prediction in this project. Instead of using co-linear analysis, we applied a technique in which all tracks within a given region were used to predict the residual tidal constituents.

First, an Arctic grid of $1^{\circ}$ of latitude by $3^{\circ}$ of longitude (optimal based on experiments) was used to select the altimetry data. For each crossing of each pass of each satellite, the averaged latitude, longitude, time and sea surface height $h(t)$ for that particular crossing is computed and the averaged SSH is saved for the subsequent tidal analysis.

The compiled set of all the altimeter observations was analyzed using the "response method" (Andersen, 1995) for the remaining semidiurnal and diurnal constituents, supplemented with harmonic analysis methods for the two largest shallow water non-linear constituents (M4 and MS4, not provided afterwards) as well as the annual variation in sea level. This results in the formalism of Eq. 1 relating the observational heights $h(t)$ to the unknown parameters (Andersen, 1999 and Andersen et al, 2006): 


$$
\begin{aligned}
h(t) & =\sum_{m=1}^{2} \sum_{k=-K}^{K}\left[u_{k} a^{m}(t-\Delta k)+v_{k} b^{m}(t-\Delta k)\right] \quad \text { (diurnal, semidiurnal) } \\
& +\sum_{\mathrm{n}=1}^{\mathrm{N}}\left[\mathrm{H} 1_{\mathrm{n}} \cos \left(\sigma_{\mathrm{n}} \mathrm{t}\right)+\mathrm{H} 2_{\mathrm{n}} \sin \left(\sigma_{\mathrm{n}} \mathrm{t}\right)\right] \quad \text { (shallow water) } \\
& +\mathrm{H} 1_{\mathrm{ann}} \cos \left(\sigma_{\mathrm{ann}} \mathrm{t}\right)+\mathrm{H} 2_{\mathrm{ann}} \sin \left(\sigma_{\mathrm{ann}} \mathrm{t}\right) \quad \text { (annual variation) }
\end{aligned}
$$

where $\mathrm{a}^{\mathrm{m}}(\mathrm{t}-\Delta \mathrm{k})$ and $\mathrm{b}^{\mathrm{m}}(\mathrm{t}-\Delta \mathrm{k})$ are the real and imaginary components of the time-varying part of the tide-generating potential associated with each band and lagged by $\Delta \mathrm{k}$ days.

The unknown coefficients sought are $u_{k}$ and $v_{k}$ for the diurnal and semidiurnal constituents, respectively, and $\mathrm{H} 1_{\mathrm{n}}$ and $\mathrm{H} 2_{\mathrm{n}}$, the coefficients for each shallow water constituent of frequency $\sigma_{\mathrm{n}}$. Finally, $\mathrm{H} 1_{\text {ann }}$ and $\mathrm{H} 2_{\text {ann }}$ are the coefficients for the annual variation of frequency $\sigma_{\text {ann }}=1 / 365$ days (Andersen, 1995).

Subsequently, the response parameters $\left(\mathrm{u}_{\mathrm{i}}, \mathrm{v}_{\mathrm{i}}\right)$ are turned into tidal constituents. These harmonic constituents as well as the shallow water constituent parameters are corrected by $8 \%$ to account for the residual loading effect of the residual geocentric tide estimated in the response solution. Finally, the FES2004 ocean tide constituents are interpolated onto the location of the cells and the ocean tide signal from this model is restored in order to obtain the final altimetry-derived tidal constituents (Fig. 10).

M2 Amplitude

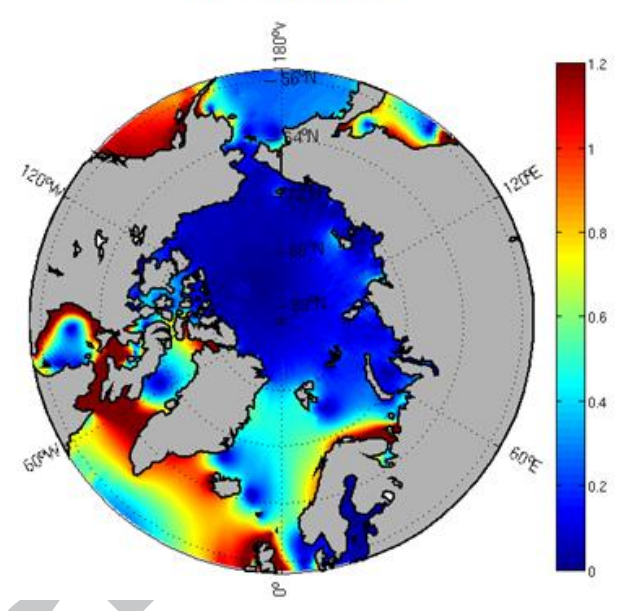

M2 Phase

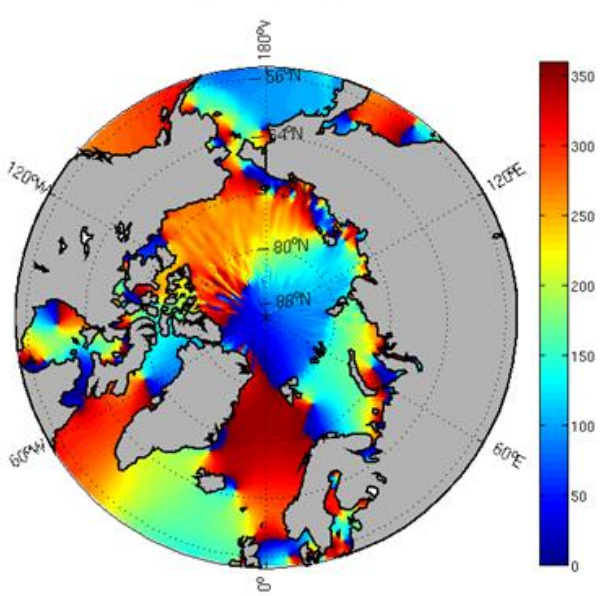

Figure 10: The M2 tidal constituents (amplitude in meters and phase in degrees) derived from satellite altimetry in the Arctic Ocean, interpolated to a regular grid for the entire Arctic Ocean.

A comparison with tide gauges was performed for the altimetry-derived tidal constituents to make a sanity check on them (Fig. 11). It is important to note that the altimetry-derived tidal constituents are only available on a relatively coarse grid $\left(1^{\circ} \times 3^{\circ}\right)$. Hence they are not comparable in accuracy to most global ocean tide models if the comparison is performed between the points of this $1^{\circ} \times 3^{\circ}$ grid. At the points of the grid, the altimetry-derived tidal constituents are comparable to the ocean tide models in terms of accuracy. 
M2 Amplitude

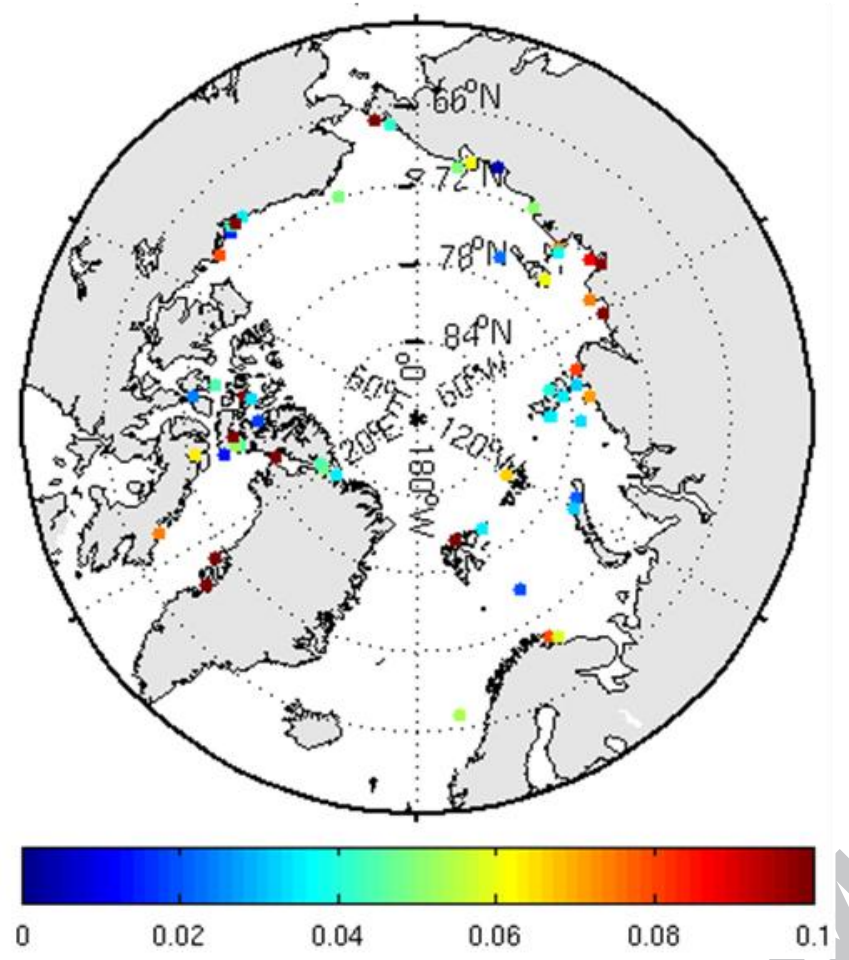

M2 Phase

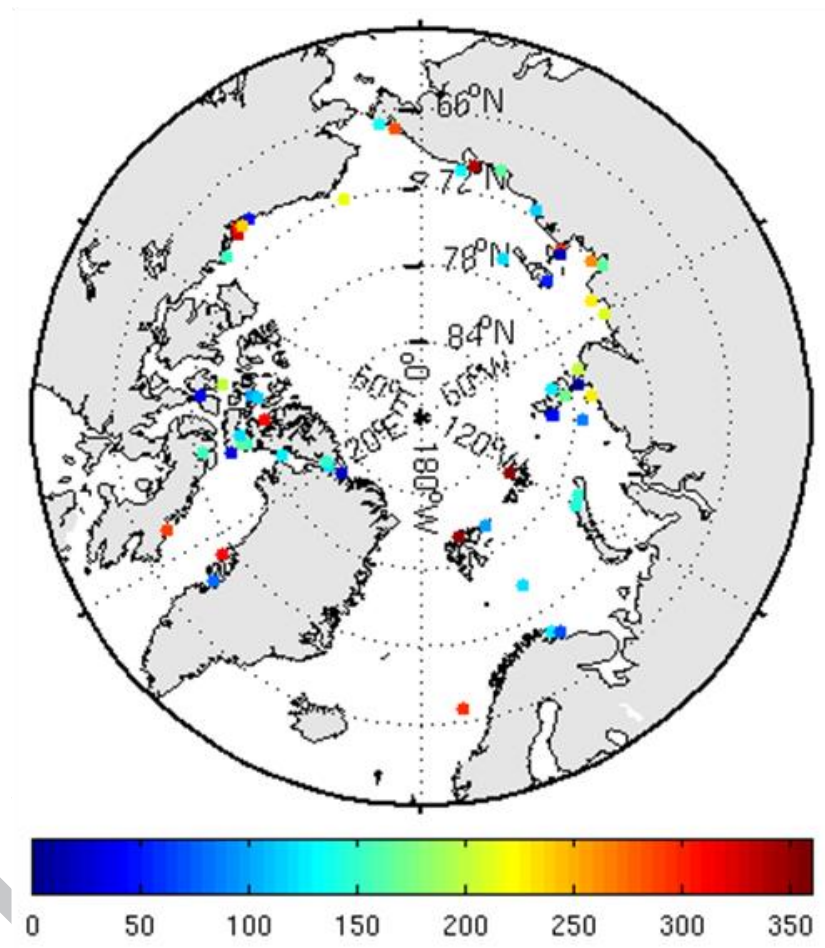

Figure 11: Residuals between the altimetry-derived ocean tide constituents and the tide gaugederived tidal constituents for amplitude (in meters) and phase (in degrees) of M2. Phase differences of $0^{\circ}$ and $360^{\circ}$ both mean that the compared phases are the same.

In total, the altimetry-derived tidal constituents are available on 1745 points in the Arctic regional model domain (Fig.12, a). By construction of the grid, the density of points highly increases close to the North Pole. On the other hand, the amplitude of the tide is very low close to the North Pole, which means that the model errors are small in this region. Given that the errors in the prior hydrodynamic solution are small and that the altimetry data are not perfect, the choice was made to maintain a balance between the weight of the observations and the weight of the model. This is why the altimetry dataset was decimated in the open ocean before the data assimilation. On the shelves, all the altimetry data were kept in the selection. The final altimetry-derived dataset contains 507 points (Fig. 12, b), with a higher density of points on the Siberian shelves and in the Bering Strait. 


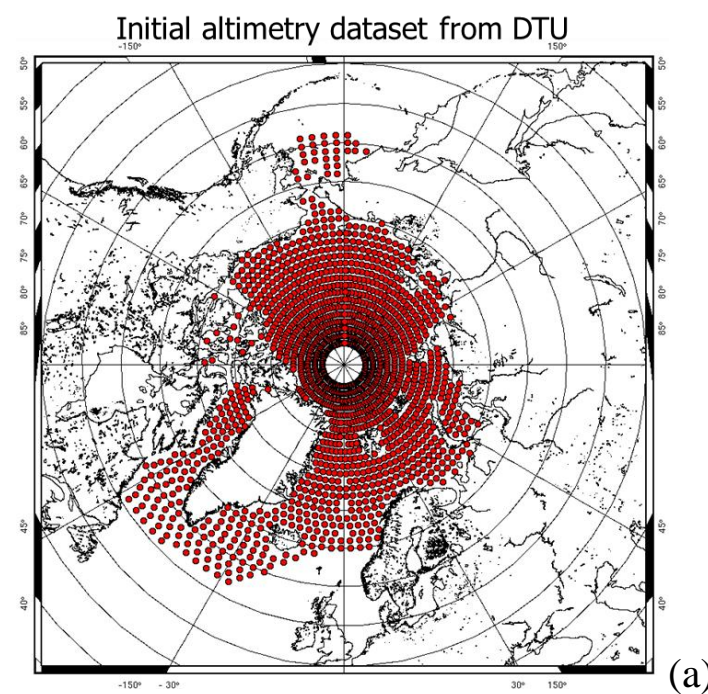

Decimated altimetry dataset for assimilation

(a)

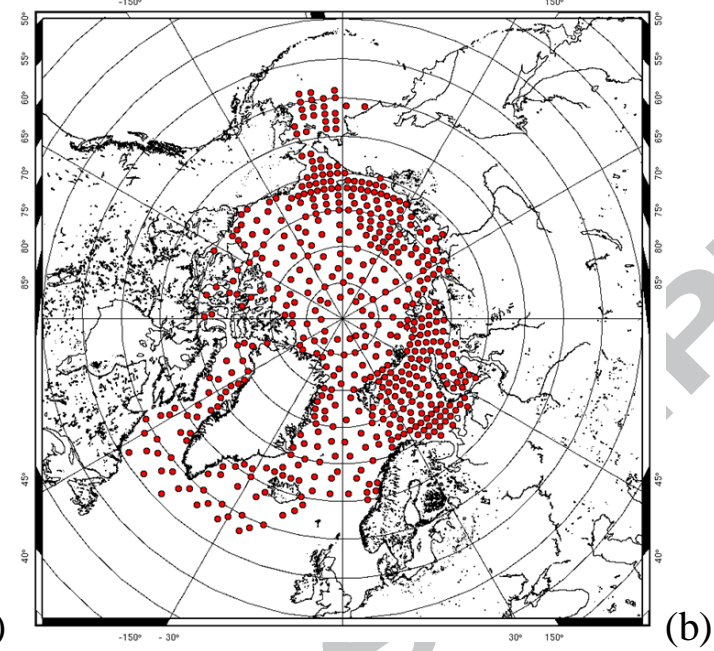

Figure 12: Initial ( $a, 1745$ points) and decimated (b, 507 points) altimetry-derived tidal constituent dataset processed by DTU Space, selection over the Arctic tidal model domain only.

The same selection was performed for all the assimilated tidal components (M2, S2, K1, O1, $\mathrm{N} 2$, P1, Q1), except for the K2 tidal component, for which no altimetry data was assimilated, due to its strong alias with the semi-annual signal at the Envisat repeat period.

Finally, as the data assimilation process needs observation error estimates, a single arbitrary value was chosen for each tidal component (see Tab. 2). For the main tidal components (M2, K1 and S2) the error was set equivalent to about 5-10\% of the tidal component RMS amplitude in the region, with some iterative adjustment in order to obtain the most optimal assimilated solution. For the smaller tidal components, using a percentage of the RMS amplitude to determine the error would lead to errors under the millimeter, which is not representative of the accuracy of the observation datasets. Indeed, the observations are not perfect and the intrinsic error of altimetry and tide gauge sea surface height observations is close to $1 \mathrm{~cm}$. This is why the error was set to $1 \mathrm{~cm}$ for all the smaller tidal components. These values are the same as for the tide gauges (see Tab. 2). Of course, an error estimate evaluated at each point of the altimetry data grid during the tidal harmonic analysis process would have helped to discriminate possible dubious altimetry observations but it was not available at that time. With a fixed arbitrary value, all the altimetry observations have the same weight in the data assimilation process, whatever their quality.

\subsubsection{Tide gauge data}

As already mentioned in section 3, the tide gauge observations are scarce and sometimes of poor or suspect quality. The database of 121 tide gauge stations resulted from a long-term strict editing process but an additional selection was performed before using this dataset in the data assimilation process. Indeed, the assimilation of highly variable observations can have a large impact on the tidal solution quality. This more restrictive selection was performed on the M2 main tidal component, by comparing the tide gauge observations to an assimilation test containing only altimetry data and thus totally independent from the tide gauge observations. The altimetry dataset is rather homogeneous in the Arctic Ocean, without any large jump observed from one point to the other. All the tide gauges that showed vector difference larger than $20 \mathrm{~cm}$ with this altimetry-only assimilated solution were discarded from the tide-gauge database. The final tide gauge dataset used for the data assimilation process contains 105 stations. 
For most of the tide gauge stations, the time series are unfortunately not available and the number of tidal components is reduced to two or three components. The tidal constituents of all the available components were assimilated. In addition, there are no error estimates associated with the tide-gauge-derived tidal constituents. This information is necessary in the data assimilation process. As for the altimetry data, an arbitrary value was chosen for all the tide gauges, depending on the amplitude of the tidal components and the intrinsic error of the tide gauge observations. The number of stations, the RMS of the tide amplitude and the error estimate values for each tidal component are summarized in Tab. 2.

Table 2: Number of tide gauge stations in the assimilation dataset, root mean square of the tide height amplitude and error estimate values attributed to the tide-gauge-derived tidal constituents, for each tidal component.

\begin{tabular}{|l|c|c|c|c|c|c|c|c|}
\hline Tidal component & M2 & S2 & K1 & O1 & K2 & N2 & P1 & Q1 \\
\hline $\begin{array}{l}\text { Number of tide gauge } \\
\text { stations }\end{array}$ & 105 & 100 & 96 & 94 & 51 & 61 & 52 & 36 \\
\hline $\begin{array}{l}\text { RMS of tide height } \\
\text { amplitude (cm) }\end{array}$ & 33 & 10 & 8 & 3 & 3 & 7 & 2 & 0.6 \\
\hline Error estimate & $2 \mathrm{~cm}$ & $1 \mathrm{~cm}$ & $1.5 \mathrm{~cm}$ & $1 \mathrm{~cm}$ & $1 \mathrm{~cm}$ & $1 \mathrm{~cm}$ & $1 \mathrm{~cm}$ & $1 \mathrm{~cm}$ \\
\hline
\end{tabular}

\section{Optimal tidal atlas}

The final dataset of tide gauge and altimetry-derived observations used for the data assimilation process contains 612 observations (Fig. 13). It should be noticed that the full dataset is only available for the M2 tidal component. For all the other tidal components, the observations assimilated into the model are part of this dataset, as the tidal constituents are not always available in the tide gauge observations (see Tab. 2). Finally, only tide gauge observations were assimilated in the case of the $\mathrm{K} 2$ tidal component, due to its strong alias with the semi-annual signal in the altimetry data, as mentioned above. 


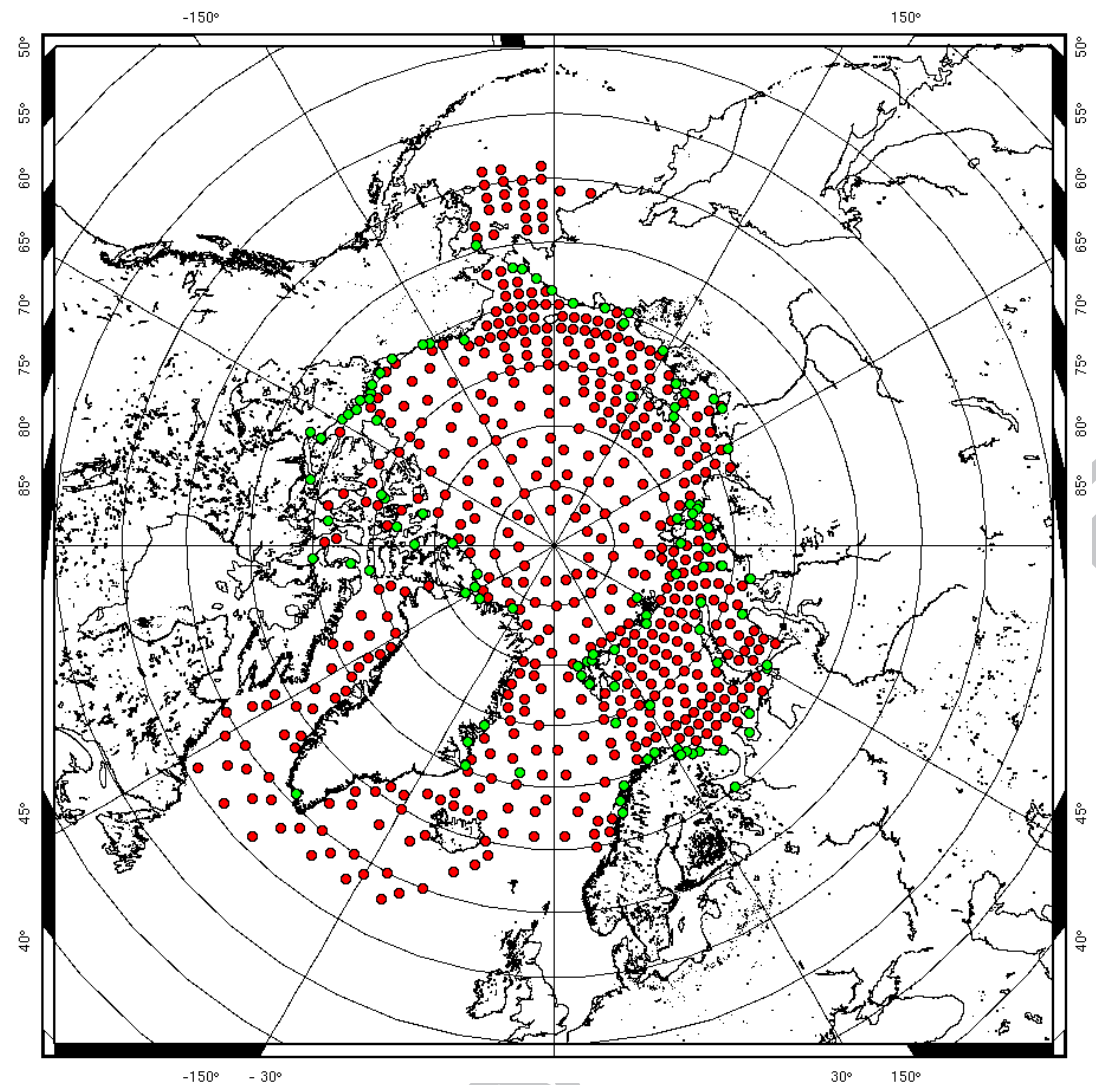

Figure 13: Final assimilation dataset (tide gauge stations in green and altimetry data in red) for the M2 tidal component.

Of course, one could argue that using most of the altimetry and tide gauge observations in the data assimilation process does not leave any independent data for the validation. However, the main objective of this work being to produce the most accurate tidal model in the Arctic Ocean, the choice was made to assimilate as many accurate observations as possible, given the small number of good-quality observations. As the data used for the assimilation are included in the validation databases, the validation process is biased compared to an independent validation. However, this analysis gives indications about the efficiency of the data assimilation process and highlights some differences in the performance of the various tidal models available.

Two databases were used to compute the validation results presented hereafter:

- the tide gauge database before the last editing specifically performed for the assimilation (121 stations);

- the complete altimetry-derived database computed by DTU Space with the Envisat and CryoSat-2 data (1745 points).

The validation was done in the frequency domain, for each tidal component, by computing the vector differences between the optimal (i.e. assimilated) regional Arctic model (Arctide2017) and the validation databases. These vector differences were compared to the results obtained with the global models in the same region and with the AOTIM assimilated regional tidal model from Padman and Erofeeva (2004). The global vector differences computed for each model and for each tidal component, against the tide gauge and the altimetry databases respectively, are showed in Fig. 14 and Fig. 15. The results obtained with the prior hydrodynamic solutions (no data assimilation) of 
the regional Arctic model ("Arctic hydro") are showed to estimate the impact of the assimilation process.

It should be noticed that the vector differences are generally higher when comparing to the tide gauge dataset than when comparing to the altimetry dataset. The tide gauge stations are often located in sheltered regions and fjords that are not representative of the open ocean tide, contrary to the altimetry data, and where the model is less precise. In addition, there may be some seasonal artefacts in the comparisons, due to the fact that more tide gauge and altimetry measurements are available in summertime, when the sea ice cover is at its lowest.

A first thing to note is the fact that all the models show equivalent performances even if they are based on different methods (Stammer et al, 2014). Indeed, the GOT4.8, DTU10 and EOT11 models are empirical models, based on an a priori global tidal model (FES2004) on which a layer of altimetry and tide gauge observations is applied through an optimal interpolation process. The FES2004, FES2012, FES2014, TPXO8 and AOTIM models are based on hydrodynamic simulation with data assimilation. Again, it should be noticed that all or part of the tide gauge observations used for the validation were assimilated in these models, which biases the validation.

Regarding the AOTIM regional model, we note that the N2 tidal constituent downloaded from https://www.esr.org/research/polar-tide-models/list-of-polar-tide-models/aotim-5/ seems to have a problem, as the comparison with both the tide gauge and the altimetry databases unexpectedly shows very large discrepancies. The same results were obtained with the AODTM N2 tidal constituent, downloaded from the same source. As a consequence, the comments on the N2 tidal constituents in the following paragraphs do not include the AOTIM model.

The comparison between the "Arctic hydro" solution, in red, and the "Arctide2017" optimal (assimilated) solution, in purple, shows the impact of the data assimilation on the regional tidal model. The improvement due to the assimilation is quite noticeable for most of the tidal components, for both validation databases. Again, as parts of these databases have been assimilated in the Arctide2017 model (and are strongly correlated with the data that were not assimilated, in the case of the altimetry database), what is highlighted here is the fact that the assimilation worked well and the model was well constrained by the observations, as the differences are reduced. For some components, the improvement is small, but coherent with the amplitudes of these components ( $\mathrm{P} 1$, Q1). 

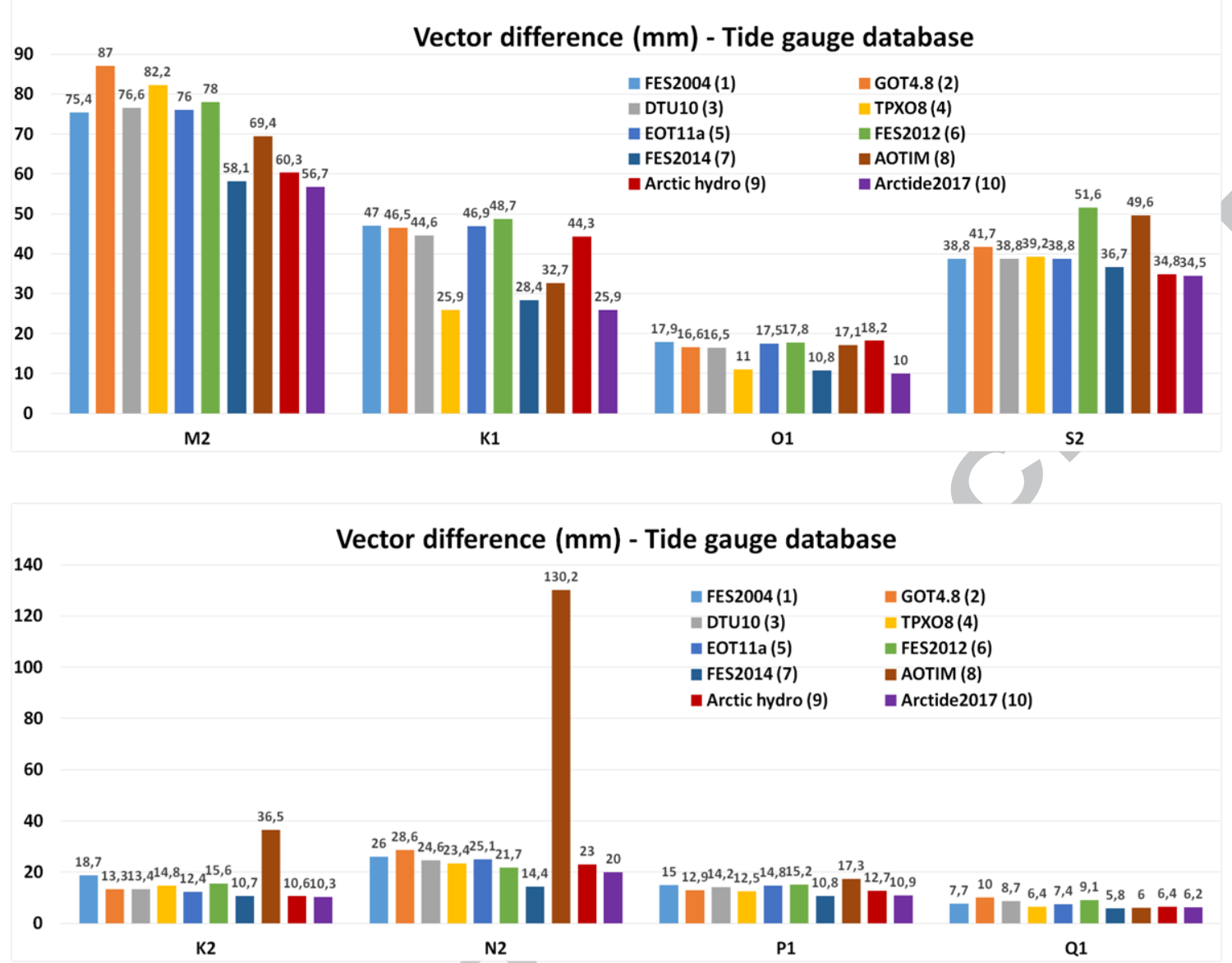

Figure 14: Vector differences between the tidal models and the tide gauge database for each tidal component. The numbers in brackets give the bar number of each model. 

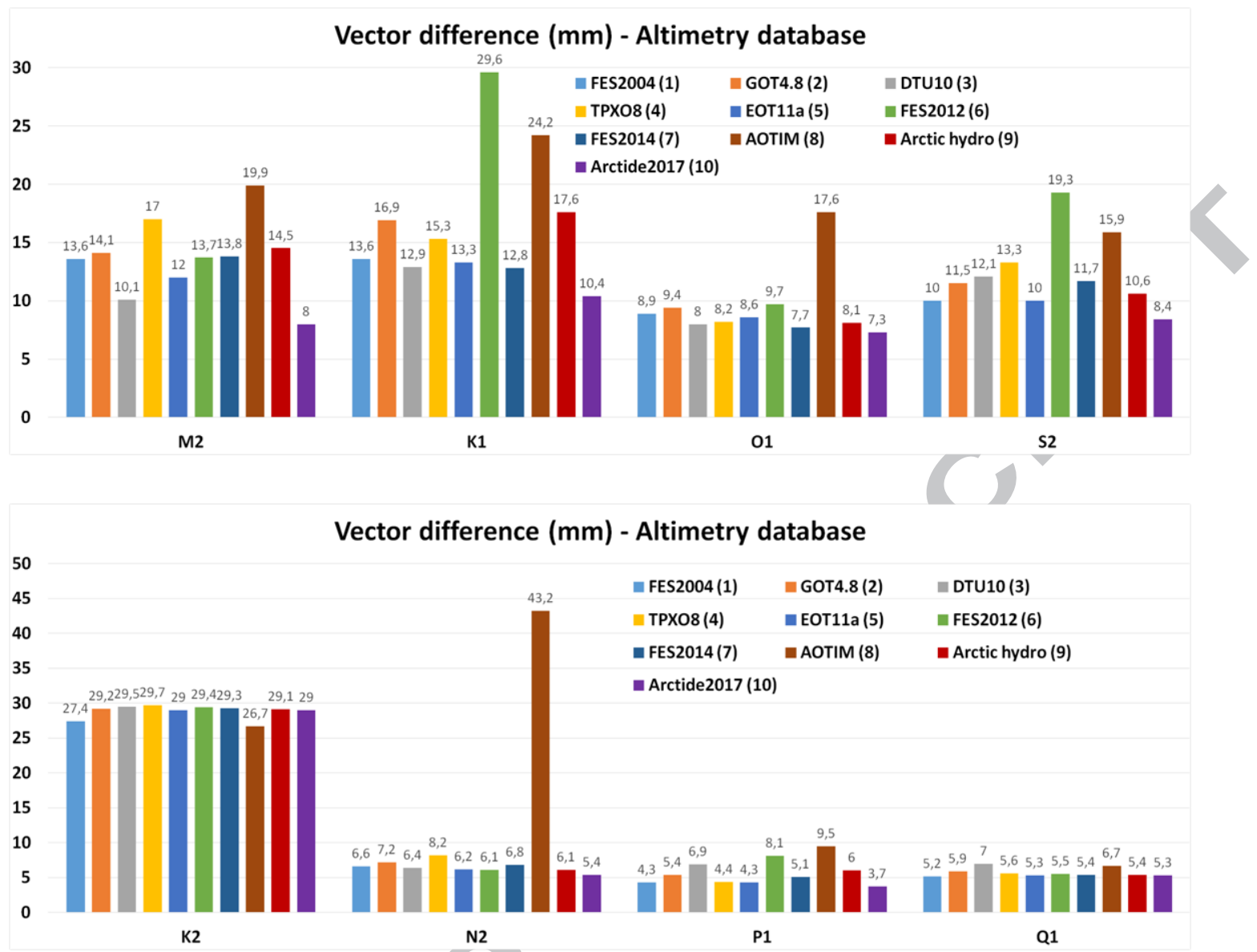

Figure 15: Vector differences between the tidal models and the altimetry database for each tidal component. The numbers in brackets give the bar number of each model.

The comparison to the other models highlights a number of points.

For the M2 and K1 components, the comparison to the tide gauge database (Fig. 14) shows a general improvement of about $2 \mathrm{~cm}$ for the Arctide2017 optimal regional model, compared to the majority of the global models and the AOTIM regional model. The improvement is close to $2 \mathrm{~mm}$ compared to FES2014. These two models obtain the best scores with this database, which was used in the assimilation (totally for FES2014, partly for the Arctide2017 regional model). The better result obtained by the Arctide2017 regional model is consequently due to the higher resolution mesh and to the better physics in the T-UGOm hydrodynamic model version used for this work. For M2, Fig. 15 shows a large reduction of the global vector difference to the altimetry database for Arctide2017, compared to FES2014. The FES2014 global model was assimilated with altimetryderived tidal constituents that were computed at the ERS/Envisat crossover points at the high latitudes. It did not benefit from the CryoSat- 2 mission data and from the specific harmonic analysis processing implemented by DTU Space.

Fig. 16 brings more information to this result on M2 as it shows the geographical repartition of the vector differences between the altimetry data and the FES2014 global model (left) and the Arctide2017 regional model (right). In particular, it appears very clearly on these maps that the main reductions of vector differences in Arctide2017 compared to FES2014 occur in the Baffin Bay, in the North West Passage and on the Siberian shelf. On the contrary, larger vector differences are noticeable for the Arctide2017 regional model in the southern part of the Baffin Bay. This may be due to the fact that the Hudson Bay was not included in the Arctide2017 model domain, as it would demand specific care to obtain an accurate tide solution, such as the implementation of a 
local tidal model.
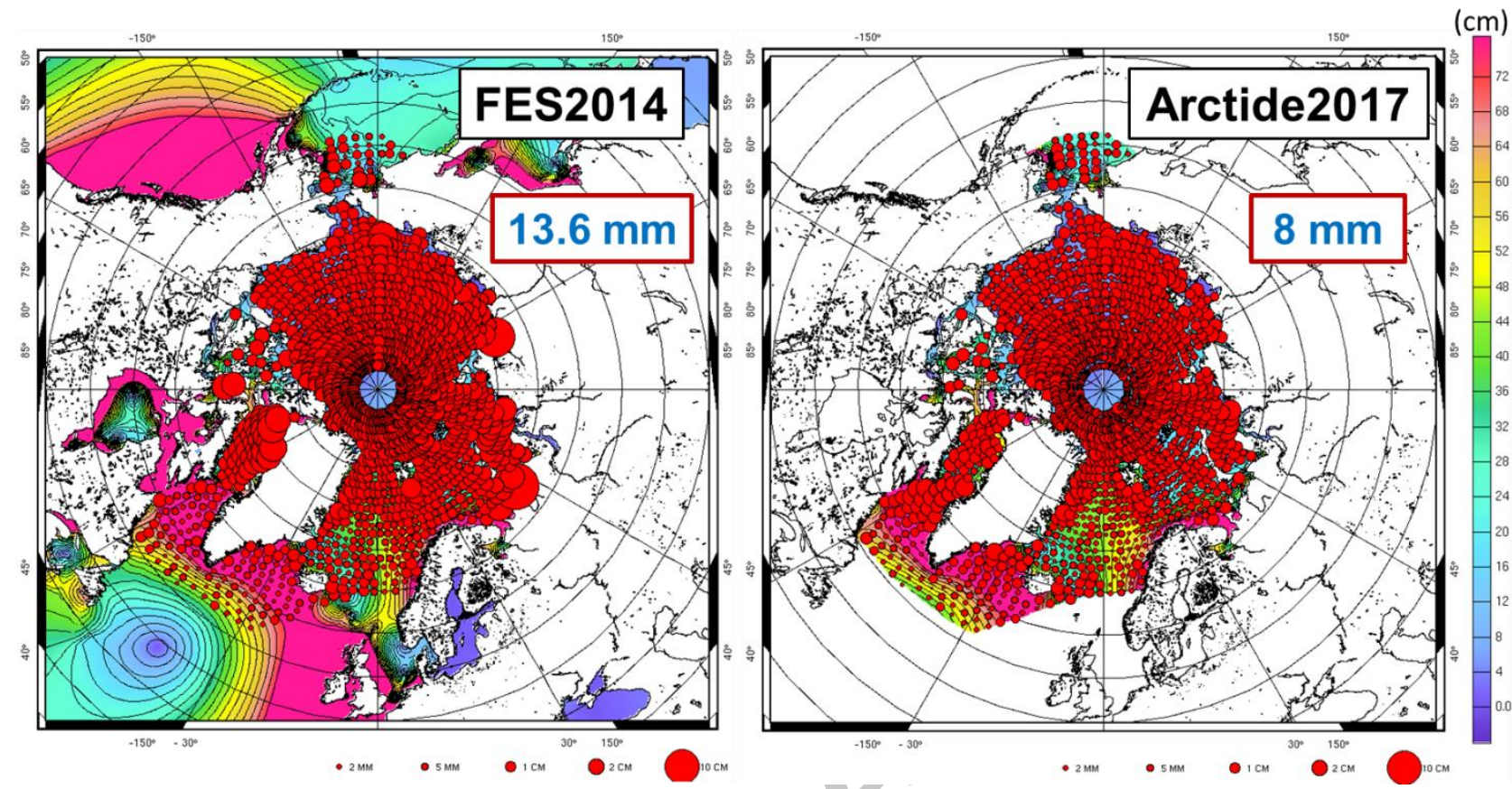

Figure 16: Vector difference between the altimetry database and the FES2014 global tidal model (left) and the Arctide2017 regional model (right), for the M2 tidal component. The global vector difference over all the altimetry points is indicated (in $\mathrm{mm}$ ). The background colour map is the amplitude of the M2 tidal component from the models (in $\mathrm{cm}$ ).

The O1, S2, P1, Q1 and N2 tidal components show similar results, with a global improvement of the regional solution thanks to the data assimilation and better performances than the global models and the AOTIM regional model, when the differences are significant.

As previously explained, the $\mathrm{K} 2$ tidal component had a special treatment regarding the assimilated dataset: only tide gauge observations were used due to the aliasing problems and the difficulty to separate between this tidal component signal and the other processes with semi-annual signals in the altimetry observations. This leads to the best solution when comparing to the tide gauge database, and to a solution that is very close to the other models when comparing to the altimetry data. The fact that the vector differences to the altimetry database are very large for all the models (about $3 \mathrm{~cm}$ ), compared to the amplitude of this tidal component (less than $2 \mathrm{~cm}$ on average), confirms that the tidal harmonic analysis on the altimetry data is not accurate for this particular tidal component.

Globally, all the validation results are coherent and demonstrate the better accuracy of the Arctide2017 regional tidal model in the Arctic Ocean, compared to the global and AOTIM regional tidal models.

\section{Conclusions}

Tidal modelling in the Arctic Ocean is challenging because of many aspects. The complexity of the coastline, the difficulty to get access to precise bathymetry information for many technical and strategic reasons, the scarcity of reliable in situ tidal measurements and the complexity of the interactions between the ocean dynamics processes and the sea ice cover are some of these aspects.

However, this paper shows that, today, regional tidal modelling at high resolution (from a few 
hundreds of meters on the shelves to about $40 \mathrm{~km}$ offshore) enables to reach accuracy of a few centimetres to a few tens of centimetres even in the most complex areas of the Arctic Ocean. This is particularly promising in terms of tide correction for the satellite altimetry missions reaching these latitudes but also for the ocean dynamics studies in this region and for the maritime activities that need precise tidal elevation estimates.

The good performances of the Arctide2017 regional tidal model are due to several factors: (1) the fine resolution of the hydrodynamic model unstructured mesh, which has been highly increased compared to the FES2014 global model, (2) the choice of the most appropriate bathymetry dataset available, (3) the physics in the T-UGOm hydrodynamic model that has been locally tuned in order to obtain a prior hydrodynamic solution as close to the observations as possible, (4) the specific processing of the altimetry data (CryoSat-2 and Envisat) performed by DTU Space in order to obtain accurate altimetry-derived tidal constituents, (5) the strict editing of the tide gauge observations, (6) the assimilation of altimetry and tide gauge observations in the a priori hydrodynamic solution.

The Arctide2017 model contains eight assimilated tidal components (Semidiurnal: M2, S2, K2, N2. Diurnal: K1, O1, P1 and Q1), which is of interest for local studies as many papers refer only to the analysis of the M2 tidal component.

Finally, the Arctide2017 tidal model was built on the basis of the FES2014 global tidal model (FES2014 tidal boundary conditions and regional improvement of the resolution of the FES2014 global mesh). It is thus possible to integrate this regional model into the global one and obtain a global model with an improved solution in the Arctic Ocean, with perfect match at the boundaries thanks to the unstructured mesh.

Some additional and independent validation activities will be performed to assess the quality of the Arctide2017 regional model but the first assessment presented in this paper already proves the high accuracy of this tidal solution. In the medium term, new regional tidal solutions should be computed as some possibilities of improvement have been identified, such as in the description of the physics in the T-UGOm hydrodynamic model, in the bathymetry dataset and in the altimetry data processing.

\section{Aknowledgement}

This work was funded in the framework of an extension of the CryoSat Plus for Ocean (CP4O) ESA STSE (Support to Science Element) project. The authors warmly thank the two anonymous reviewers for their very helpful comments and suggestions.

\section{References}

Amante, C. and B. W. Eakins (2009), ETOPO1 1 Arc-Minute Global Relief Model: Procedures, Data Sources and Analysis. NOAA Technical Memorandum NESDIS NGDC-24, 19 pp, March 2009.

Andersen, O. B. (1994), Ocean tides in the northern North Atlantic Ocean and adjacent seas from ERS-1 altimetry, J. Geophys. Res., 99 (C11), 22557-22573, http://dx.doi.org/10.1029/94JC01433

Andersen, O. B. (1995), Global ocean tides from ERS-1 and TOPEX/POSEIDON altimetry, J. Geophys Res. 100 (C12), 25249-25259, http://dx.doi.org/10.1029/95JC01389

Andersen, O. B. (1999), Shallow water tides on the northwest European shelf from 
TOPEX/POSEIDON altimetry. J. Geophys. Res, 104, 7729-7741, http://dx.doi.org/10.1029/1998JC900112

Andersen, O. B., Egbert, G. D, Erofeeva, L., and Ray R. (2006), Mapping nonlinear shallow water tides: a look at the past and future, Ocean Dynamics 56 (5), 416-429. DOI: 10.1007/s10236006-0060-7, http://dx.doi.org/10.1007/s10236-006-0060-7

Andersen, O. B., and R. Scharroo (2010), Range and Geophysical Corrections in Coastal Regions: And Implications for Mean Sea Surface Determination, in: Vignudelli S., Kostianoy A., Cipollini P., Benveniste J. (eds) Coastal Altimetry. Springer, Berlin, Heidelberg, pp103-145, ISBN: 978-3-642-12795-3, http://dx.doi.org/10.1007/978-3-642-12796-0_5

Andersen, O. B., Knudsen, P., Stenseng, L. (2015), The DTU13 MSS (mean sea surface) and MDT (mean dynamic topography) from 20 years of satellite altimetry, in: Jin S., Barzaghi R. (eds) IGFS 2014. International Association of Geodesy Symposia, vol 144. Springer, Cham, pp. 110, http://dx.doi.org/10.1007/1345_2015_182

Bennett, A. F. (1992), Inverse Methods in Physical Oceanography. Cambridge University Press, ISBN: 9780521385688

Carrère, L., Lyard, F., Cancet, M., Guillot, A., Roblou, L. (2012), FES2012: A new global tidal model taking advantage of nearly twenty years of altimetry, in Proceedings of the " 20 Years of Progress in Radar Altimetry" Symposium, Venice, Italy, 24-29 September 2012, Benveniste, J. and Morrow, R., Eds., ESA Special Publication SP-710, 2012. http://dx.doi.org/10.5270/esa.sp710.altimetry2012

Carrère, L., Lyard, F., Cancet, M., Guillot, A., Picot, N., Dupuy, S. (2015), FES2014: A new global tidal model, presented at the Ocean Surface Topography Science Team meeting, Reston, USA.

Chen, G. and L. Hui (2000), The Effect of Temporal Aliasing in Satellite Altimetry, Photogrammetric Engineering \& Remote Sensing, Vol. 66, No. 5, pp. 639-644

Cheng Y. and O. Andersen (2011), Multimission empirical ocean tide modeling for shallow waters and polar seas, Journal of Geophysical Research, Volume 116, Issue C11, (ISSN: 0148-0227), DOI: http://dx.doi.org/10.1029/2011JC007172

Echevin V., De Mey, P. and Evensen G. (2000), Horizontal and vertical structure of the representer functions for sea surface measurements in a coastal circulation model. J. Phys. Oceanog. 30: 2627-2635, http://dx.doi.org/10.1175/1520-0485(2000)030<2627:HAVSOT>2.0.CO;2

Evensen G. (2003), The Ensemble Kalman Filter: theoretical formulation and practical implementation, Ocean Dynamics 53: 343-367, http://dx.doi.org/10.1007/s10236-003-0036-9

Godin, G. (1980), Modification of the tide in the Canadian Arctic by an ice cover, Manuscript Rep. Ser., 56, Dep. of Fish. and Oceans, Ottawa, Ont., Canada

Godin, G. (1986), Modification by an Ice Cover of the Tide in James Bay and Hudson Bay, Arctic, Vol. 39, No. 1, March 1986, pp. 65-67

Jakobsson, M., Macnab, R., Mayer, L., et al (2008), An improved bathymetric portrayal of the Arctic Ocean: Implications for ocean modeling and geological, geophysical and oceanographic analyses, Geophysical Research Letters, 35, L07602, http://dx.doi.org/10.1029/2008GL033520.

Jakobsson, M., Mayer, L. A., Coakley, B., et al. (2012), The International Bathymetric Chart of the Arctic Ocean (IBCAO) Version 3.0, Geophysical Research Letters, 39, L12609, http://dx.doi.org/ 10.1029/2012GL052219 
Kagan, B. A. and E.V. Sofina (2010), Ice-induced seasonal variability of tidal constants in the Arctic Ocean, Continental Shelf Research, Vol. 30, pp. 643-647, http://dx.doi.org/10.1016/j.csr.2009.05.010

Kowalik, Z. (1981), A study of the M2 tide in the ice-covered Arctic, Modeling Identification Control, 2 (4), pp. 201-223, http://dx.doi.org/10.4173/mic.1981.4.2

Kowalik, Z. and Proshutinsky, A. Y. (1994), The Arctic Ocean Tides, in The Polar Oceans and Their Role in Shaping the Global Environment (eds O. M. Johannessen, R. D. Muench and J. E. Overland), American Geophysical Union, Washington, D. C. doi: 10.1029/GM085p0137

Le Bars, Y., F. Lyard, C. Jeandel, and L. Dardengo (2010), The AMANDES tidal model for the Amazon estuary and shelf, Ocean Modelling, 31 (3-4), 132-149, https://doi.org/10.1016/j.ocemod.2009.11.001

Lyard, F (1997a), The tides in the Arctic Ocean from a finite element model, Journal of Geophysical Research, Vol. 102, No. C7, pp. 15611-15638, http://dx.doi.org/10.1029/96JC02596

Lyard, F (1997b), Data Assimilation in a Wave Equation: A Variational Representer Approach for the Grenoble Tidal Model, J. Computational Physics, Volume 149, Issue 1, 10 February 1999, Pages 1-31. http://dx.doi.org/10.1006/jcph.1998.5966

Lyard, F., Lefevre, F., Letellier, T. and O. Francis (2006), Modelling the global ocean tides: modern insights from FES2004, Ocean Dynamics 56, 394-415, http://dx.doi.org/10.1007/s10236-0060086-x

Padman, L., and S. Erofeeva (2004), A barotropic inverse tidal model for the Arctic Ocean, Geophys. Res. Lett., 31, L02303, doi:10.1029/2003GL019003.

Schaffer, J., and R., Timmermann (2016): Greenland and Antarctic ice sheet topography, cavity geometry, and global bathymetry (RTopo-2), links to NetCDF files. Dataset \#856844. http://dx.doi.org/10.1594/PANGAEA.856844

Supplement to: Schaffer, J., Timmermann, R., Arndt, J. E., Kristensen, S. S., Mayer, C., Morlighem, M. and D. Steinhage (2016), A global, high-resolution data set of ice sheet topography, cavity geometry, and ocean bathymetry. Earth System Science Data, 8(2), 543557, http://dx.doi.org/10.5194/essd-8-543-2016

Smith, W. H. F. and D. T. Sandwell (1997), Global Seafloor Topography from Satellite Altimetry and Ship Depth Soundings, Science 277: 1956-1962

St-Laurent, P., F. J. Saucier, and J.-F. Dumais (2008), On the modification of tides in a seasonally ice-coyered sea, J. Geophys. Res., 113, C11014, http://dx.doi.org/10.1029/2007JC004614

Stammer, D., Ray, R. D., Andersen, O. B., Arbic, B. K., et al. (2014), Accuracy assessment of global barotropic ocean tide models, Review of Geophysics, 52, 243-282, http://dx.doi.org/10.1002/2014RG000450

Stenseng, L., (2011). Polar Remote Sensing by CryoSat-type Radar Altimetry. Copenhagen: DTU Space. Ph.d. Thesis downloadable from space.dtu.dk

Timmermann, R., Le Brocq, A. M., Deen, T. J., Domack, E. W., et al. (2010), Antarctic ice sheet topography, cavity geometry, and global bathymetry (RTopo 1.0.5-beta). PANGAEA. doi:10.1594/PANGAEA.741917, Supplement to: Timmermann, R., Le Brocq, A. M., Deen, T. J., Domack, E. W.,et al. (2010): A consistent dataset of Antarctic ice sheet topography, cavity geometry, and global bathymetry. Earth System Science Data, 2 (2), 261-273, 
http://dx.doi.org/10.5194/essd-2-261-20100

\section{Figure captions}

Figure 1: Resolution (in km) of the refined regional (a) and the FES2014 (b) unstructured grids in the Arctic Ocean.

Figure 2: Zoom on the FES2014 (a) and refined regional (b) unstructured grids in the North West Passage.

Figure 3: Tide gauge stations over the Arctic Ocean used for the model validation.

Figure 4: Composite bathymetry (in m) from LEGOS used for the implementation of the regional tidal model in the Arctic Ocean. The main seas of the region are also indicated.

Figure 5: Hydrodynamic model performance for the M2 tidal component, using either the R-Topo1.0 .5 beta bathymetry (a) or the composite bathymetry from LEGOS (b). The colors show the M2 amplitude (in $\mathrm{cm}$ ) and the red dots show the vector differences between the model simulations and the tide gauges.

Figure 6: Vector difference between the hydrodynamic model and the tide gauge stations for the main tidal components (M2, S2, K1 and O1), for each hydrodynamic simulation performed in order to tune the bottom friction coefficient (roughness length $\mathrm{Z} 0$ in $\mathrm{m}$ ).

Figure 7: Vector differences between the tide gauge observations and tidal models: the regional hydrodynamic simulation in the Arctic Ocean (no data assimilation), the AODTM regional hydrodynamic simulation, the FES2014 global hydrodynamic simulation and the FES2014 assimilated global model, for the main tidal components. The numbers in brackets give the bar number of each model.

Figure 8: Energy dissipation due to the bottom friction for the prior hydrodynamic solution. The polygons show the zones where the bottom friction coefficient was varied in order to build the ensemble of simulations.

Figure 9: Sea ice extent in March 2014 (a) and September 2014 (b) and median ice edge (thin pink line) computed over 30 months of March (a) and September (b), from 1981 to 2010. Maps from the NSIDC.

Figure 10: The M2 tidal constituents (amplitude in meters and phase in degrees) derived from 
satellite altimetry in the Arctic Ocean, interpolated to a regular grid for the entire Arctic Ocean.

Figure 11: Residuals between the altimetry-derived ocean tide constituents and the tide gaugederived tidal constituents for amplitude (in meters) and phase (in degrees) of M2.

Figure 12: Initial (a, 1745 points) and decimated (b, 507 points) altimetry-derived tidal constituent dataset processed by DTU Space, selection over the Arctic tidal model domain only.

Figure 13: Final assimilation dataset (tide gauge stations and altimetry data) for the M2 tidal component.

Figure 14: Vector differences between the tidal models and the tide gauge database for each tidal component. The numbers in brackets give the bar number of each model.

Figure 15: Vector differences between the tidal models and the altimetry database for each tidal component. The numbers in brackets give the bar number of each model.

Figure 16: Vector difference between the altimetry database and the FES2014 global tidal model (left) and the Arctide2017 regional model (right), for the M2 tidal component. The global vector difference over all the altimetry points is indicated (in $\mathrm{mm}$ ). The background colour map is the amplitude of the M2 tidal component from the models (in $\mathrm{cm}$ ). 
Arctide2017, A High-Resolution Regional Tidal Model in the Arctic Ocean

M. Cancet ${ }^{(\mathrm{a})}$, O. B. Andersen ${ }^{(\mathrm{b})}$, F. Lyard ${ }^{(\mathrm{c})}$, D. Cotton ${ }^{(\mathrm{d})}$, J. Benveniste ${ }^{(\mathrm{e})}$

Figures

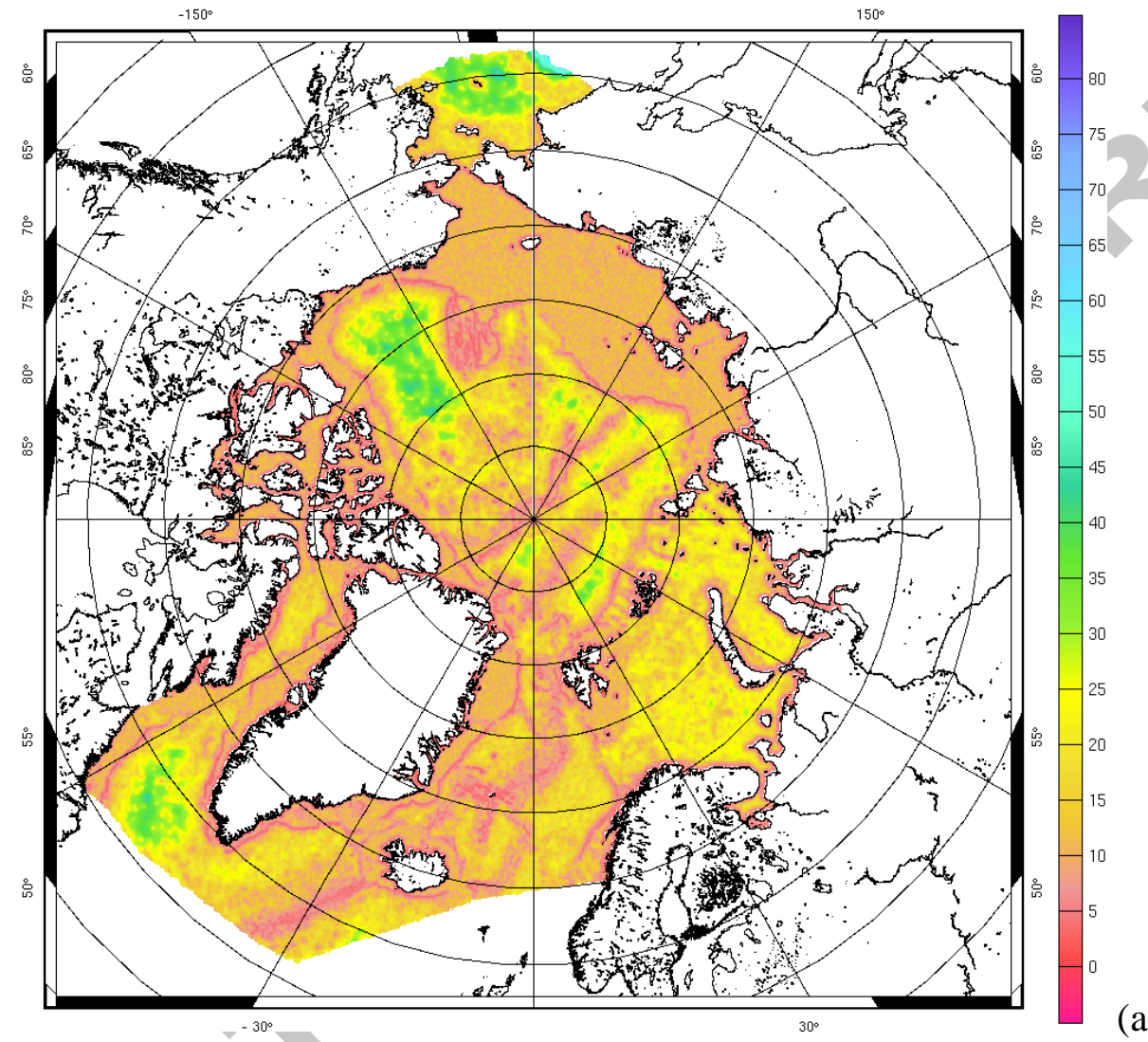

(a) 


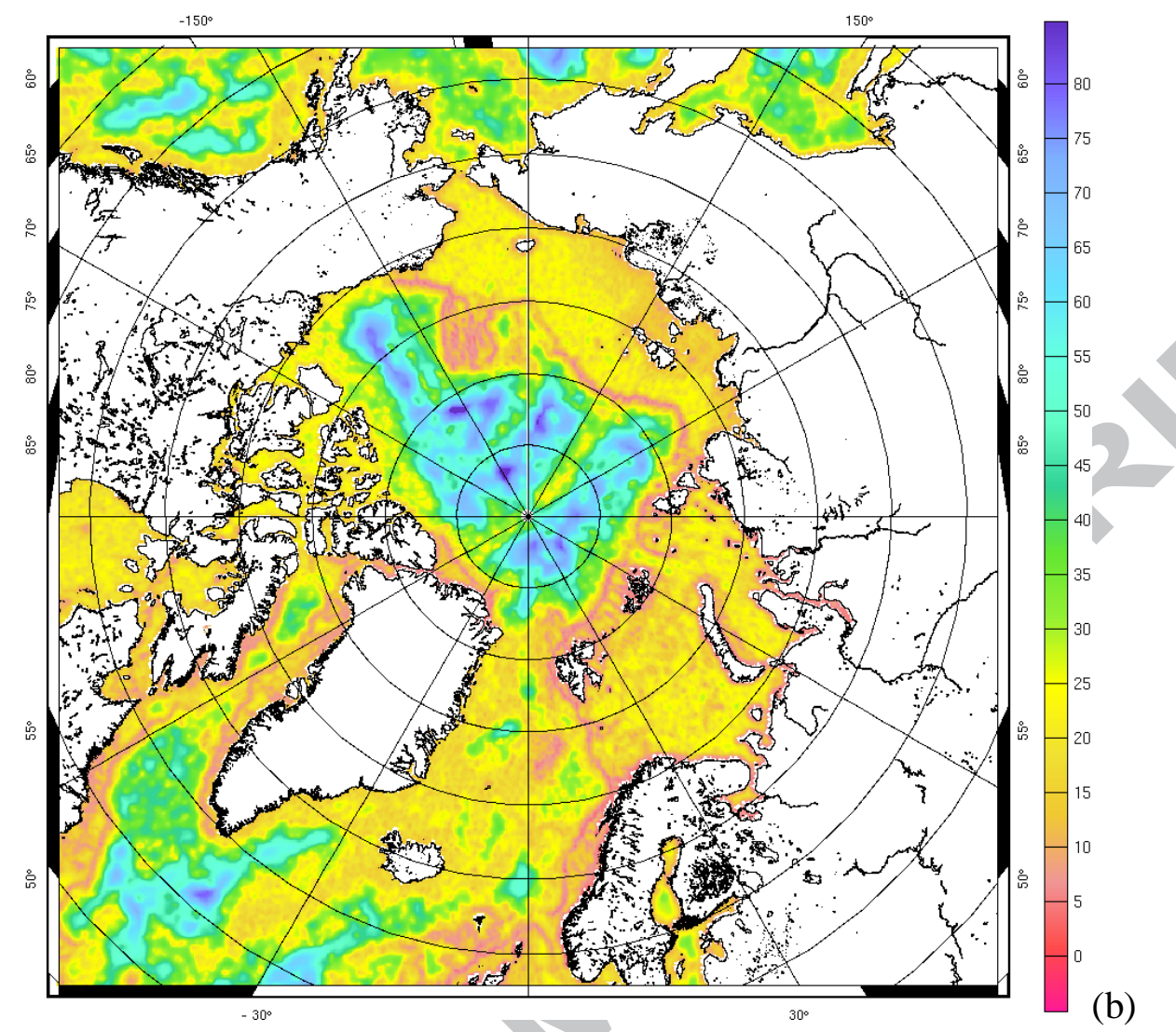

Figure 1: Resolution (in km) of the refined regional (a) and the FES2014 (b) unstructured grids in the Arctic Ocean.

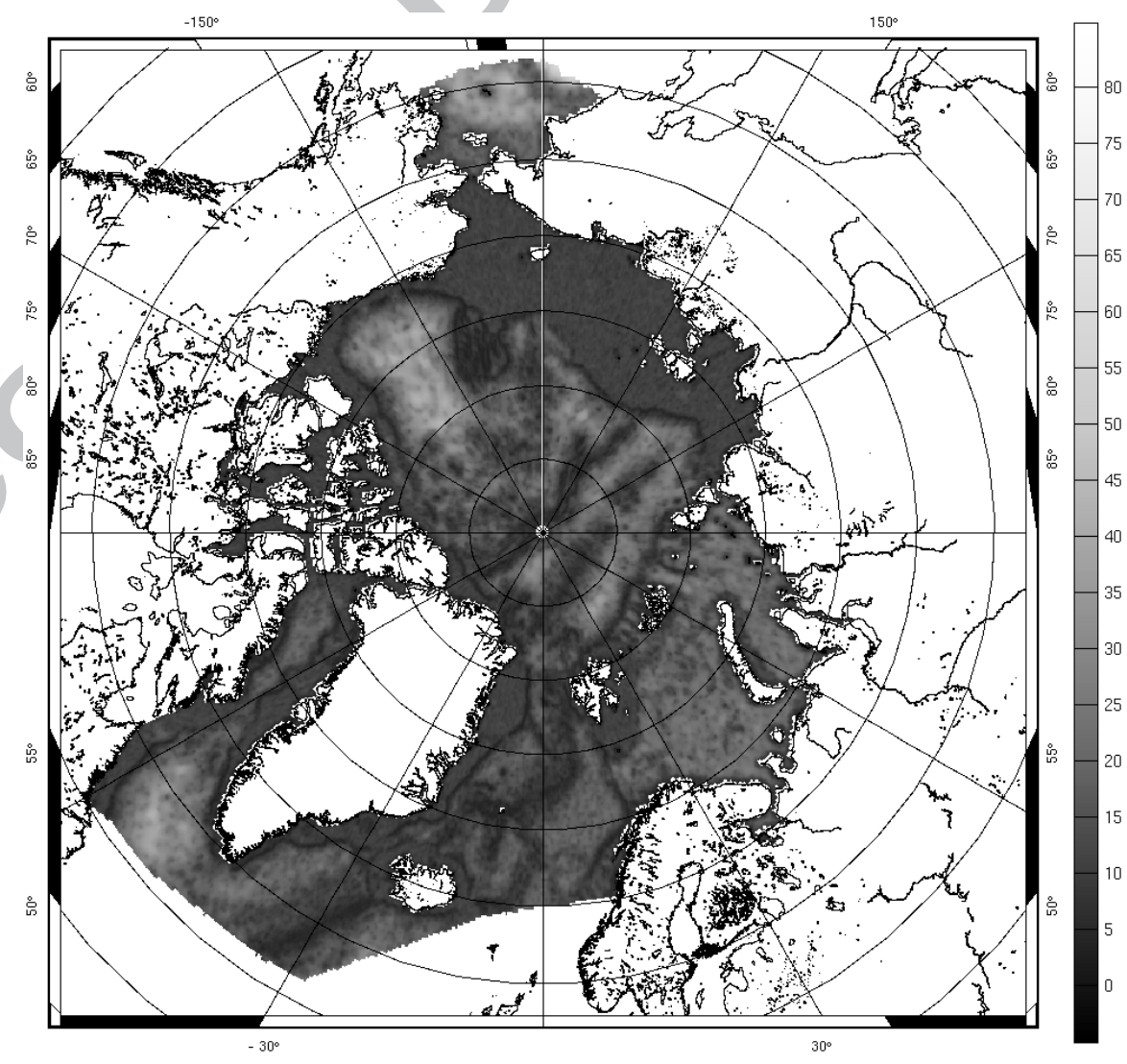

(a) 


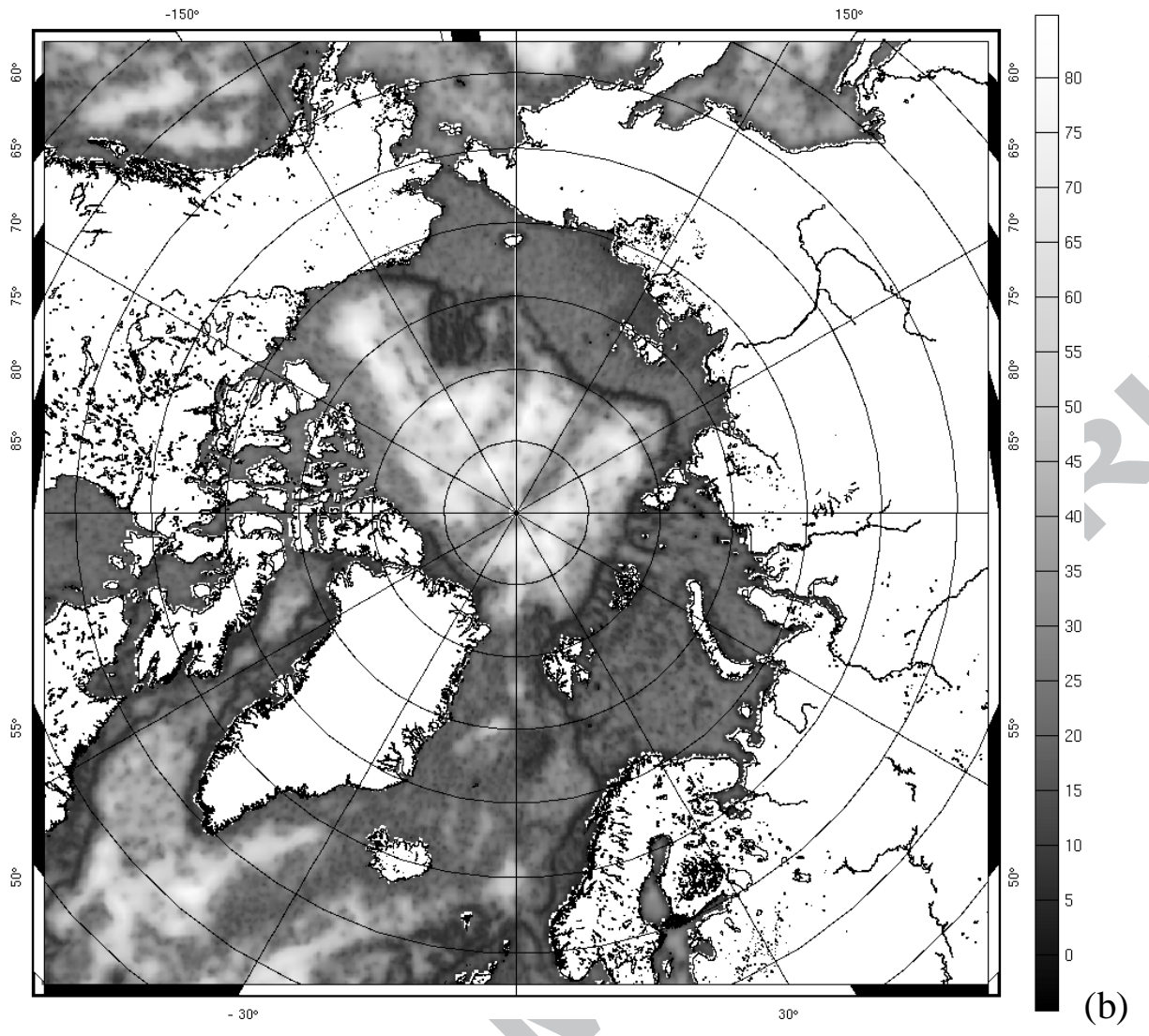

Figure 1 (black and white): Resolution (in km) of the refined regional (a) and the FES2014 (b) unstructured grids in the Arctic Ocean.

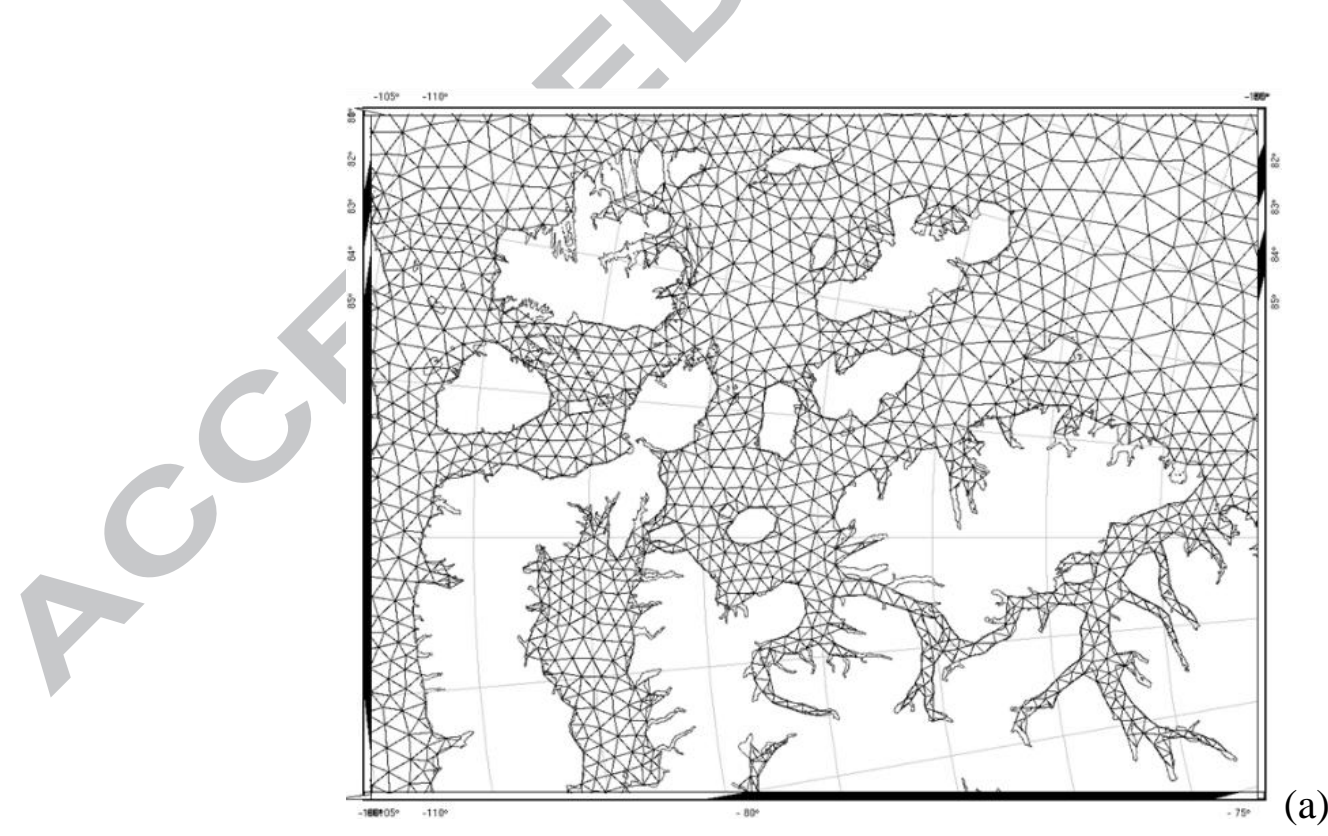




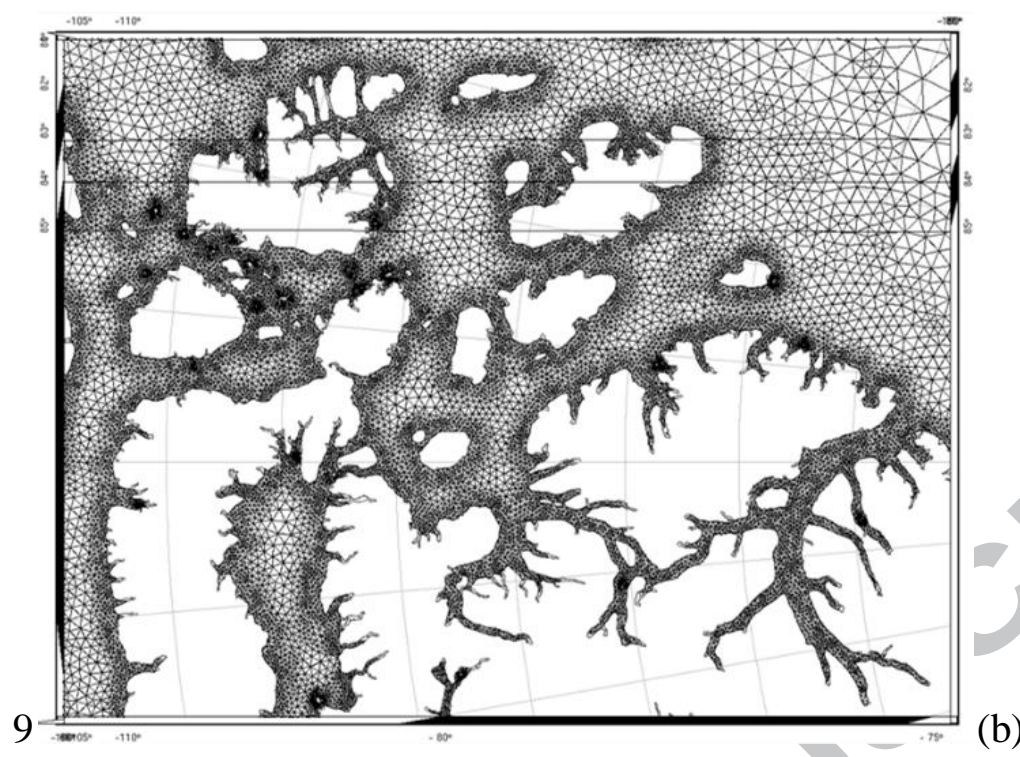

Figure 2: Zoom on the FES2014 (a) and refined regional (b) unstructured grids in the North West Passage.

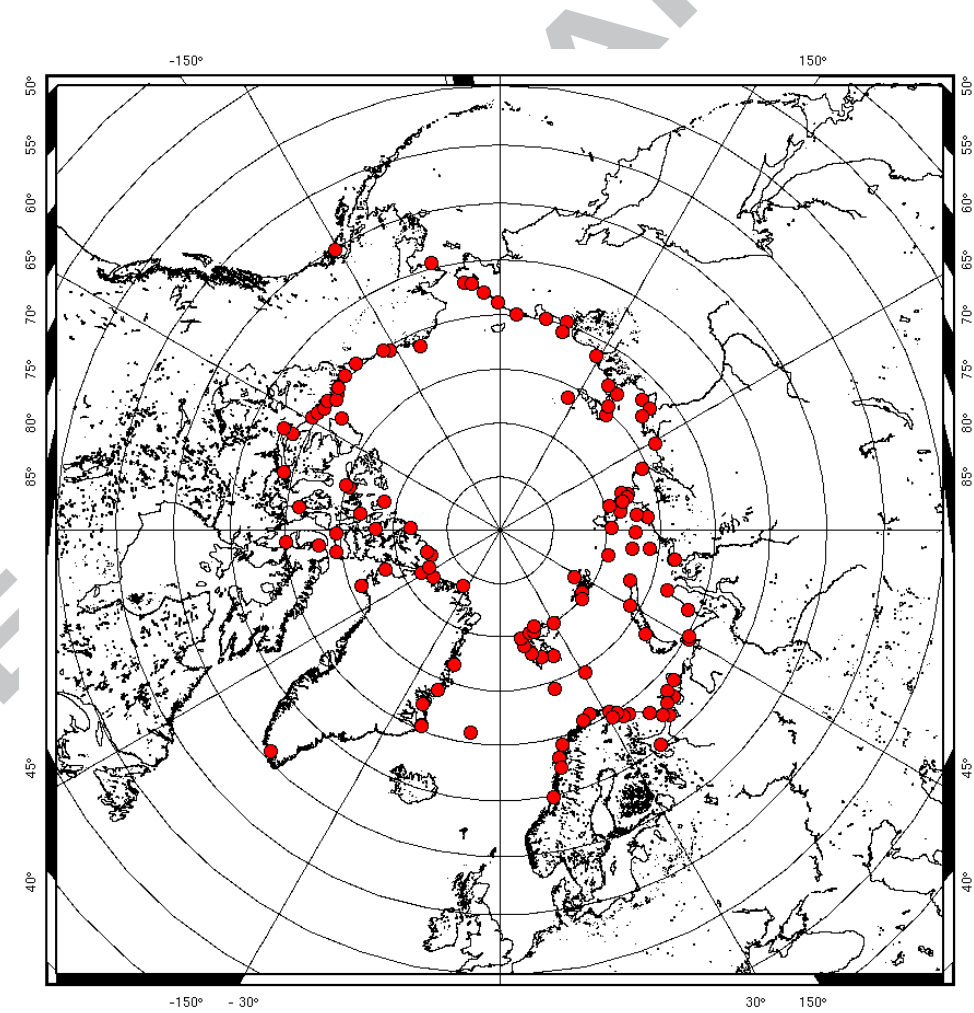

Figure 3: Tide gauge stations over the Arctic Ocean used for the model validation. 


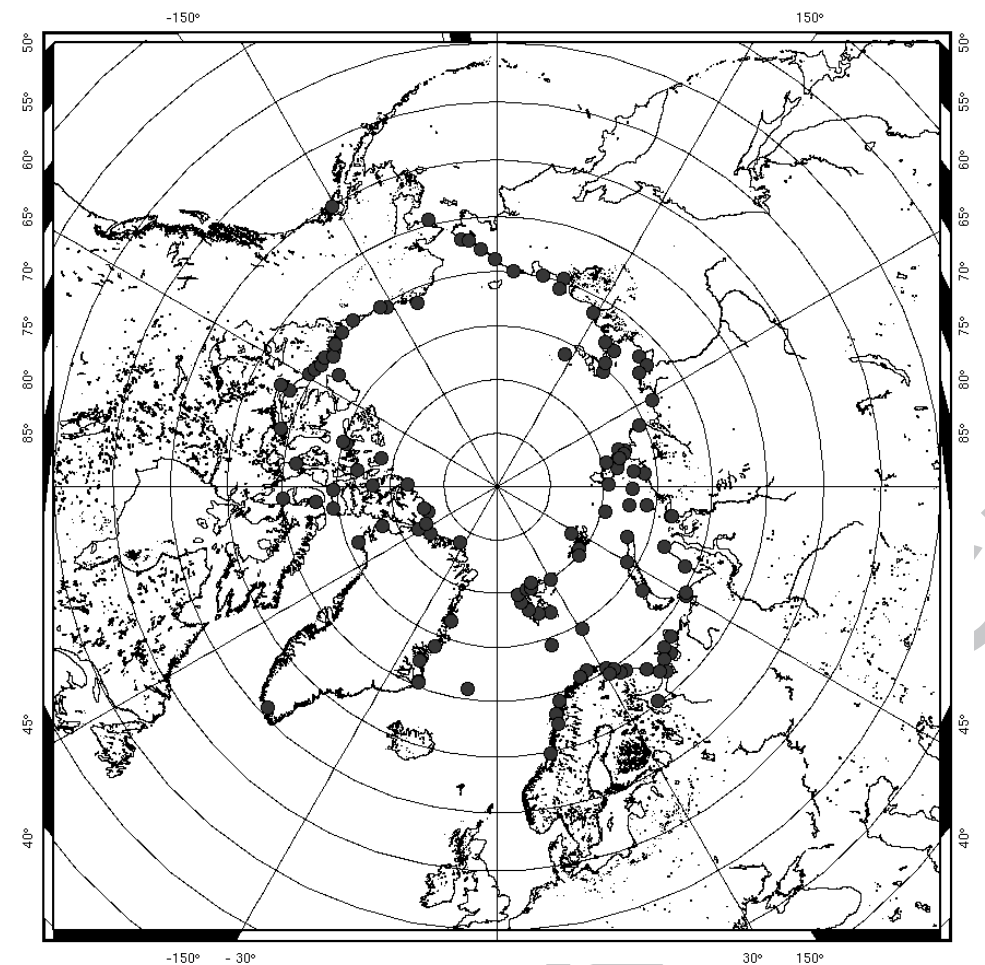

Figure 3 (black and white): Tide gauge stations over the Arctic Ocean used for the model validation. 


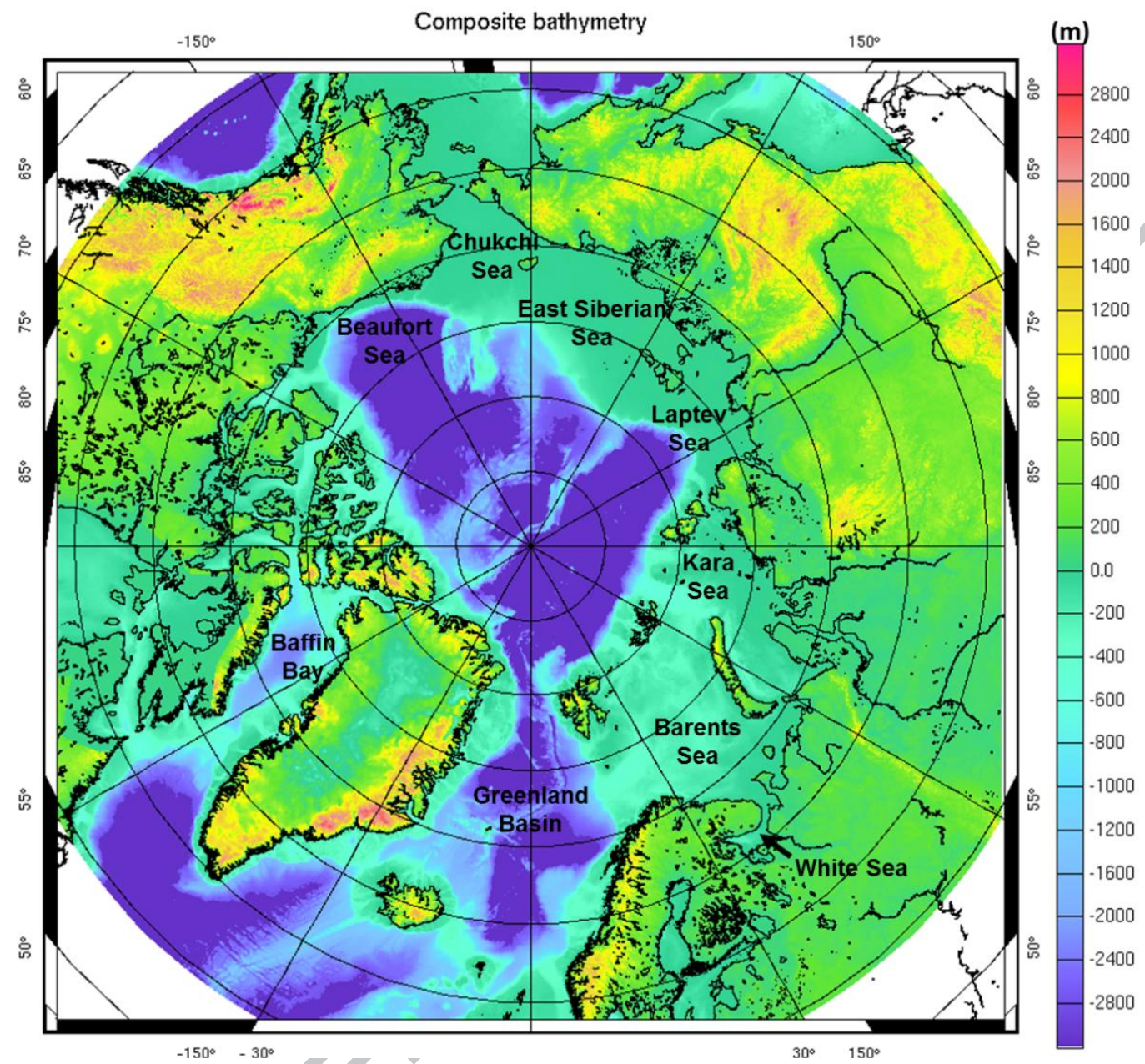

Figure 4: Composite bathymetry (in $m$ ) from LEGOS used for the implementation of the regional tidal model in the Arctic Ocean. The main seas of the region are also indicated. 


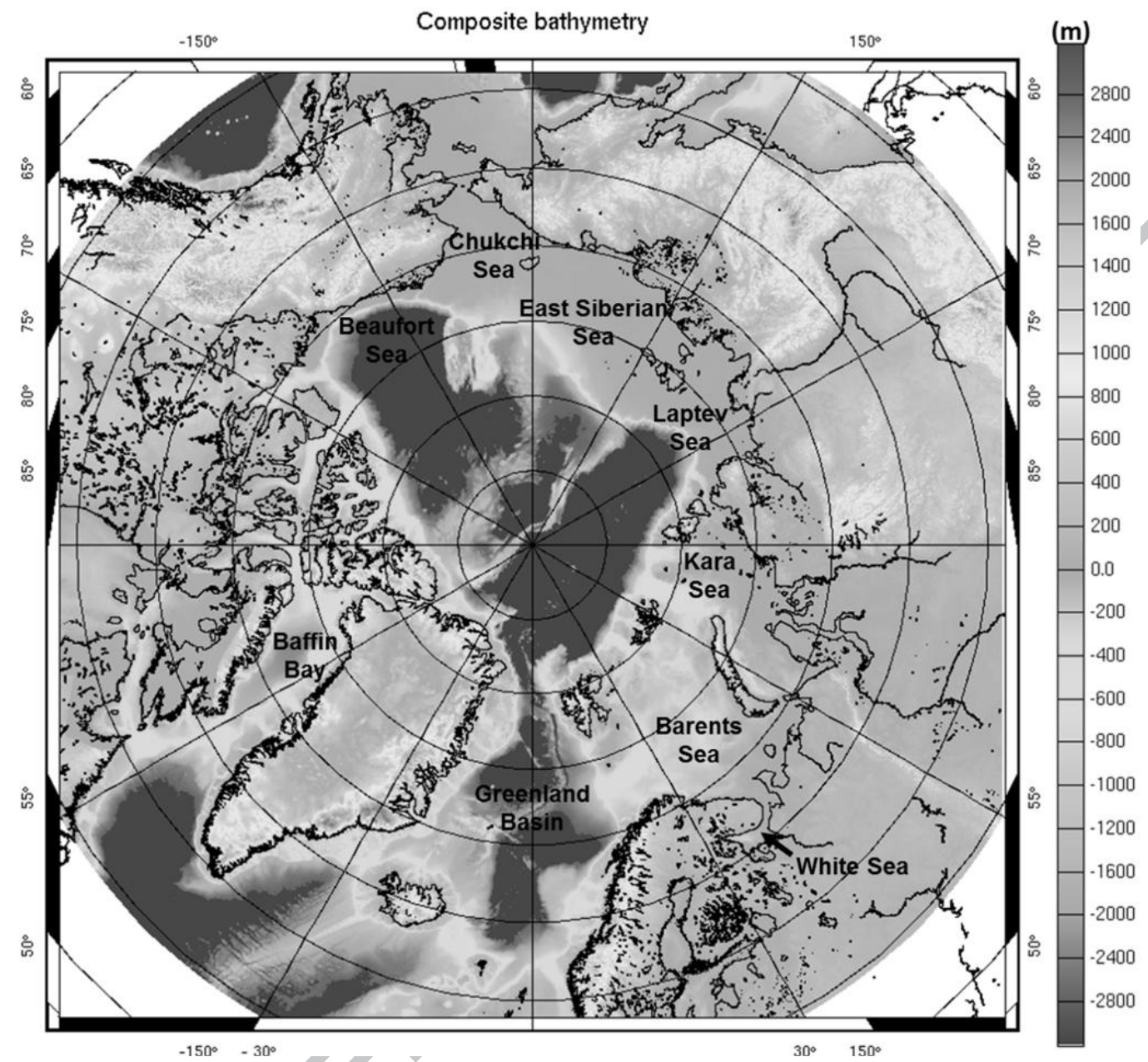

Figure 4 (black and white): Composite bathymetry (in $\mathrm{m}$ ) from LEGOS used for the implementation of the regional tidal model in the Arctic Ocean. The main seas of the region are also indicated. 


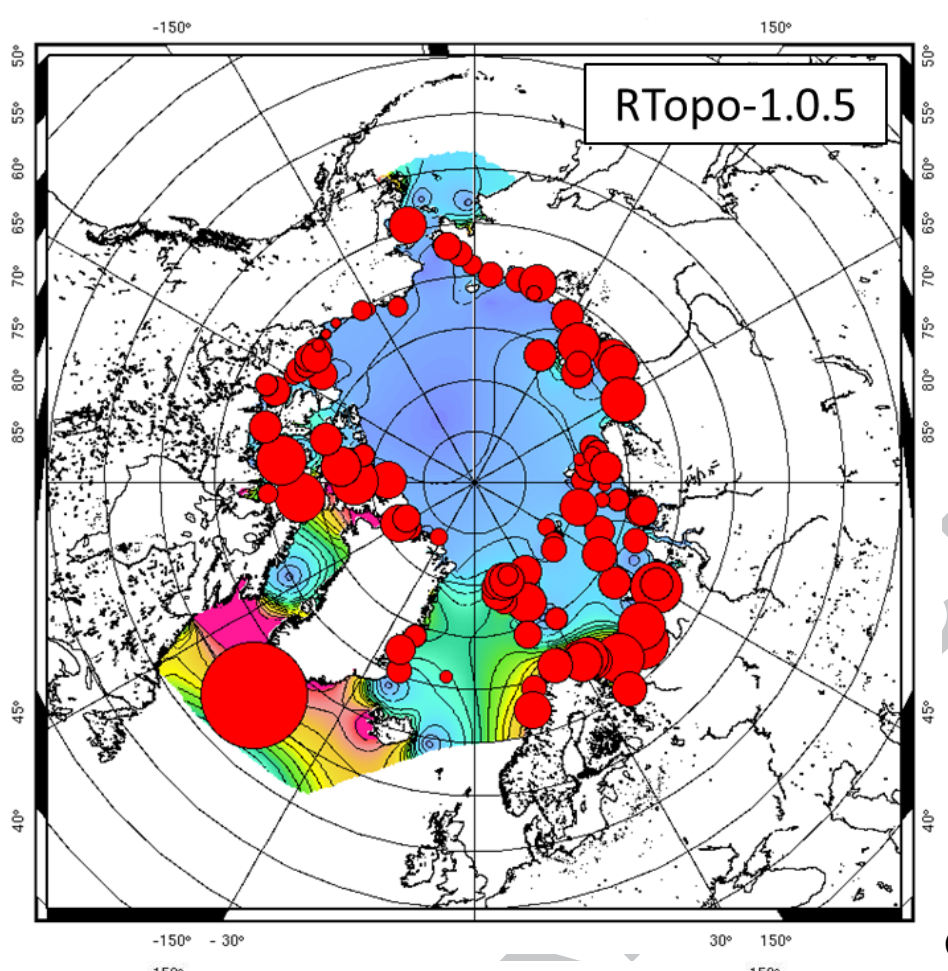

(a)

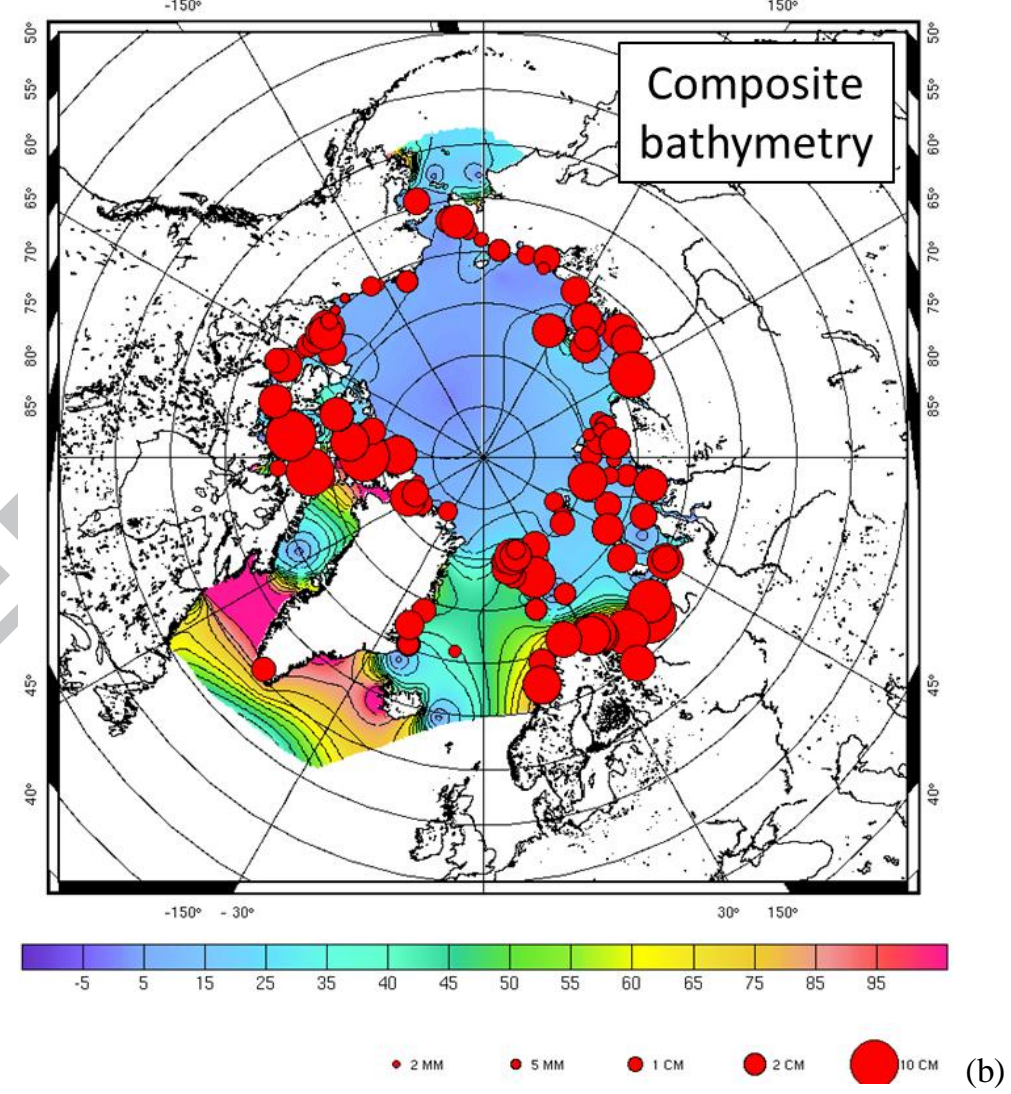

Figure 5: Hydrodynamic model performance for the M2 tidal component, using either the R-Topo1.0.5 beta bathymetry (a) or the composite bathymetry from LEGOS (b). The colors show the M2 amplitude (in $\mathrm{cm}$ ) and the red dots show the vector differences between the model simulations and the tide gauges. 


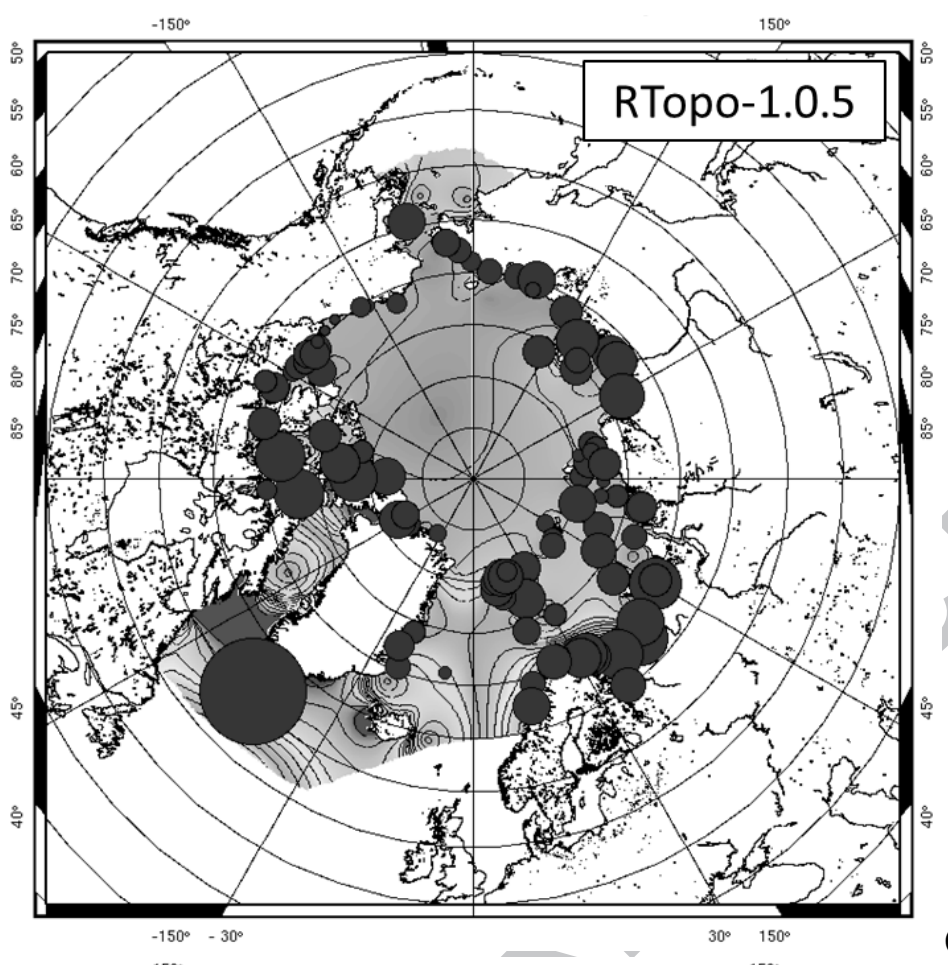

(a)

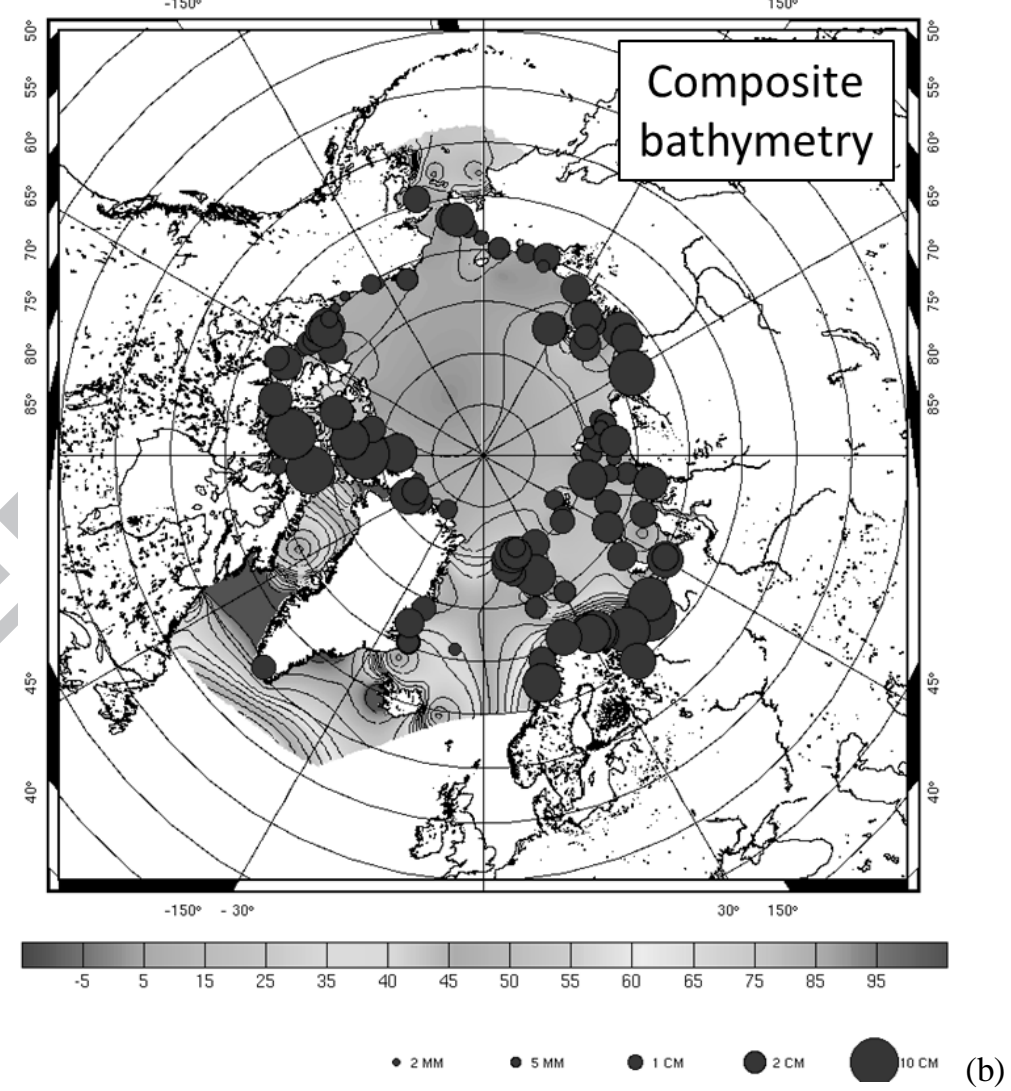

Figure 5 (black and white): Hydrodynamic model performance for the M2 tidal component, using either the R-Topo-1.0.5 beta bathymetry (a) or the composite bathymetry from LEGOS $(b)$. The colors show the M2 amplitude (in $\mathrm{cm}$ ) and the red dots show the vector differences between the model simulations and the tide gauges. 


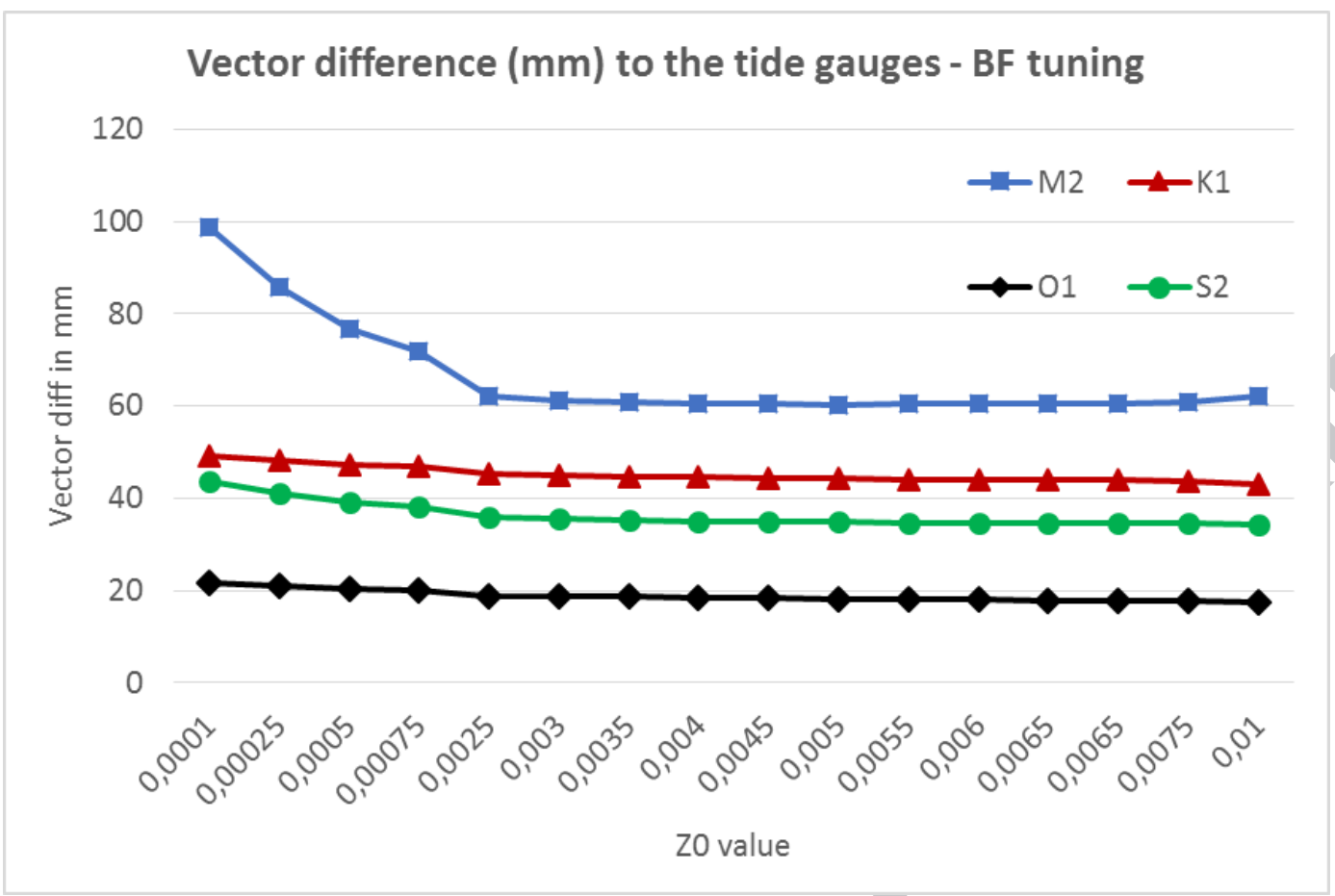

Figure 6: Vector difference between the hydrodynamic model and the tide gauge stations for the main tidal components (M2, S2, K1 and O1), for each hydrodynamic simulation performed in order to tune the bottom friction coefficient (roughness length $\mathrm{ZO}$ in $\mathrm{m}$ ).

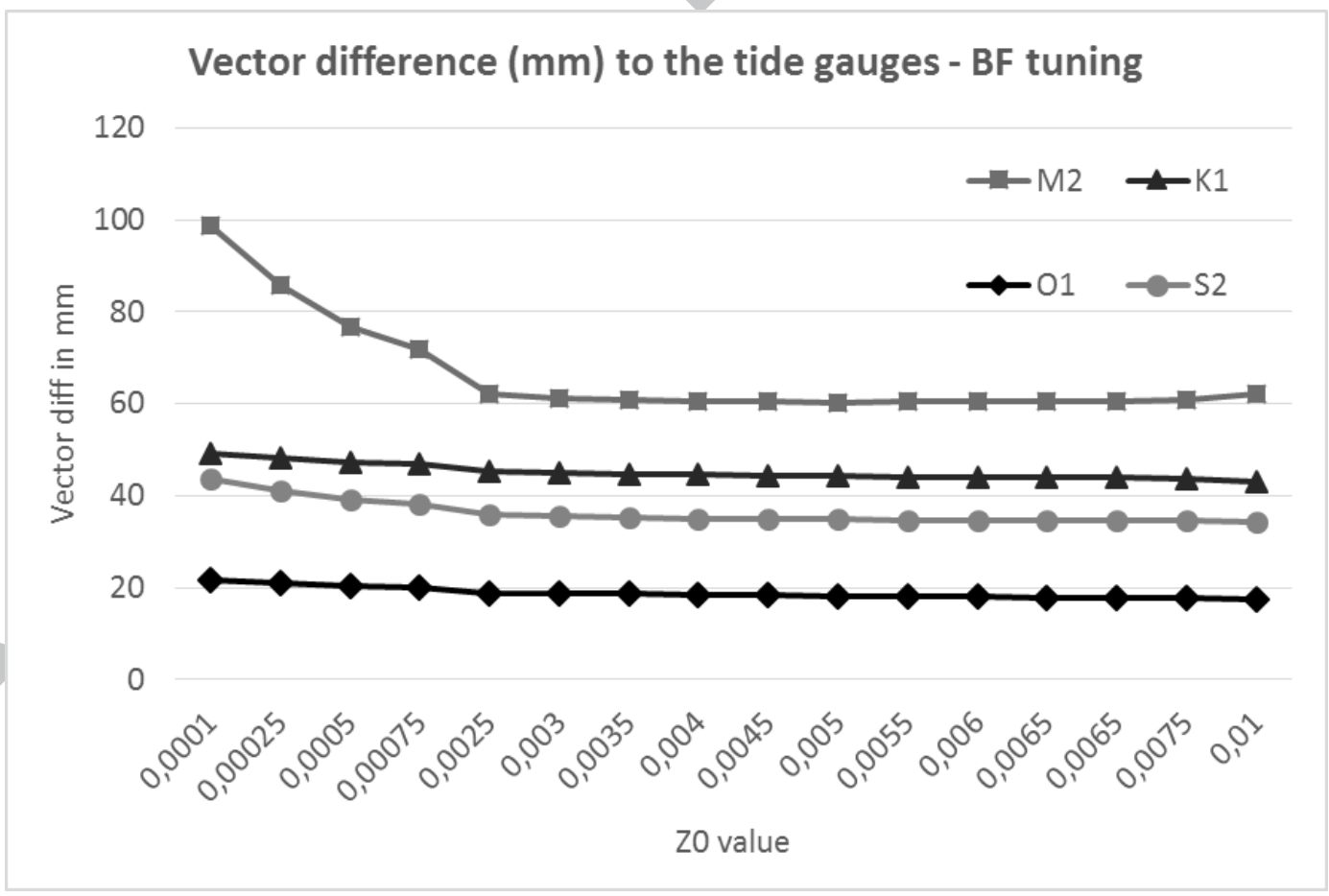

Figure 6 (black and white): Vector difference between the hydrodynamic model and the tide gauge stations for the main tidal components (M2, S2, K1 and O1), for each hydrodynamic simulation performed in order to tune the bottom friction coefficient (roughness length $\mathrm{ZO}$ in $\mathrm{m}$ ). 


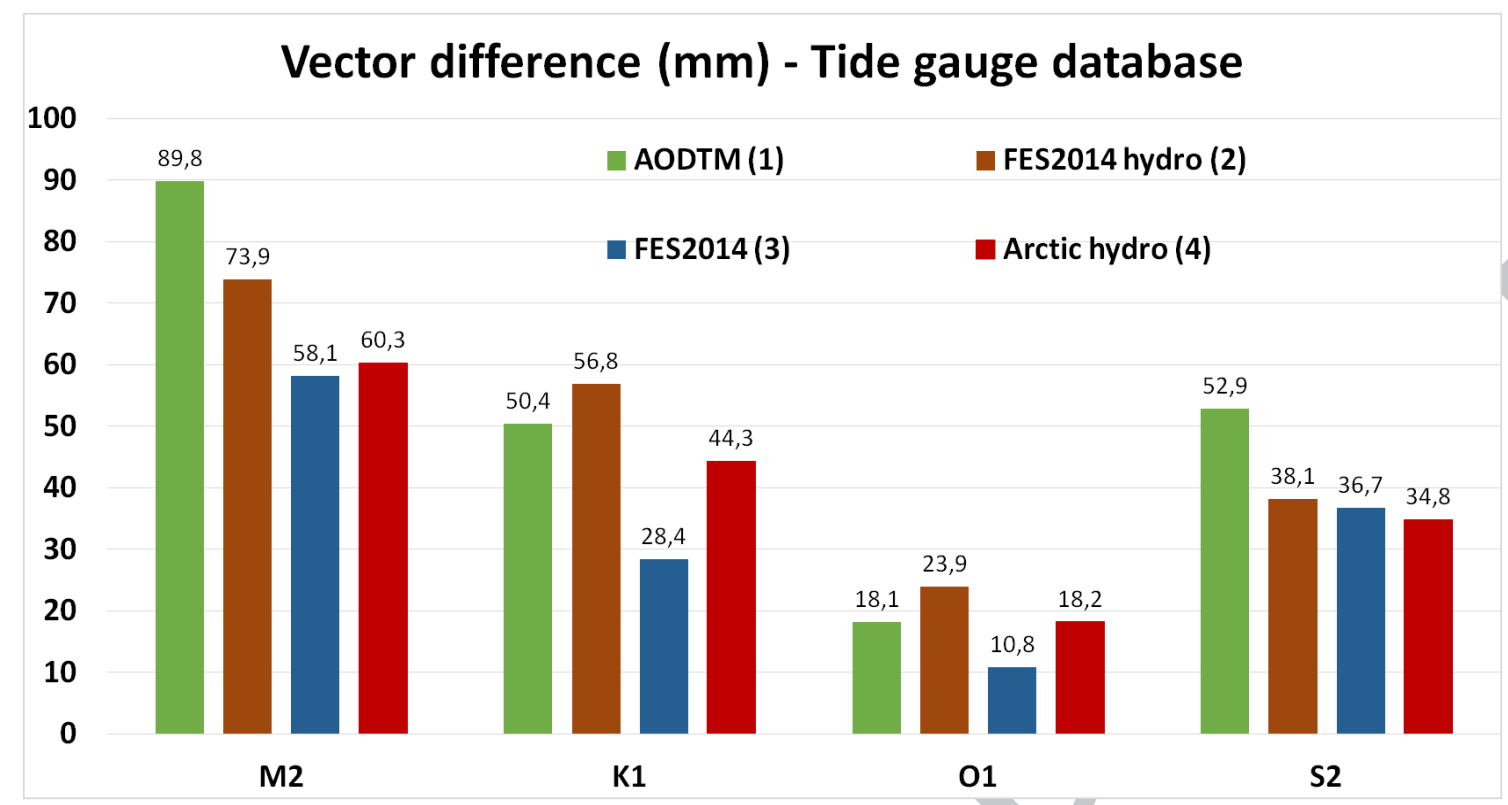

Figure 7: Vector differences between the tide gauge observations and tidal models: the regional hydrodynamic simulation in the Arctic Ocean (no data assimilation), the AODTM regional hydrodynamic simulation, the FES2014 global hydrodynamic simulation and the FES2014 assimilated global model, for the main tidal components. The numbers in brackets give the bar number of each model.

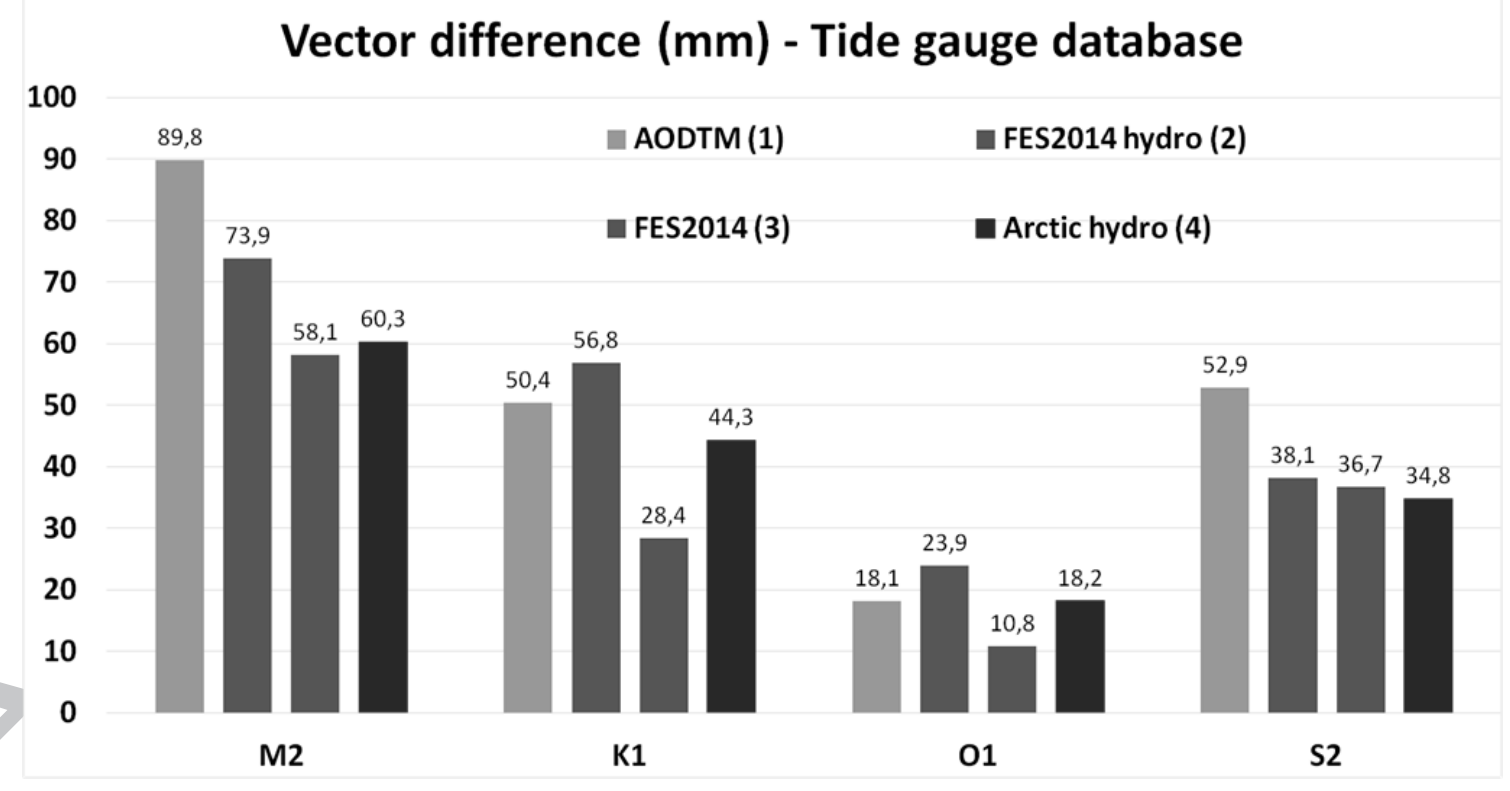

Figure 7 (black and white): Vector differences between the tide gauge observations and tidal models: the regional hydrodynamic simulation in the Arctic Ocean (no data assimilation), the AODTM regional hydrodynamic simulation, the FES2014 global hydrodynamic simulation and the FES2014 assimilated global model, for the main tidal components. The numbers in brackets give the bar number of each model. 


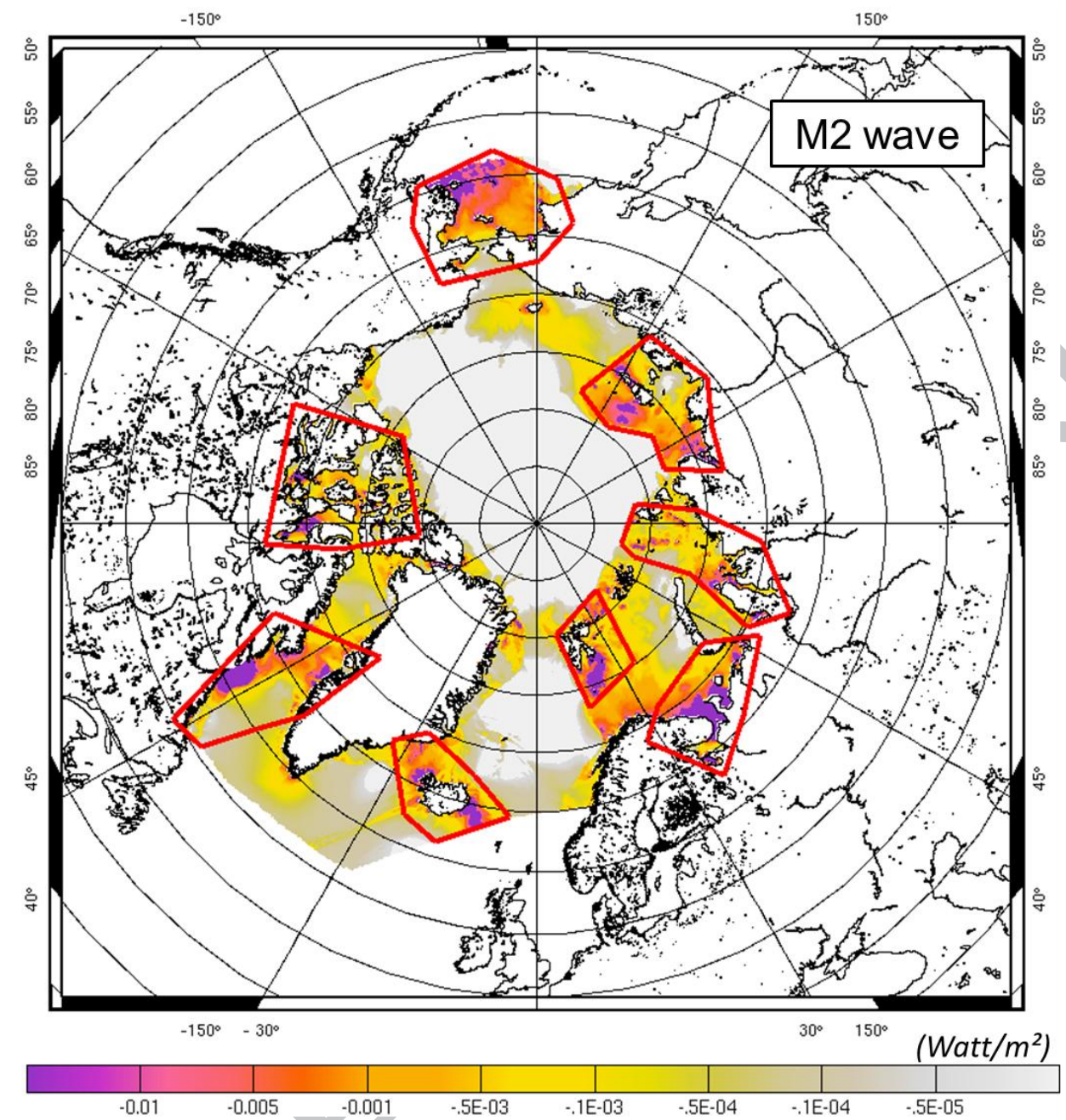

Figure 8: Energy dissipation due to the bottom friction for the prior hydrodynamic solution. The polygons show the zones where the bottom friction coefficient was varied in order to build the ensemble of simulations. 


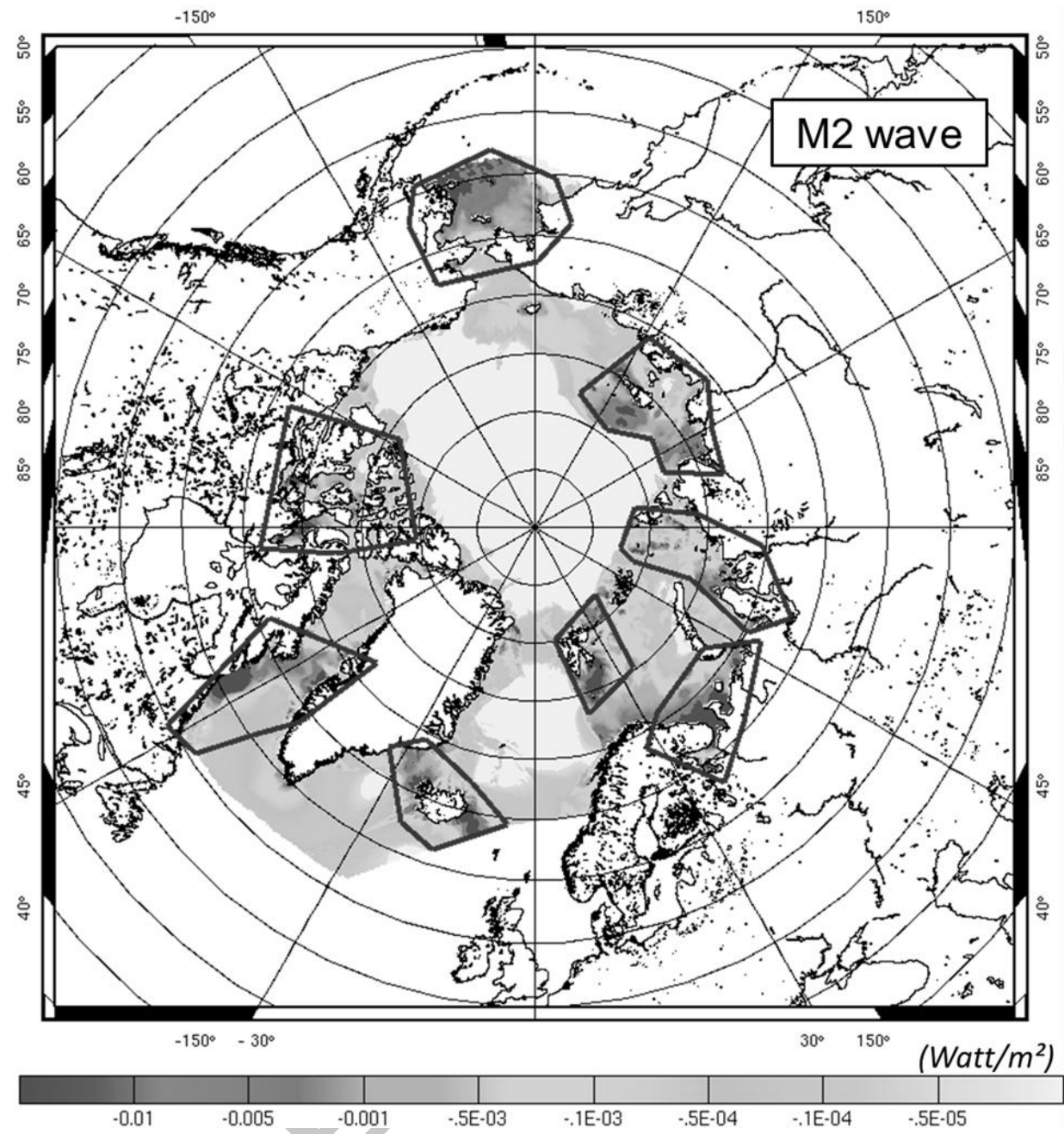

Figure 8 (black and white): Energy dissipation due to the bottom friction for the prior hydrodynamic solution. The polygons show the zones where the bottom friction coefficient was varied in order to build the ensemble of simulations. 

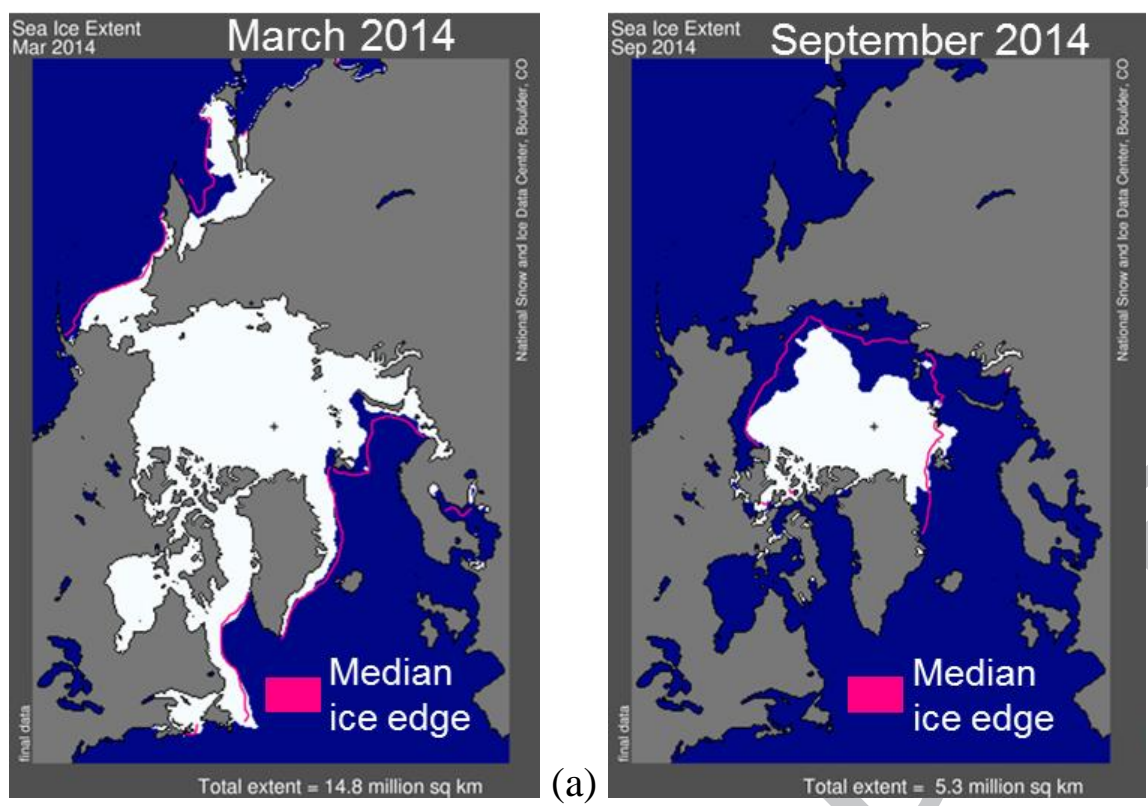

(b)

Figure 9: Sea ice extent in March 2014 (a) and September 2014 (b) and median ice edge (thin pink line) computed over 30 months of March (a) and September (b), from 1981 to 2010. Maps from the NSIDC.
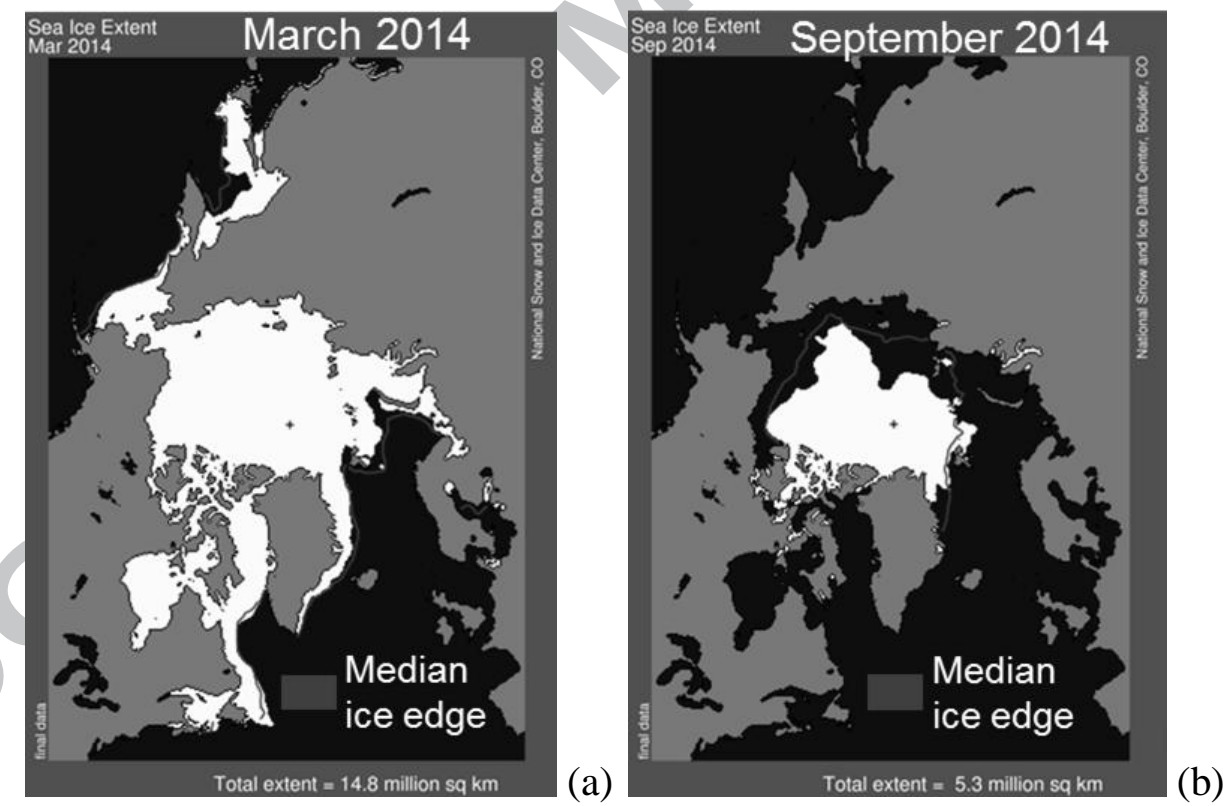

Figure 9 (black and white): Sea ice extent in March 2014 (a) and September 2014 (b) and median ice edge (thin pink line) computed over 30 months of March (a) and September (b), from 1981 to 2010. Maps from the NSIDC. 

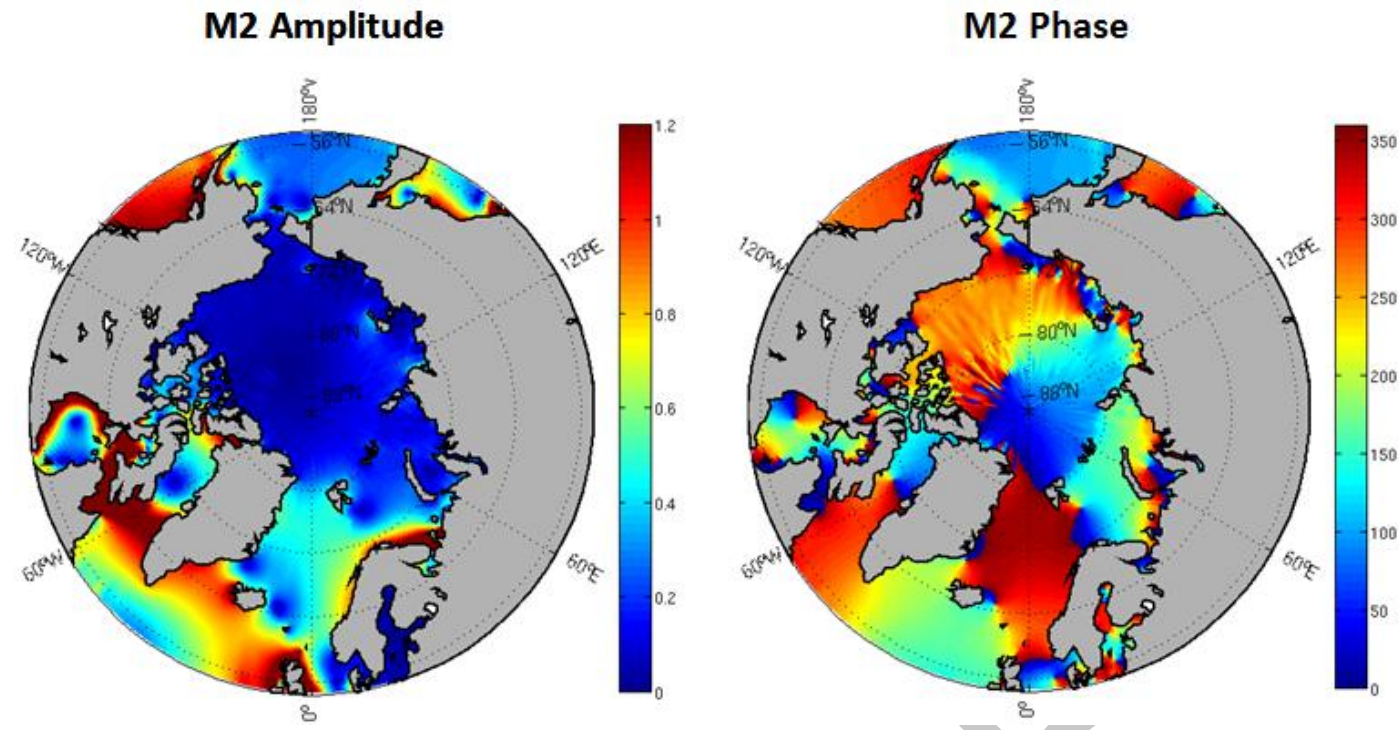

Figure 10: The M2 tidal constituents (amplitude in meters and phase in degrees) derived from satellite altimetry in the Arctic Ocean, interpolated to a regular grid for the entire Arctic Ocean.
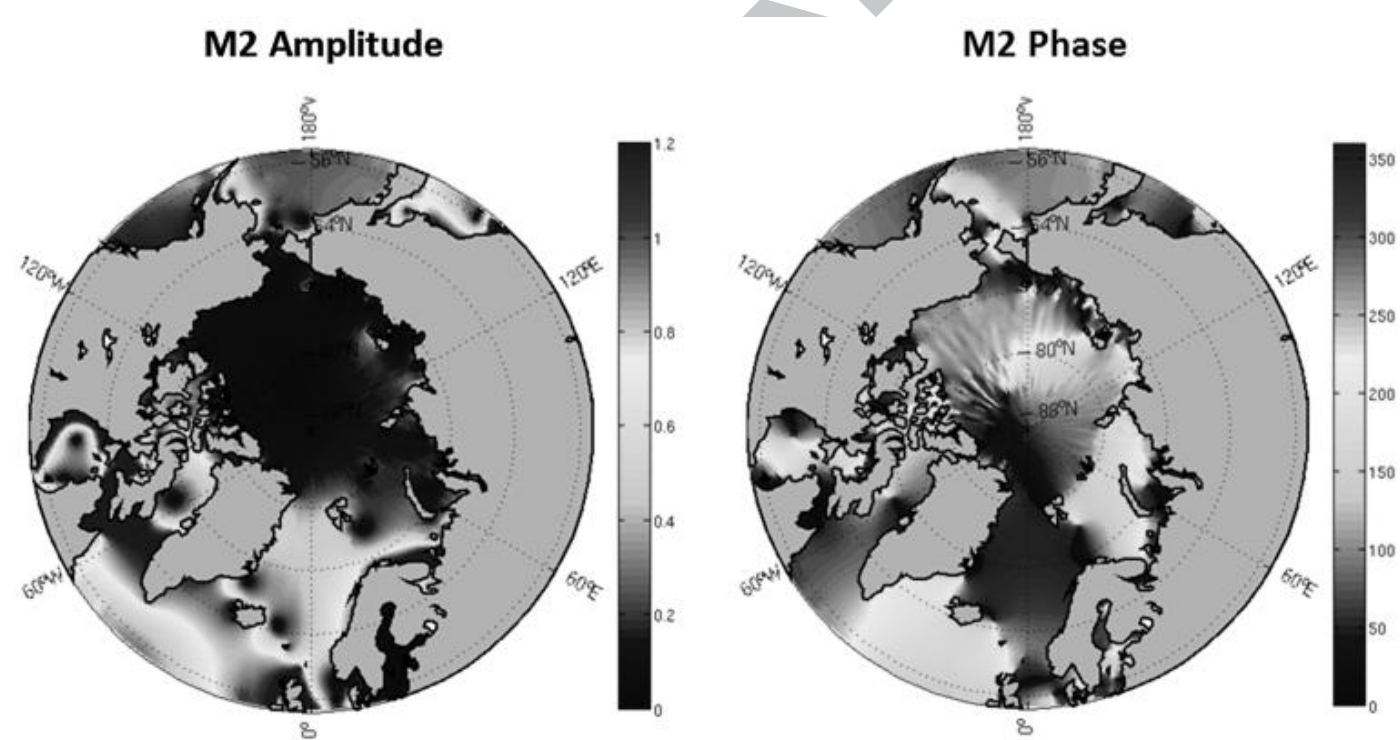

Figure 10 (black and white): The M2 tidal constituents (amplitude in meters and phase in degrees) derived from satellite altimetry in the Arctic Ocean, interpolated to a regular grid for the entire Arctic Ocean. 

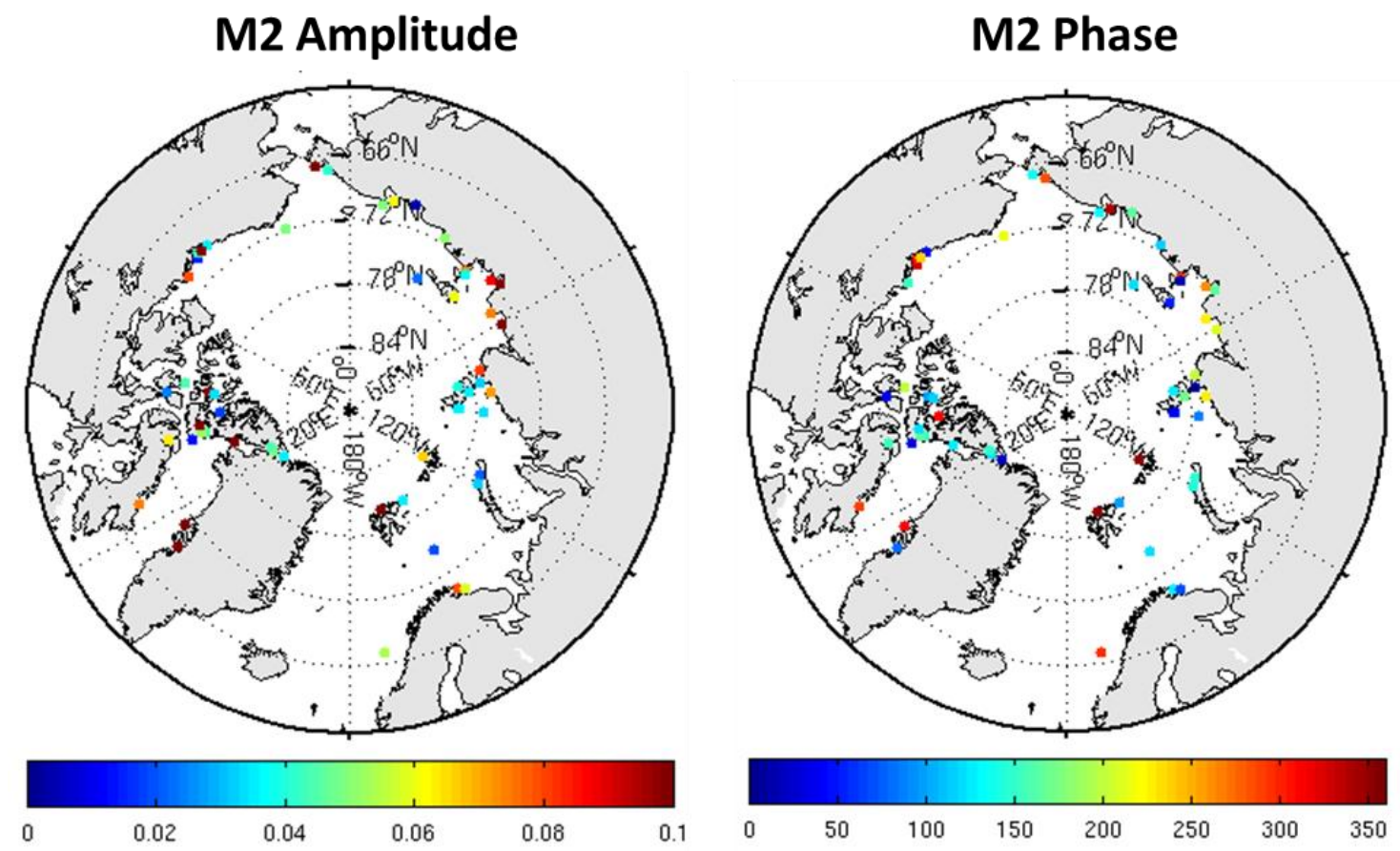

Figure 11: Residuals between the altimetry-derived ocean tide constituents and the tide gaugederived tidal constituents for amplitude (in meters) and phase (in degrees) of M2. Phase differences of $0^{\circ}$ and $360^{\circ}$ both mean that the compared phases are the same.

\section{M2 Amplitude}

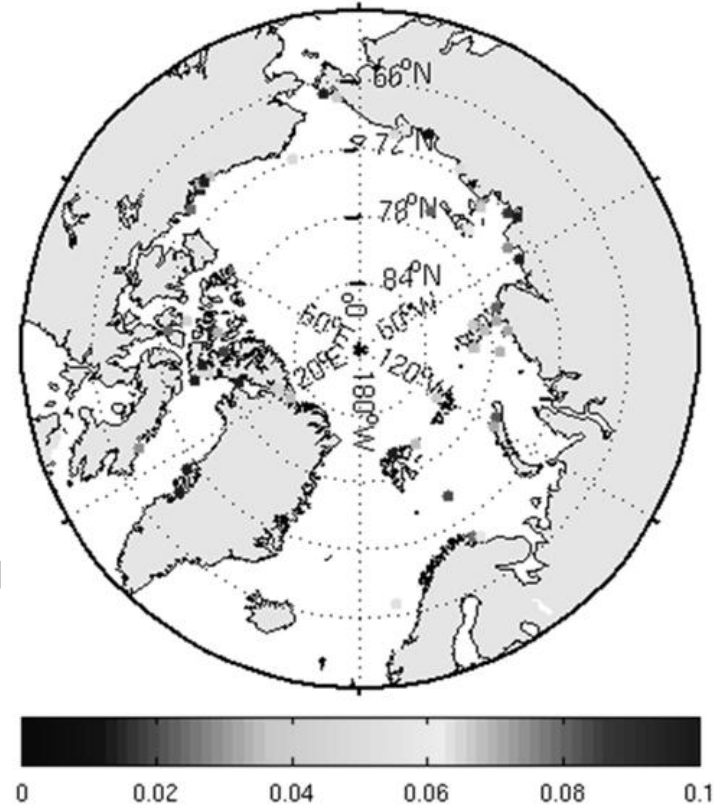

\section{M2 Phase}

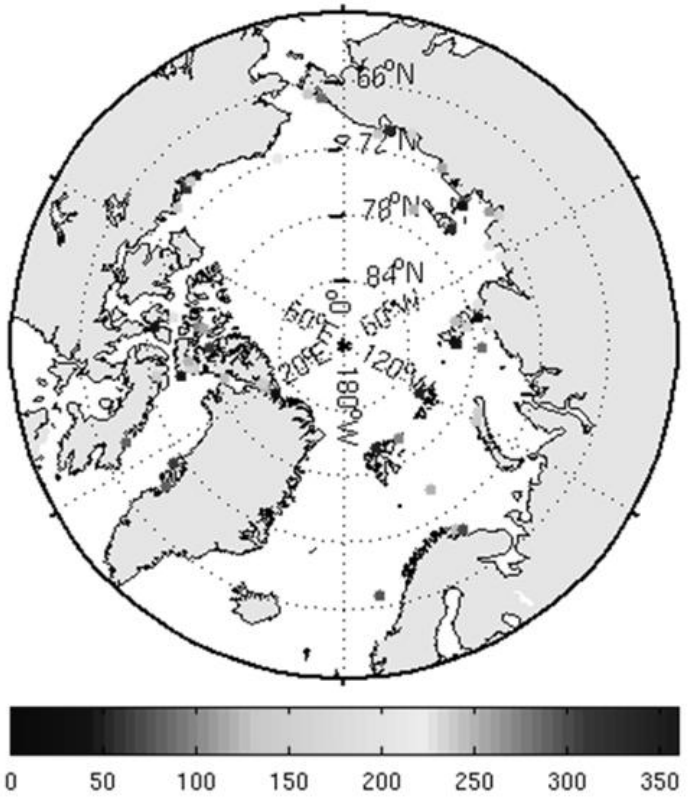

Figure 11 (black and white): Residuals between the altimetry-derived ocean tide constituents and the tide gauge-derived tidal constituents for amplitude (in meters) and phase (in degrees) of M2. Phase differences of $0^{\circ}$ and $360^{\circ}$ both mean that the compared phases are the same. 

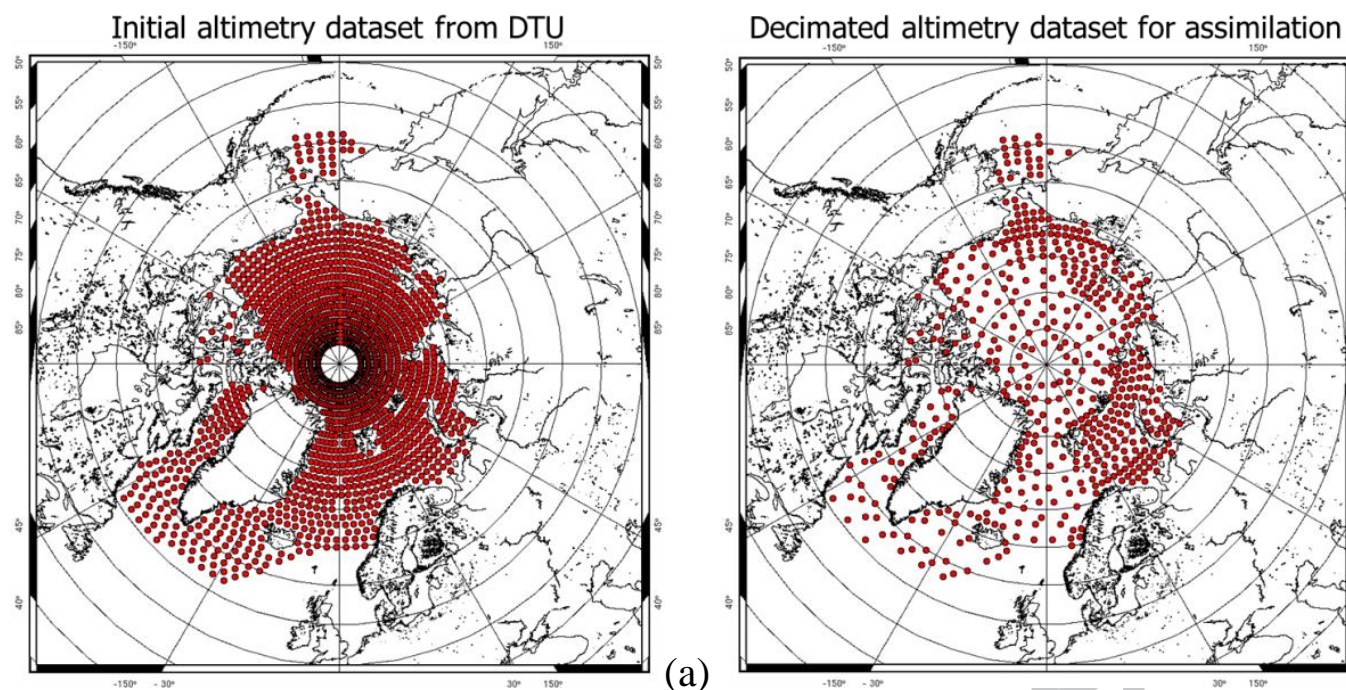

(a)

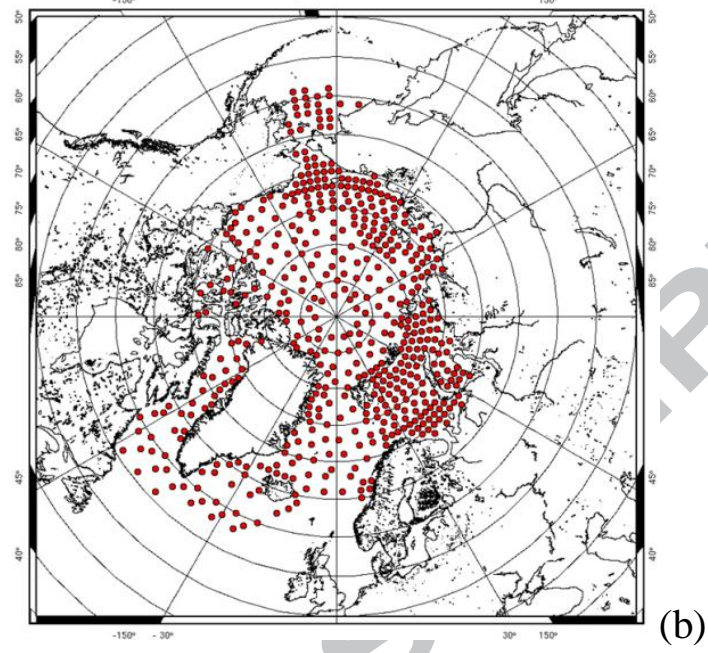

Figure 12: Initial (a, 1745 points) and decimated (b, 507 points) altimetry-derived tidal constituent dataset processed by DTU Space, selection over the Arctic tidal model domain only.

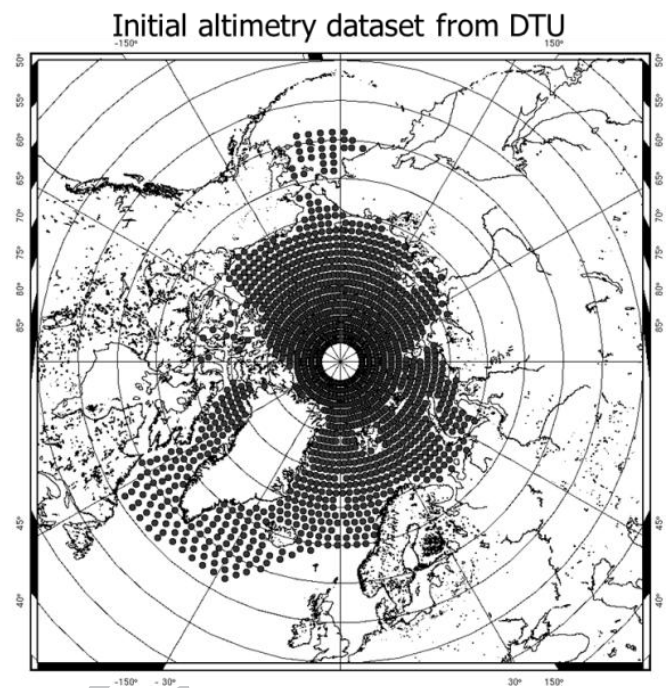

Decimated altimetry dataset for assimilation

(a)

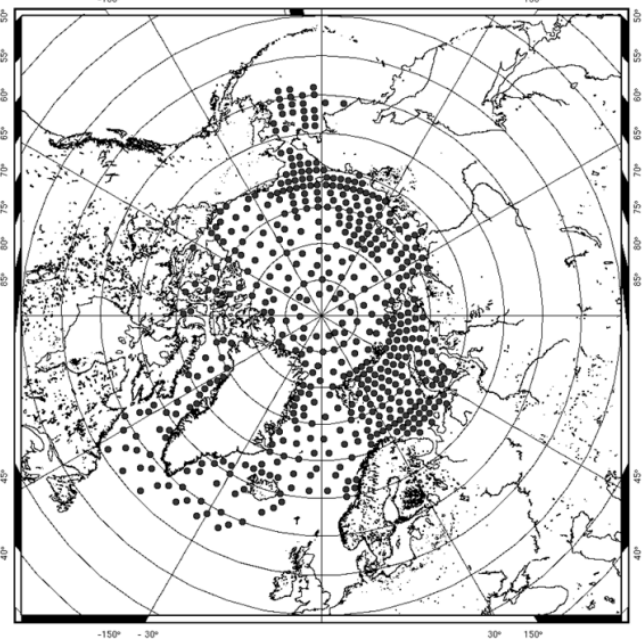

(b)

Figure 12 (black and white): Initial (a, 1745 points) and decimated (b, 507 points) altimetryderived tidal constituent dataset processed by DTU Space, selection over the Arctic tidal model domain only. 


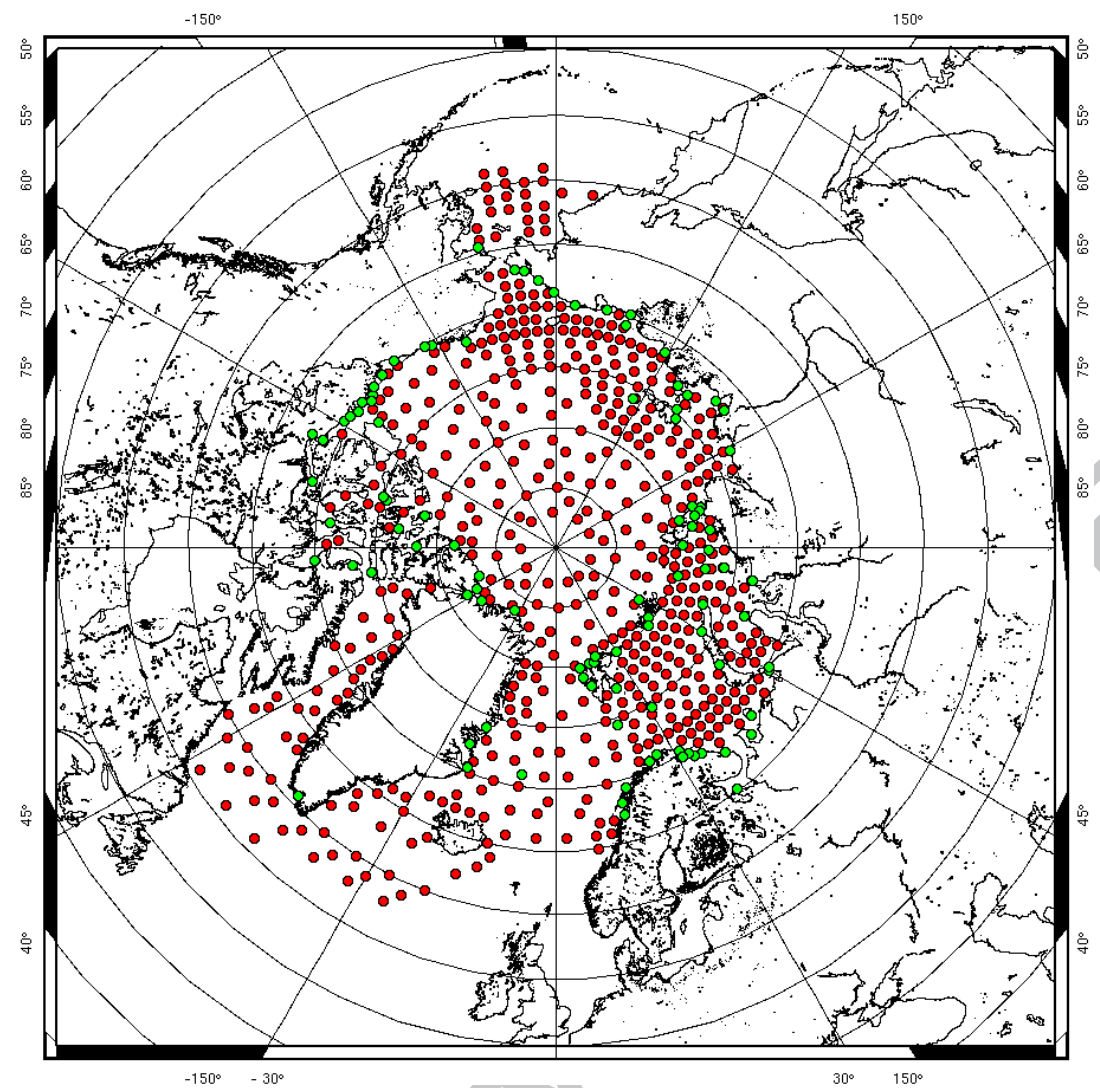

Figure 13: Final assimilation dataset (tide gauge stations in green and altimetry data in red) for the M2 tidal component. 


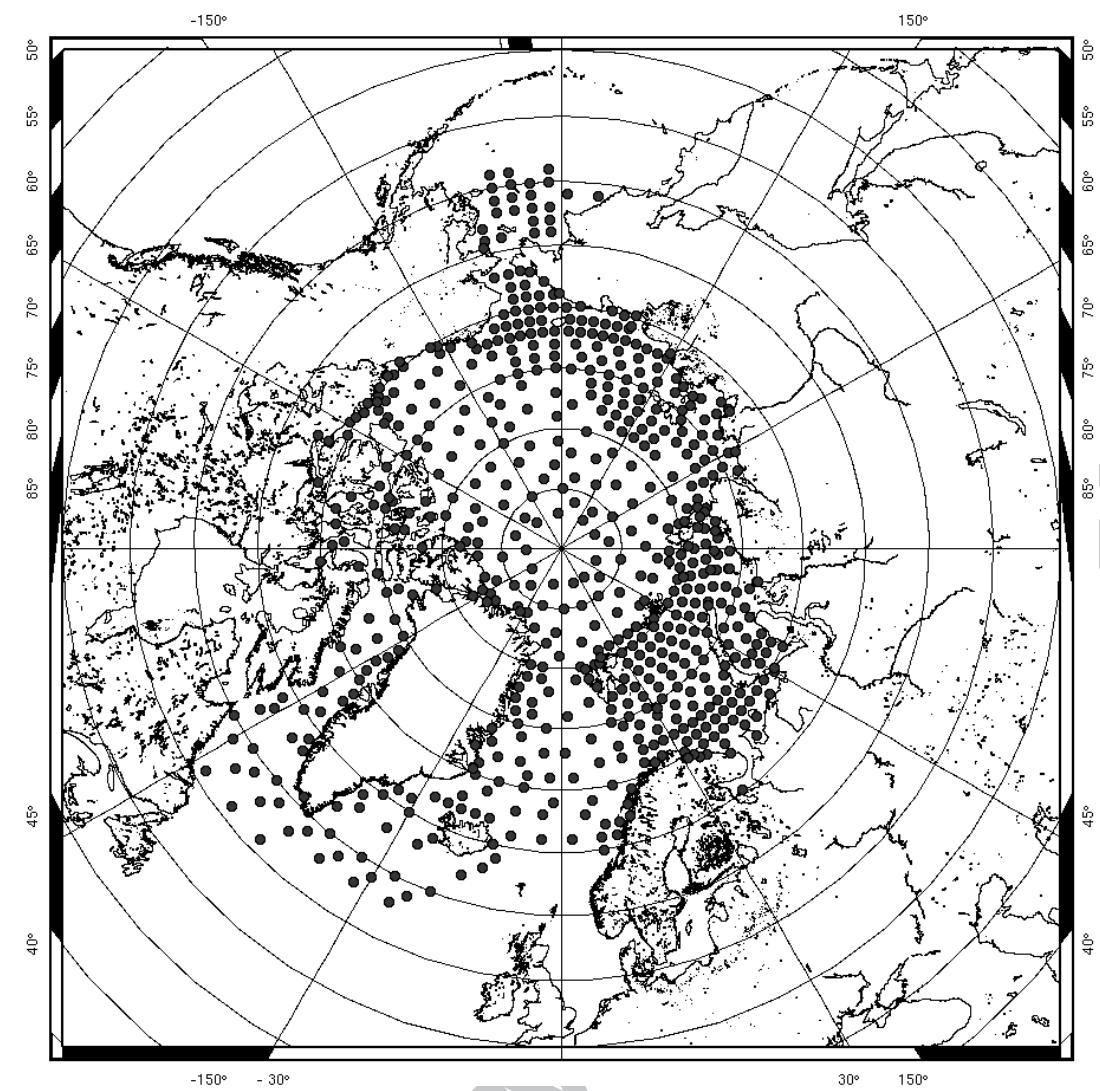

Figure 13 (black and white): Final assimilation dataset (tide gauge stations and altimetry data) for the M2 tidal component. 

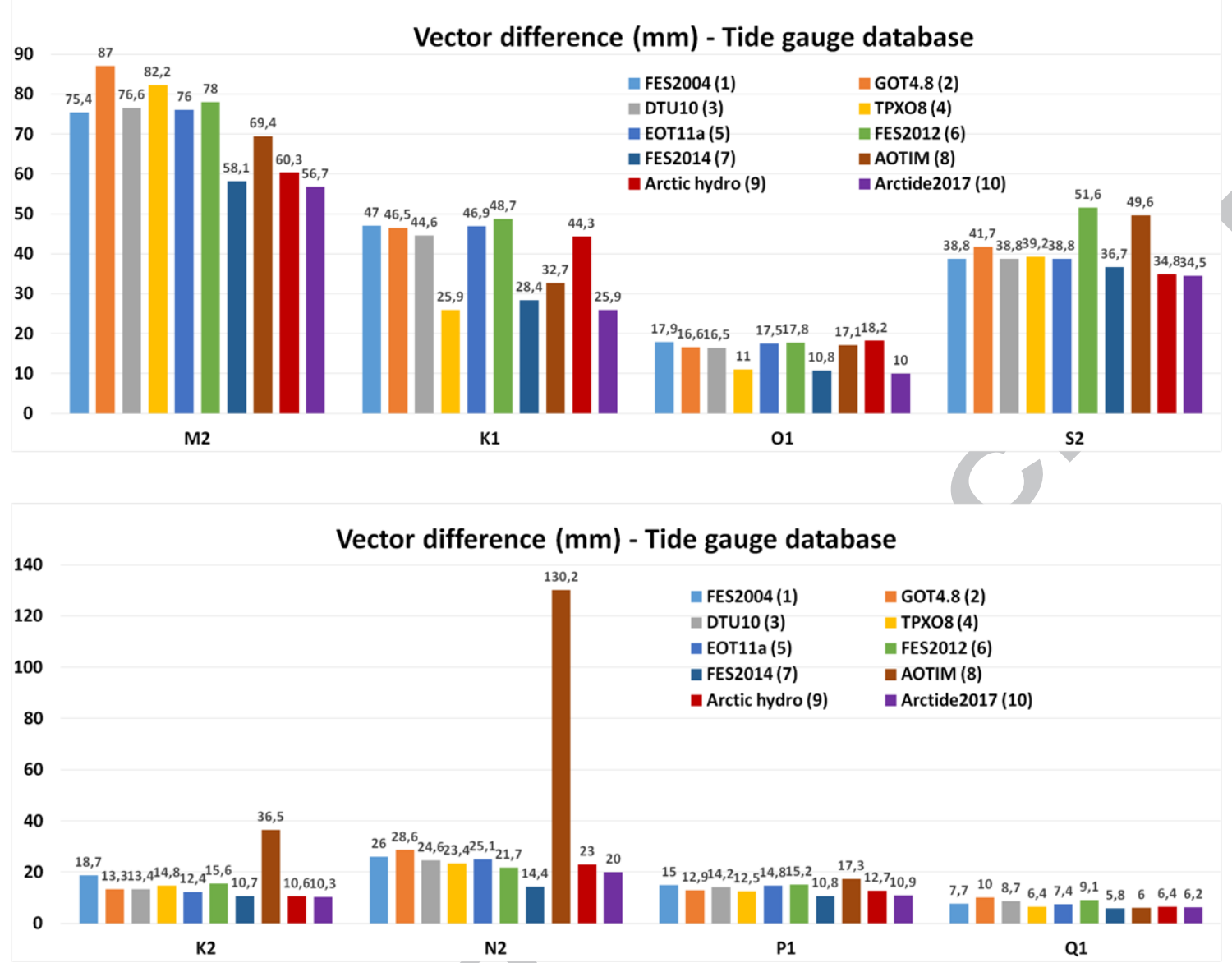

Figure 14: Vector differences between the tidal models and the tide gauge database for each tidal component. The numbers in brackets give the bar number of each model. 

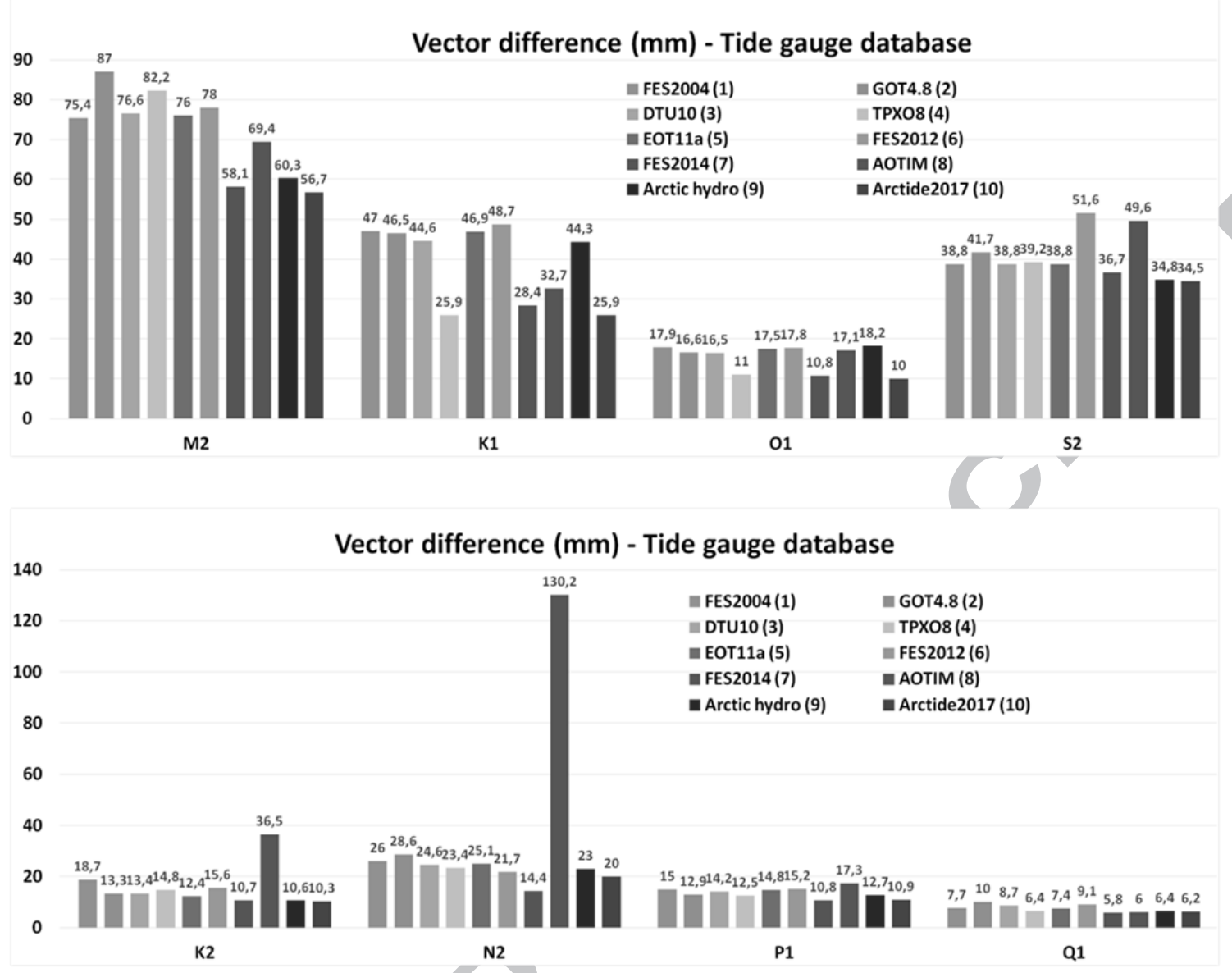

Figure 14 (black and white): Vector differences between the tidal models and the tide gauge database for each tidal component. The numbers in brackets give the bar number of each model. 

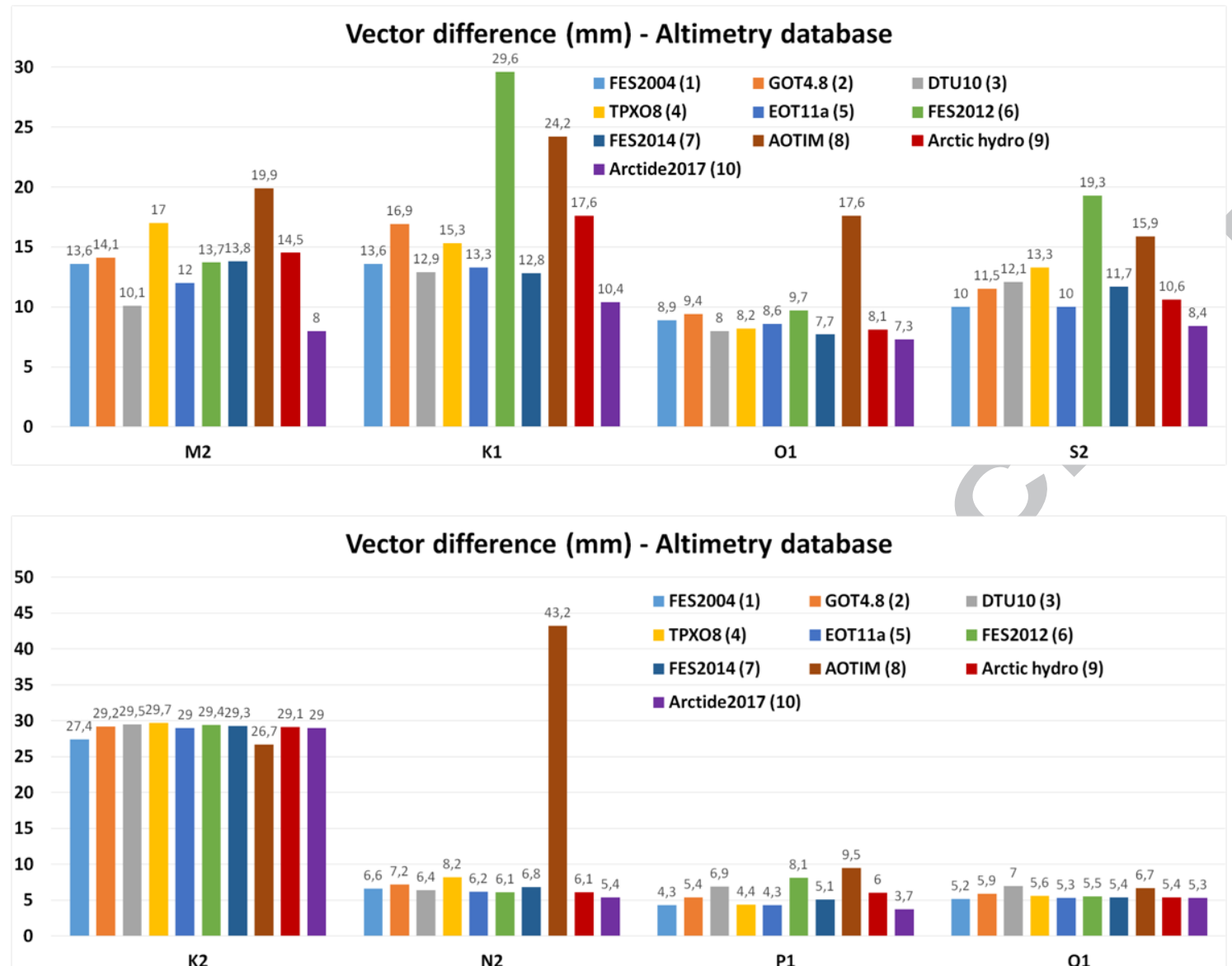

Figure 15: Vector differences between the tidal models and the altimetry database for each tidal component. The numbers in brackets give the bar number of each model. 


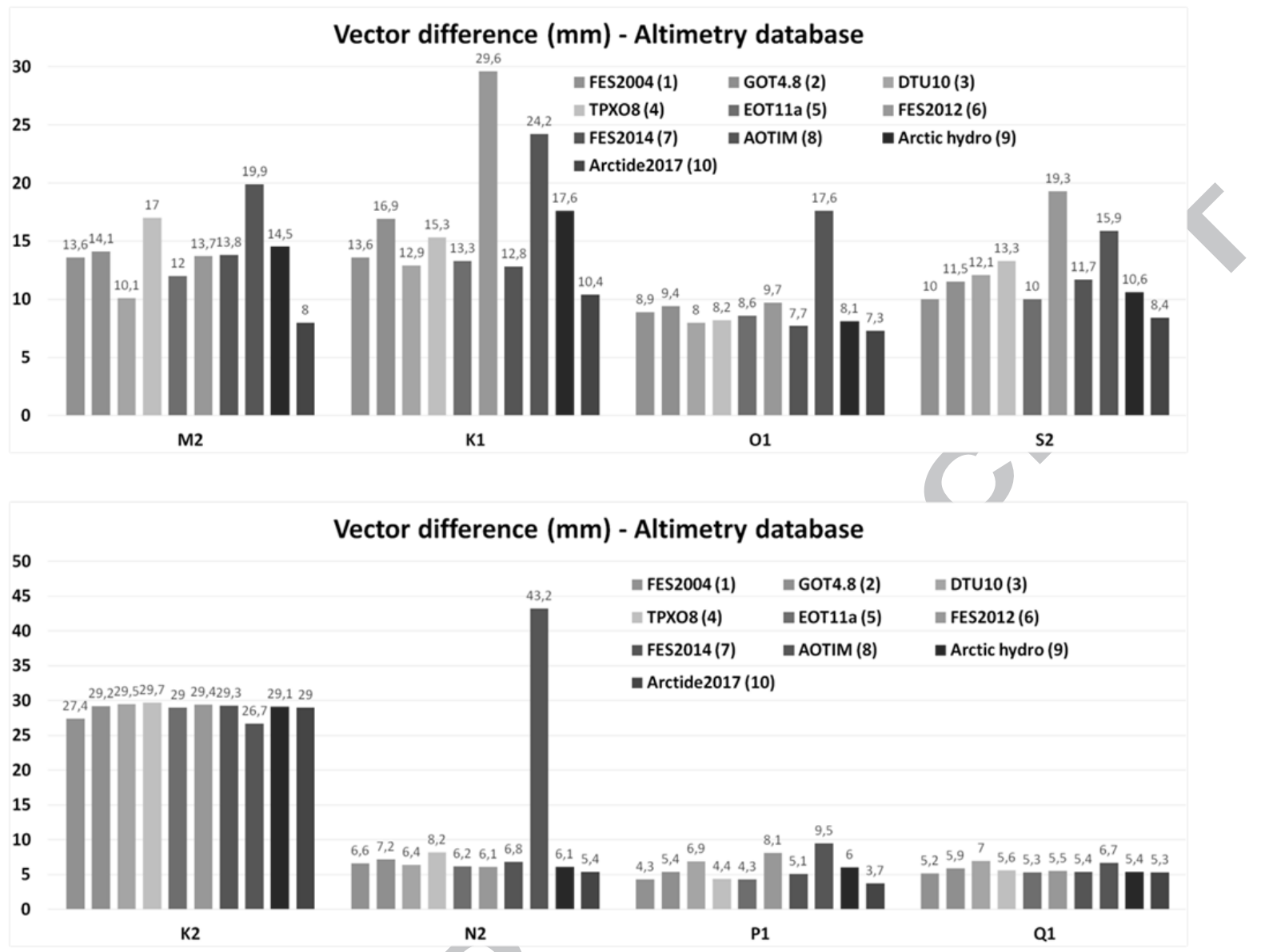

Figure 15 (black and white): Vector differences between the tidal models and the altimetry database for each tidal component. The numbers in brackets give the bar number of each model. 

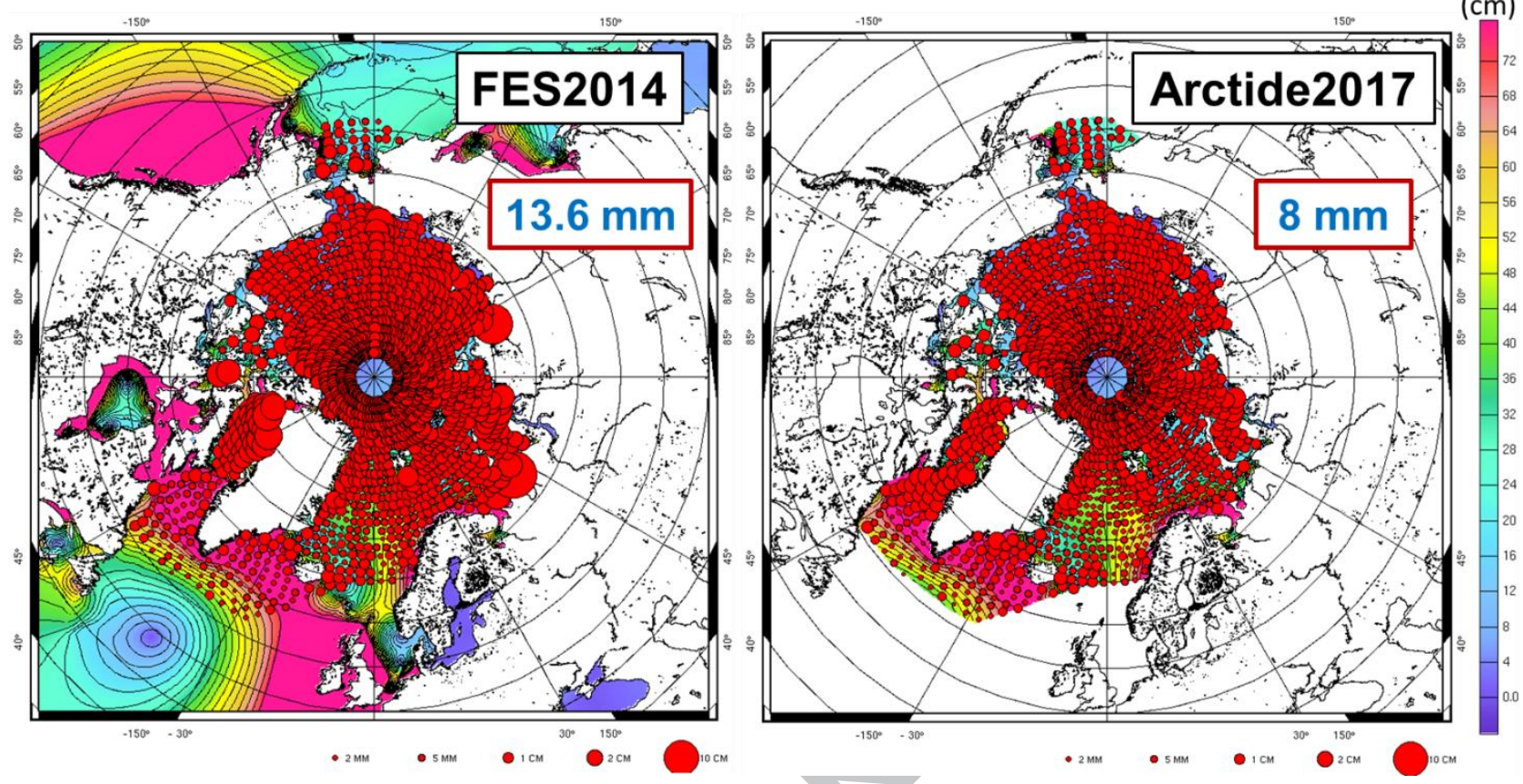

Figure 16: Vector difference between the altimetry database and the FES2014 global tidal model (left) and the Arctide2017 regional model (right), for the M2 tidal component. The global vector difference over all the altimetry points is indicated (in $\mathrm{mm}$ ). The background colour map is the amplitude of the M2 tidal component from the models (in $\mathrm{cm}$ ).

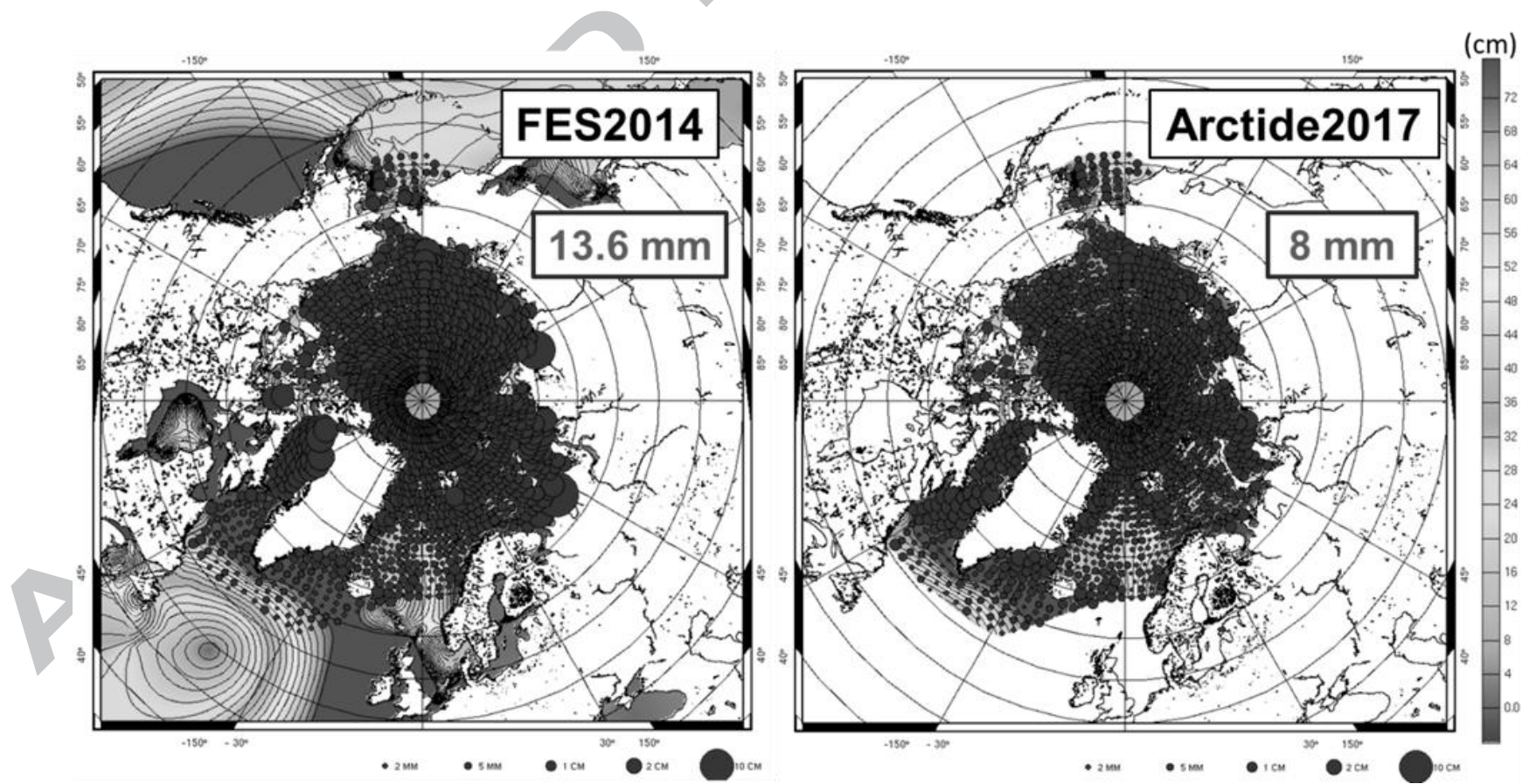

Figure 16 (black and white): Vector difference between the altimetry database and the FES2014 global tidal model (left) and the Arctide2017 regional model (right), for the M2 tidal component. The global vector difference over all the altimetry points is indicated (in $\mathrm{mm}$ ). The background colour map is the amplitude of the M2 tidal component from the models (in cm). 
Arctide2017, A High-Resolution Regional Tidal Model in the Arctic Ocean

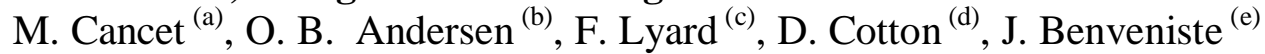

Tables

Table 1: Alias periods for the main tidal components, for the CryoSat-2 and Envisat repeat periods.

\begin{tabular}{|l|c|c|c|c|}
\hline Mission & M2 & S2 & K1 & O1 \\
\hline CryoSat-2 & 112 years & Infinite & 90 years & 60 years \\
\hline Envisat & 95 days & Infinite & 1 year & 75 days \\
\hline
\end{tabular}

Table 2: Number of tide gauge stations in the assimilation dataset, root mean square of the tide height amplitude and error estimate values attributed to the tide-gauge-derived tidal constituents, for each tidal component.

\begin{tabular}{|l|c|c|c|c|c|c|c|c|}
\hline Tidal component & M2 & S2 & K1 & O1 & K2 & N2 & P1 & Q1 \\
\hline $\begin{array}{l}\text { Number of tide gauge } \\
\text { stations }\end{array}$ & 105 & 100 & 96 & 94 & 51 & 61 & 52 & 36 \\
\hline $\begin{array}{l}\text { RMS of tide height } \\
\text { amplitude (cm) }\end{array}$ & 33 & 10 & 8 & 3 & 3 & 7 & 2 & 0.6 \\
\hline Error estimate & $2 \mathrm{~cm}$ & $1 \mathrm{~cm}$ & $1.5 \mathrm{~cm}$ & $1 \mathrm{~cm}$ & $1 \mathrm{~cm}$ & $1 \mathrm{~cm}$ & $1 \mathrm{~cm}$ & $1 \mathrm{~cm}$ \\
\hline
\end{tabular}

